\title{
A Comprehensive Review on Pharmacokinetic Profile of Some Traditional Chinese Medicines
}

\author{
Piyush Mehta ${ }^{1}$ and Vividha Dhapte ${ }^{2}$ \\ ${ }^{1}$ Department of Quality Assurance, Bharati Vidyapeeth University, Poona College of Pharmacy, Pune-38, Maharashtra, India \\ ${ }^{2}$ Department of Pharmaceutics, Bharati Vidyapeeth University, Poona College of Pharmacy, Pune-38, Maharashtra, India
}

Correspondence should be addressed to Vividha Dhapte; vividhadhapte@gmail.com

Received 3 April 2016; Revised 16 July 2016; Accepted 1 August 2016

Academic Editor: Jing-Hsien Chen

Copyright (C) 2016 P. Mehta and V. Dhapte. This is an open access article distributed under the Creative Commons Attribution License, which permits unrestricted use, distribution, and reproduction in any medium, provided the original work is properly cited.

\begin{abstract}
Herbal medicines are the oldest and most widely used form of treatment for welfare of mankind. Herbal medicines possess strong reputation as complementary treatment across the globe due to their easy accessibility and safety. Particularly traditional Chinese medicines (TCM) are very popular due to their desirable therapeutic effects. They already have been proven for their remarkable potential in treatment of wide range of disease ailments. The major drawback in using herbal medicines is lack of standardisation aspects due to the complexity of chemical constituents. Pharmacokinetics study of such medicines helps forecast a range of events related to efficacy, safety, and toxicity profile of them. Apart from this, pharmacokinetics studies also recommended by various regulatory agencies during diverse stages of herbal drug development. Thus it is highly essential to have knowledge about the pharmacokinetic properties of any herbal drug. Thus it was thought that it will be worthwhile to compile the pharmacokinetic data of TCM which will be helpful for the researchers involved in further research on TCM. To portray entire picture about absorption, distribution, metabolism, and excretion (ADME) of some TCM, this well-designed scientific review covers the pharmacokinetic profile of 50 TCM available from 2003 and onwards.
\end{abstract}

\section{Introduction}

Since time immemorial traditional medicines play pivotal role in welfare of mankind. Ayurveda (India) and traditional Chinese medicine (China) are popular in culture specific clinical practices since thousands of years. These traditional medicines have already achieved unique reliability and reputation outside realm of traditional medicine due to their crucial therapeutic values. These are commonly employed as complementary treatment for various diseases and to maintain the health conditions. Traditional medicine has become a colloquial phrase which commonly points out to herbal medicinal product, phytomedicine, natural products, and botanicals. Traditional medicines have dominated the human pharmacopoeia for thousands of years [1,2].

Predominantly herbal medicines are massive source of phytochemicals, including various primary and secondary metabolites. The therapeutic values of these herbal medicines are attributed to plethora of active compounds. Therapeutic efficacy of such herbal material is very difficult to interpret due to their multicomponent nature. As they are frequently used in community to strengthen health condition, it is essential to consider their scientific and biomedical scope. Pharmacokinetic data helps to explore the scientific and biomedical scope of such herbal medicines. In accordance with World Health Organization (WHO), the data available for efficacy and safety of herbal medicines was far away to meet for worldwide use [3]. Apart from WHO, it is also of prime importance of regulatory aspects of various countries. Even though sophisticated analytical tools, molecular-biological models, and emerging clinical studies help to reveal the pharmacokinetics of multicomponent medicinal herbs and then also complete evidenced based pharmacokinetics, pharmacodynamics, and metabolisms studies are in paucity. Hence in current state, pharmacokinetic studies have become a fundamental part of drug development process. Pharmacokinetic profile of phytoconstituents serves as substrate for designing dosage form with optimal efficacy and minimal toxicity. 
TCM play a greater role in the treatment of many ailments. Although there are numerous research papers that deal with pharmacokinetic properties of different phytoconstituents from TCM there are number of phytoconstituents yet to be scrutinized for their kinetic properties. The aim of the current review is to explore the ADME, pharmacokinetics, tissue distribution, and metabolism of various TCM. Present review offers crucial pharmacokinetic information about 50 medicinal plants of TCM gathered from various reputed electronic search engines from 2003 and onward. In addition, the analytical conditions utilised for the pharmacokinetics are also compiled which will be useful for the researchers to get prelim idea while developing analytical methods for new constituents or repeating the existing methods. The review provides researcher a significant platform to carry out further studies in domain of pharmacokinetics.

\section{Flavonoid}

2.1. Scutellaria baicalensis Georgi. Roots of Scutellaria baicalensis Georgi (Skullcap) (Lamiaceae) are very well known in TCM for treatment of various disease conditions. Skullcap decoction is commonly used to treat fever. Additionally, skullcap tincture is also used to treat various allergic reactions. Baicalein (5,6,7-trihydroxyflavone) is a flavonoid obtained from skullcap roots. After oral administration it biotransforms to active metabolite, that is, baicalin (7-O$\beta$-glucopyranuronoside). Baicalein shows variety of pharmacological actions that is anti-inflammatory, antifibrotic, antioxidant, and antiviral.

A high performance liquid chromatography (HPLC) system was equipped with mass spectrometer (6110 series, Agilent Technologies, USA) place at selective ion monitoring (SIM) mode. Chromatographic separation was achieved using SB-C18 $\left(2.1 \times 50 \mathrm{~mm}, 2.7 \mu \mathrm{m}, 40^{\circ} \mathrm{C}\right)$ Agilent Poroshell 120 column. The mobile phase is composed of water containing $0.1 \%$ formic acid and acetonitrile $(78: 22, \mathrm{v} / \mathrm{v})$. The total run time and flow rate were $13 \mathrm{~min}$ and $0.3 \mathrm{~mL} / \mathrm{min}$, respectively. Luteolin (purity $>98 \%$ ) was used as internal standard (IS). Lowest limit of quantification (LLOQ) for baicalein and baicalin was 8.0 and $12 \mathrm{ng} / \mathrm{mL}$. The reported pharmacokinetic profile of baicalein and baicalin is given in Table 1. After oral administration of baicalein in monkey it undergoes first-pass metabolism and hence plasma concentration and area under the plasma concentration-time curve (AUC) of baicalin were much higher in comparison to the baicalein at each dose level. After intravenous administration of baicalein is quickly metabolized to baicalin, similar results are seen in rats and human beings. Parent molecule and its metabolite show nonlinear absorption and elimination after oral administration [4].

2.2. Mangifera indica L. Mangiferin (2-b-D-glucopyranosyl$1,3,6,7$-tetrahydroxyxanthone) is a bioactive flavonoid isolated from Mangifera indica L. (Anacardiaceae). It shows antidiabetic, hepatoprotective, antioxidation, antitumor, antiHIV, immunomodulatory, and anti-inflammatory activities.

HPLC system was composed of single quadrupole mass spectrometer with electrospray ionization (ESI) source in negative ion mode. Chromatographic separation was performed on Waters Symmetry C18 analytical column $(250 \times$ $4.6 \mathrm{~mm}, 5.0 \mu \mathrm{m}$, and $40^{\circ} \mathrm{C}$.) The isocratic mobile phase is composed of methanol and $0.5 \%$ aqueous formic acid $(30: 70$, $\mathrm{v} / \mathrm{v})$. The elution run time, flow rate, and volume of injection were $10 \mathrm{~min}, 1.0 \mathrm{~mL} / \mathrm{min}$, and $10 \mu \mathrm{L}$, respectively. The limit of detection (LOD) and limit of quantitation (LOQ) were found to be 2.0 and $5.0 \mathrm{ng} / \mathrm{mL}$, respectively. The pharmacokinetic parameters after administration of mangiferin to human volunteers are given in Table 2. In present investigation mangiferin exhibits nonlinear pharmacokinetic behavior. It gets absorbed in gastrointestinal tract (GIT) and shows hepatic first-pass metabolism. It is one of the crucial reasons for low bioavailability of mangiferin. To improve health-promoting effects we have to tailored new kinds of dosage forms [5].

2.3. Smilax glabra Roxb. Astilbin is a flavonoid compound isolated Smilax glabra Roxb. (Liliaceae). Astilbin undergoes extensive biotransformation specifically due to enzyme catechol-O-methyl transferase. It gives rise to $3^{\prime}$-O-methylastilbin, a major metabolite of astilbin, which plays important role against the inhibition activated $\mathrm{T}$ lymphocytes.

HPLC system was equipped with quadrupole mass spectrometer (LC-MS-2010A, Shimadzu, Japan) with an ESI probe using selective ion monitoring (SIM) mode. Chromatographic separation was achieved on a Shim-pack C18 column $\left(150 \times 2.0 \mathrm{~mm}, 5.0 \mu \mathrm{m}, 40^{\circ} \mathrm{C}\right.$, LC-10AD, Shimadzu, Japan). The binary gradient mobile phase consists of $5.0 \%$ methanol:95\% water and 95\% methanol:5\% water. Both mixtures contain $0.01 \%$ formic acid. The flow rate was $0.2 \mathrm{~mL} / \mathrm{min}$. Silybin was used as IS. The pharmacokinetic parameters of astilbin and $3^{\prime}$-O-methylastilbin are given in Table 3. The pharmacokinetic data, that is, $\mathrm{AUC}_{(0-t)}$, indicate that exposure of $3^{\prime}$-O-methylastilbin was slightly lower than that of unchanged drug [6].

2.4. Erigeron breviscapus (Vaniot). Erigeron breviscapus (Vaniot) (Compositae) contains scutellarin (scutellarein 7-O$\beta$-D-glucuronide) as major bioactive flavonoid glucuronides in it. Scutellarin is also present in Scutellaria lateriflora, Tripora divaricata, and Teucridium parvifolium. It shows wide range of pharmacological actions ranging from cardiovascular diseases, migraine to memory impairment. Presently scutellarin was used as treatment for platelet aggregation, dilating blood vessels, decreasing the viscosity of blood, and improving microcirculation and also in case of reduced blood platelet count.

A HPLC (Agilent 1100, Wilmington, DE) system was composed of mass spectrometer (Finnigan LCQ, San Jose, CA) with ESI in positive ion mode. Chromatographic separation was achieved using a Diamonsil C18 column $(200 \times$ $4.6 \mathrm{~mm}, 5.0 \mu \mathrm{m}, 25^{\circ} \mathrm{C}$, Dikma, Beijing, China) and protected by a $4.0 \times 3.0 \mathrm{~mm}$ Security Guard C18 $(5.0 \mu \mathrm{m})$ guard column (Phenomenex, Torrance, CA). The gradient mobile phase was composed of water and methanol; both contain $0.1 \%$ formic acid in it. The flow rate was $0.5 \mathrm{~mL} / \mathrm{min}$. Baicalin $(98.0 \%$ purity) was used as IS. The pharmacokinetic parameters of isoscutellarin are given in Table 4. In intestine scutellarin 
TABLE 1: Reported pharmacokinetic profile of baicalein and baicalin after three oral doses of baicalein and one i.v. dose of baicalein $(n=4)$ [4].

\begin{tabular}{lccccccc}
\hline Group $(\mathrm{mg} / \mathrm{kg})$ & Parameter & $\mathrm{AUC}_{(0-t)}(\mu \mathrm{g} / \mathrm{Lh})$ & $C_{\max }(\mu \mathrm{g} / \mathrm{L})$ & $T_{\max }(\mathrm{h})$ & $t_{1 / 2}(\mathrm{~h})$ & $\mathrm{MRT}(\mathrm{h})$ & $F_{\mathrm{abs}}(\%)$ \\
\hline \multirow{2}{*}{50} & Baicalein & $454.3 \pm 121.7$ & $167.3 \pm 73.2$ & $1.6 \pm 0.3$ & $1.4 \pm 1.0$ & $2.9 \pm 0.3$ & 23.0 \\
& Baicalin & $18366.3 \pm 4796.3$ & $4216.7 \pm 1380.7$ & $3.8 \pm 0.5$ & $4.1 \pm 0.8$ & $5.1 \pm 0.4$ & \\
\hline \multirow{2}{*}{150} & Baicalein & $1156.1 \pm 205.2$ & $318.4 \pm 51.8$ & $1.4 \pm 0.6$ & $6.4 \pm 3.6$ & $5.9 \pm 0.8$ & 19.9 \\
& Baicalin & $47654.9 \pm 15208.0$ & $7194.7 \pm 4984.5$ & $4.0 \pm 0.8$ & $4.1 \pm 0.5$ & $7.2 \pm 2.5$ & \\
\hline \multirow{2}{*}{500} & Baicalein & $2526.9 \pm 1537.3$ & $612.5 \pm 316.0$ & $2.3 \pm 1.2$ & $13.4 \pm 9.5$ & $6.2 \pm 1.5$ & 13.1 \\
& Baicalin & $104717.4 \pm 52674.3$ & $13687.0 \pm 2215.8$ & $3.5 \pm 0.6$ & $6.5 \pm 3.6$ & $9.0 \pm 4.1$ & - \\
\hline \multirow{2}{*}{ i.v. 10} & Baicalein & $7421.5 \pm 1079.9$ & $30409.2 \pm 4610.7$ & 0.033 & $4.8 \pm 5.0$ & $0.4 \pm 0.2$ & - \\
& Baicalin & $4389.7 \pm 860.4$ & $6146.6 \pm 3363.4$ & 0.083 & $0.9 \pm 0.2$ & $3.3 \pm 0.4$ & - \\
\hline
\end{tabular}

TABLE 2: Reported pharmacokinetic parameters of mangiferin in humans beings $(n=7)$ [5].

\begin{tabular}{lccc}
\hline Parameters & $0.1 \mathrm{~g}$ & $0.3 \mathrm{~g}$ & $0.9 \mathrm{~g}$ \\
\hline $\begin{array}{l}\mathrm{AUC}_{(0-t)} \\
(\mathrm{ng} / \mathrm{mL} \cdot \mathrm{h})\end{array}$ & $144.81 \pm 34.93$ & $171.64 \pm 29.18$ & $301.72 \pm 67.81^{*}$ \\
$\mathrm{AUC}_{(0-\infty)}$ & $167.90 \pm 36.92$ & $269.35 \pm 70.23$ & $415.14 \pm 88.02^{*}$ \\
$(\mathrm{ng} / \mathrm{mL} \cdot \mathrm{h})$ & & & \\
$\mathrm{MRT}_{(0-t)}(\mathrm{h})$ & $7.31 \pm 0.53$ & $15.89 \pm 4.25$ & $13.87 \pm 2.88$ \\
$t_{1 / 2}(\mathrm{~h})$ & $4.47 \pm 0.25$ & $8.80 \pm 2.27$ & $7.85 \pm 1.72$ \\
$T_{\max }(\mathrm{h})$ & $2.42 \pm 0.71$ & $2.17 \pm 0.40$ & $1.08 \pm 0.20$ \\
$\mathrm{CL}_{\mathrm{z}} / F(\mathrm{~L} / \mathrm{h})$ & $0.83 \pm 0.22$ & $1.62 \pm 0.48$ & $2.92 \pm 0.83^{*}$ \\
$V_{\mathrm{z}}(\mathrm{L})$ & $5.32 \pm 1.56$ & $15.07 \pm 3.03^{*}$ & $24.27 \pm 3.28^{* \Delta}$ \\
$C_{\max }(\mathrm{ng} / \mathrm{mL})$ & $19.94 \pm 3.47$ & $34.70 \pm 6.83$ & $38.64 \pm 6.75^{*}$ \\
\hline
\end{tabular}

${ }^{*}$ Compared with $0.1 \mathrm{~g}$ group, $P<0.05 .{ }^{\Delta}$ Compared with 0.3 g group, $P<$ 0.05 .

TABLE 3: Pharmacokinetic parameters of astilbin and $3^{\prime}$-Omethylastilbin in followed by intragastric administration astilbin (40 $\mathrm{mg} / \mathrm{kg}$ and $n=6$ ) [6].

\begin{tabular}{lcc}
\hline Parameters & Astilbin & $3^{\prime}$-O-Methylastilbin \\
\hline$C_{\max }(\mathrm{ng} / \mathrm{mL})$ & $37.7 \pm 14.7$ & $17.8 \pm 8.5$ \\
$T_{\max }(\mathrm{min})$ & $25.8 \pm 34.3$ & $101.7 \pm 50.0$ \\
$t_{1 / 2}(\mathrm{~min})$ & $161.6 \pm 44.1$ & $139.2 \pm 88.2$ \\
$\mathrm{AUC}_{(0-t)}(\mathrm{ng} \mathrm{min} / \mathrm{mL})$ & $5353.4 \pm 1456.3$ & $4120.6 \pm 2407.9$ \\
$\mathrm{AUC}_{(0-\infty)}(\mathrm{ng} \mathrm{min} / \mathrm{mL})$ & $5741.2 \pm 1567.0$ & $5131.7 \pm 3012.9$ \\
\hline
\end{tabular}

undergoes hydrolysis due to $\beta$-glucuronidase, followed by conjugation with glucuronic acid in liver. Scutellarin shows positional selectivity and species variation in conjugation. In human being, 6-OH group was more susceptible for glucuronosyl conjugation in comparison to other $4^{\prime}-, 5-$, and 7OH groups [7].

2.5. Ixeris sonchifolia (Bge.) Hance. Traditional Chinese medicine Ixeris sonchifolia (Bge.) Hance (Compositae) is also well known as "Kudiezi." Kudiezi injection is commonly prescribed for various disease conditions like relieving pain, platelet aggregation, thrombosis, and improving microcirculation. Moreover it is also used in various cardiovascular diseases. The major bioactive flavonoids present in Kudiezi injection are luteolin-7-O-gentiobioside, luteolin-7-O- $\beta$-dglucoside, and luteolin-7-O- $\beta$-d-glucuronide.

Ultra-Fast Liquid Chromatography (UFLC, Shimadzu Prominence TM) was composed of AB SCIEX 4000 QTRAP $^{\mathrm{TM}}$ mass spectrometer with a turbo ion spray interface in negative ionization mode (Foster City, CA, USA). Chromatographic separation was performed on a $\mathrm{C} 18$ column $\left(100 \times 2.1 \mathrm{~mm}, 3.0 \mu \mathrm{m}, 30^{\circ} \mathrm{C}\right.$, Venusil MP, Bonna-Agela Technologies, China). The gradient mobile phase was composed of $0.05 \%$ formic acid and acetonitrile. The injection volume and flow rate were $5.0 \mu \mathrm{L}$ and $0.4 \mathrm{~mL} / \mathrm{min}$, respectively. Pharmacokinetic parameters of three flavonoids are given in Table 5. The pharmacokinetics data showed that the plasma concentrations of three flavonoids persistently increased during intravenous drip and attained the maximum plasma concentrations around the end time of intravenous drip; then the plasma concentrations decreased quickly. Additionally, three flavonoids were eliminated quickly with the mean elimination half time between $1.10 \mathrm{~h}$ and $1.33 \mathrm{~h}$ [8].

2.6. Chrysanthemum morifolium Ramat. The flower of Chrysanthemum morifolium Ramat. (Flos Chrysanthemi) (Asteraceae) is very well known in TCM for various pharmacological actions. It is commonly used as antioxidation, cardiovascular protectant, hepatoprotectant, and being antiarrhythmic and in acute respiratory conditions. Currently, Flos Chrysanthemi extract (FCE) was under clinical investigation for cardiovascular ailments in China. Luteolin $\left(3^{\prime}, 4^{\prime}, 5,7\right.$-tetrahydroxy flavone) and apigenin (4',5,7-trihydroxy flavone) are two major bioactive flavonoids present in FCE. Both are exhibited as anticancer, anti-inflammatory, and neuroprotective also. Chrysoeriol (4',5,7-trihydroxy- $3^{\prime}$-methoxy flavone) and diosmetin $\left(3^{\prime}, 5,7\right.$-trihydroxy- $4^{\prime}$-methoxy flavone) are the two methylated metabolites of luteolin. Both metabolites are known for anti-inflammatory, antioxidant, and osteoporosis treatment.

HPLC system was equipped with variable wavelength detector (VWD) detector. Chromatographic separation was performed on C18 column $\left(250 \times 4.6 \mathrm{~mm}, 5.0 \mu \mathrm{m}, 30 \pm 1^{\circ} \mathrm{C}\right.$, Zorbax SB, Agilent, USA). The mobile phase was composed of $0.1 \%$ formic acid, acetonitrile, and methanol. The flow rate and injection volume were $1.0 \mathrm{~mL} / \mathrm{min}$ and $50 \mu \mathrm{L}$, respectively. The detection wavelength was set at $350 \mathrm{~nm}$. Quercetin was used as IS. The LLOQ of all analytes was $0.025 \mu \mathrm{g} / \mathrm{mL}$. 
TABLE 4: Pharmacokinetic parameters of isoscutellarin after p.o. administration of scutellarin ( $60 \mathrm{mg}$ and $n=20$ healthy Chinese beings) [7].

\begin{tabular}{lcccc}
\hline Parameters & Mean & SD & Maximum values & Minimum values \\
\hline $\mathrm{AUC}_{(0-t)}(\mathrm{ng} / \mathrm{mL} \cdot \mathrm{h})$ & 459.3 & 151.4 & 707.4 & 160.7 \\
$\mathrm{AUC}_{(0-\infty)}(\mathrm{ng} / \mathrm{mL} \cdot \mathrm{h})$ & 464.0 & 154.0 & 713.0 & 162.1 \\
$t_{1 / 2}(\mathrm{~h})$ & 3.08 & 0.55 & 4.05 & 2.22 \\
$\mathrm{AUMC}_{(0-t)}\left(\mathrm{ng} / \mathrm{mL} \cdot \mathrm{h}^{2}\right)$ & 4017 & 2029 & 7717 & 1070 \\
$\mathrm{AUMC}_{(0-\infty)}\left(\mathrm{ng} / \mathrm{mL} \cdot \mathrm{h}^{2}\right)$ & 4102 & 2090 & 7824 & 1093 \\
$\mathrm{MRT}(\mathrm{h})$ & 8.87 & 2.10 & 11.94 & 6.35 \\
$\mathrm{CL} / F(\mathrm{~L} / \mathrm{h})$ & 147.9 & 75.8 & 370.1 & 84.2 \\
$V_{\mathrm{d}} / F(\mathrm{~L})$ & 690.1 & 490.7 & 2165 & 270.1 \\
$V_{\mathrm{dss}} / F(\mathrm{~L})$ & 1206 & 481.9 & 2496 & 717.5 \\
$T_{\max }(\mathrm{h})$ & 7.85 & 1.62 & 11.00 & 5.00 \\
$C_{\max }(\mathrm{ng} / \mathrm{mL})$ & 87.01 & 29.14 & 128.1 & 38.11 \\
\hline
\end{tabular}

TABLE 5: Pharmacokinetic parameters of luteolin-7-O-gentiobioside, luteolin-7-O- $\beta$-d-glucoside, and luteolin-7-O- $\beta$-d-glucuronide after i.v. administration of Kudiezi injection to beagle dogs $(n=6)$ [8].

\begin{tabular}{lcccccc}
\hline Analytes & $\begin{array}{c}\mathrm{AUC}_{(0-t)} \\
(\mathrm{ngh} / \mathrm{mL})\end{array}$ & $\begin{array}{c}\mathrm{AUC}_{(0-\infty)} \\
(\mathrm{ngh} / \mathrm{mL})\end{array}$ & $t_{1 / 2}(\mathrm{~h})$ & $T_{\max }(\mathrm{h})$ & $C_{\max }(\mathrm{ng} / \mathrm{mL})$ & $\begin{array}{c}\mathrm{LLOQ} \\
(\mathrm{ng} / \mathrm{mL})\end{array}$ \\
\hline Luteolin-7-O-gentiobioside & $54.42 \pm 9.90$ & $56.89 \pm 10.15$ & $1.103 \pm 0.221$ & $1.014 \pm 0.034$ & $43.82 \pm 13.68$ & 1.0 \\
Luteolin-7-O- $\beta$-d-glucoside & $56.71 \pm 7.87$ & $59.23 \pm 8.30$ & $1.330 \pm 0.267$ & $0.944 \pm 0.136$ & $51.22 \pm 14.36$ & 1.0 \\
Luteolin-7-O- $\beta$ d-glucuronide & $228.8 \pm 19.6$ & $238.7 \pm 19.7$ & $1.184 \pm 0.877$ & $1.000 \pm 0.000$ & $249.0 \pm 58.2$ & 4.0 \\
\hline
\end{tabular}

The pharmacokinetic parameters are given in Table 6. Entacapone shows 1.50 and 1.47-fold improvement in AUC of apigenin and luteolin, respectively. Additionally, it shows approximately 1.40 -fold improvement in $C_{\max }$ of apigenin and luteolin, while entacapone shows 1.44 - and 1.23-fold depletion in AUC of chrysoeriol and diosmetin, respectively. Entacapone does not show any significant change on mean residence time (MRT) of both bioactive flavonoids [9].

2.7. Citrus aurantium L. Naringin, hesperidin, neohesperidin, naringenin, and hesperetin are the major bioactive flavonoids present in the dried, mature fruit of Citrus aurantium L. (Rutaceae), that is, Fructus Aurantii (Zhiqiao). It shows antioxidant, antiviral, antiallergic, vasoprotective, anticarcinogenic, antitumor, antihypertension, and antishock actions.

HPLC (Surveyor TM) was composed of TSQ Quantum triple quadrupole mass spectrometer with ESI in negative ion mode. Chromatographic separation was achieved on a C18 column $\left(150 \times 2.1 \mathrm{~mm}, 5.0 \mu \mathrm{m}, 30^{\circ} \mathrm{C}\right.$, Zorbax SB, Agilent, USA) in presence of a C18 guard column $(5 \mu \mathrm{m}$, Phenomenex, USA). The gradient mobile phase was composed of acetonitrile and water containing $0.1 \%$ formic acid. The flow rate and injection volume were $0.3 \mathrm{~mL} / \mathrm{min}$ and $20 \mu \mathrm{L}$, respectively. Liquiritin was used as IS. The pharmacokinetic parameters and LLOQ values are given in Table 7. $\mathrm{AUC}_{(0-t)}$ of naringenin and hesperetin were much superior than those of naringin, hesperidin, and neohesperidin, although the administered doses of aglycones were rather less than those of the glycosides. This trend may be due to the hydrolysis of flavanone glycosides (naringin, hesperidin, and neohesperidin) by gastrointestinal bacteria [10].
2.8. Kaempferia parviflora. 5,7-Dimethoxy flavone (DMF), $5,7,4^{\prime}$-trimethoxy flavone (TMF), and 3,5,7,3', $4^{\prime}$-penta-methoxy flavone (PMF) are the methoxy flavones present in the Kaempferia parviflora (KP) (Zingiberaceae). It shows aphrodisiac, antipeptic ulcer, anti-inflammatory, antiallergenic, antimutagenic, antidepressive, antimicrobial, anticancer, cardioprotective, and antiobesity activity.

Liquid chromatography (LC) system was composed of mass spectrometry (Thermo Fisher Scientific TSQ Quantum) with ESI in positive ion mode. Chromatographic separation was performed on C18 column $(2.0 \times 50 \mathrm{~mm}, 5.0 \mu \mathrm{m}$, Chromolith, EMD/Millipore, Billerica, MA). The gradient mobile phase was composed of $0.5 \%$ formic acid in water and acetonitrile. The flow rate and injection volume were $200 \mu \mathrm{L} / \mathrm{min}$ and $20 \mu \mathrm{L}$, respectively. The pharmacokinetic parameters, LOD, LOQ values, and tissue distribution of methoxyflavones are given in Tables 8 and 9, respectively. The oral bioavailability of the methoxyflavones was very low. After oral administration of KP extract methoxyflavones rapidly reached a maximal plasma concentration within 1 to $2 \mathrm{~h}$. After reaching maximum plasma concentration methoxyflavones were extensively distributed to various organs followed by slow elimination. Methoxyflavones mainly excreted via urine. Demethylated glucuronide and sulfide are the metabolites present in the urine. Only demethylated methoxyflavones were found in feces [11].

2.9. Cirsium japonicum DC. Cirsium japonicum DC. (Compositae) is very well-known perennial herb in China, Japan, and Korea. It is used as being antihemorrhagic, antihypertensive, and antihepatitis agent and as being uretic. 
TABle 6: Pharmacokinetic parameters of luteolin, apigenin, chrysoeriol, and diosmetin in rats after oral administration of $100 \mathrm{mg} / \mathrm{kg}$ FCE with or without coadministration of entacapone $(20 \mathrm{mg} / \mathrm{kg})$ [9].

\begin{tabular}{|c|c|c|c|c|}
\hline \multirow{2}{*}{ Parameters } & \multicolumn{2}{|c|}{ Apigenin } & \multicolumn{2}{|c|}{ Luteolin } \\
\hline & FCE & FCE + entacapone & FCE & FCE + entacapone \\
\hline $\mathrm{AUC}_{(0-12)}(\mathrm{mg} / \mathrm{L} \cdot \mathrm{h})$ & $36.25 \pm 16$ & $54.39 \pm 24$ & $3.971 \pm 1.2$ & $5.862 \pm 1.4^{*}$ \\
\hline $\mathrm{MRT}_{(0-12)}(\mathrm{h})$ & $9.46 \pm 1.1$ & $9.25 \pm 0.9$ & $2.589 \pm 0.51$ & $2.585 \pm 0.52$ \\
\hline$t_{1 / 2 \mathrm{z}}(\mathrm{h})$ & $18.44 \pm 12$ & $10.98 \pm 5.2$ & $2.805 \pm 0.9$ & $6.671 \pm 7.4$ \\
\hline $\mathrm{CL}_{\mathrm{z}} / F(\mathrm{~L} / \mathrm{h} / \mathrm{kg})$ & $0.0876 \pm 0.060$ & $0.06940 \pm 0.046$ & $1.515 \pm 0.45$ & $0.818 \pm 0.51$ \\
\hline$V_{\mathrm{z}} / F(\mathrm{~L} / \mathrm{kg})$ & $2.497 \pm 1.5$ & $1.305 \pm 0.9$ & $5.975 \pm 2.1$ & $4.598 \pm 2.8$ \\
\hline$C_{\max }(\mathrm{mg} / \mathrm{L})$ & $3.310 \pm 0.73$ & $4.567 \pm 1.5$ & $1.684 \pm 0.21$ & $2.466 \pm 0.69$ \\
\hline \multirow{2}{*}{ Parameters } & \multicolumn{2}{|c|}{ Chrysoeriol } & \multicolumn{2}{|c|}{ Diosmetin } \\
\hline & FCE & FCE + entacapone & FCE & FCE + entacapone \\
\hline $\mathrm{AUC}_{(0-12)}(\mathrm{mg} / \mathrm{L} \cdot \mathrm{h})$ & $1.468 \pm 0.09$ & $1.017 \pm 0.17^{* *}$ & $2.869 \pm 0.74$ & $2.329 \pm 0.67$ \\
\hline $\mathrm{MRT}_{(0-12)}(\mathrm{h})$ & $11.07 \pm 0.8$ & $10.66 \pm 1.1$ & $6.568 \pm 0.8$ & $6.869 \pm 0.39$ \\
\hline$t_{1 / 2 \mathrm{z}}(\mathrm{h})$ & $26.24 \pm 9$ & $29.80 \pm 36$ & $7.359 \pm 1.5$ & $7.566 \pm 1.6$ \\
\hline $\mathrm{CL}_{\mathrm{z}} / F(\mathrm{~L} / \mathrm{h} / \mathrm{kg})$ & $1.790 \pm 0.60$ & $1.587 \pm 0.9$ & $1.773 \pm 0.54$ & $2.133 \pm 0.50$ \\
\hline$V_{\mathrm{z}} / F(\mathrm{~L} / \mathrm{kg})$ & $61.84 \pm 12$ & $59.26 \pm 50$ & $18.37 \pm 5.2$ & $23.58 \pm 9$ \\
\hline$C_{\max }(\mathrm{mg} / \mathrm{L})$ & $0.0931 \pm 0.028$ & $0.06404 \pm 0.025$ & $0.3294 \pm 0.052$ & $0.3108 \pm 0.074$ \\
\hline
\end{tabular}

Data are expressed as mean $\pm \mathrm{SD}, n=5 ;{ }^{*} P<0.05 ;{ }^{* *} P<0.01$ compared with the FCE group.

TABLE 7: Pharmacokinetic parameters for naringin, hesperidin, neohesperidin, naringenin, and hesperetin after oral administration of Fructus Aurantii extract $(n=6)[10]$.

\begin{tabular}{lccccc}
\hline Parameter & Naringin & Hesperidin & Neohesperidin & Naringenin & Hesperetin \\
\hline$C_{\max }(\mathrm{ng} / \mathrm{mL})$ & $279.1 \pm 53.83$ & $17.04 \pm 3.042$ & $418.4 \pm 72.08$ & $1088 \pm 198.7$ & $791.0 \pm 165.5$ \\
$T_{\max }(\mathrm{h})$ & $0.28 \pm 0.08$ & $0.25 \pm 0.09$ & $0.28 \pm 0.08$ & $0.42 \pm 0.21$ & $0.42 \pm 0.21$ \\
$t_{1 / 2}(\mathrm{~h})$ & $9.45 \pm 2.88$ & $3.17 \pm 1.21$ & $8.39 \pm 1.45$ & $4.43 \pm 0.60$ & $4.85 \pm 0.51$ \\
$K_{\mathrm{e}}(\mathrm{L} / \mathrm{h})$ & $0.079 \pm 0.022$ & $0.245 \pm 0.083$ & $0.085 \pm 0.014$ & $0.159 \pm 0.019$ & $0.144 \pm 0.016$ \\
$\mathrm{AUC}_{(0-t)}(\mathrm{ng} \cdot \mathrm{h} / \mathrm{mL})$ & $745.4 \pm 304.5$ & $23.41 \pm 7.237$ & $985.7 \pm 410.8$ & $7597 \pm 2778$ & $6548 \pm 2416$ \\
$\mathrm{AUC}_{(0-\infty)}(\mathrm{ng} \cdot \mathrm{h} / \mathrm{mL})$ & $867.1 \pm 337.4$ & $27.33 \pm 9.789$ & $1111 \pm 446.9$ & $7786 \pm 2842$ & $6760 \pm 2474$ \\
$\mathrm{MRT}_{(0-t)}(\mathrm{h})$ & $11.0 \pm 1.20$ & $3.91 \pm 0.51$ & $10.9 \pm 0.58$ & $10.4 \pm 1.11$ & $10.8 \pm 0.90$ \\
$\mathrm{CL} / F(\mathrm{~L} / \mathrm{h}-\mathrm{kg})$ & $3.09 \pm 1.02$ & $6.31 \pm 1.48$ & $3.41 \pm 0.84$ & $0.012 \pm 0.005$ & $0.003 \pm 0.001$ \\
$\mathrm{LLOQ}(\mathrm{ng} / \mathrm{mL})$ & 0.50 & 0.50 & 0.35 & 0.50 & 0.5 \\
\hline
\end{tabular}

TABLE 8: Pharmacokinetic parameters of methoxyflavones after single oral and i.v. $250 \mathrm{mg} / \mathrm{kg}$ dose of KP in rats [11].

\begin{tabular}{lcccc}
\hline Parameters & Route & PMF & TMF & DMF \\
\hline AUC $(\mathrm{h} \cdot \mathrm{g} / \mathrm{mL})$ & Oral & $3.65 \pm 0.63^{* * * * *}$ & $6.96 \pm 1.11^{* * *}$ & $7.01 \pm 1.37^{* * *}$ \\
& IV & $76.77 \pm 19.50^{* *}$ & $275.66 \pm 86.06$ & $5.04 \pm 1.10$ \\
$t_{1 / 2}(\mathrm{~h})$ & Oral & $3.12 \pm 1.34$ & $4.19 \pm 1.45$ & $5.85 \pm 1.72$ \\
& IV & $2.36 \pm 1.89$ & $0.15 \pm 0.04^{* * *}$ & $3.75 \pm 1.01$ \\
$K_{\mathrm{e}}\left(\mathrm{h}^{-1}\right)$ & Oral & $0.28 \pm 0.17^{* * *}$ & $0.32 \pm 0.12$ & $0.13 \pm 0.03^{* * *}$ \\
& IV & $0.61 \pm 0.22^{*}$ & $337.00 \pm 62.17$ & $0.32 \pm 0.11$ \\
$\mathrm{CL}(\mathrm{mL} / \mathrm{h})$ & Oral & $622.85 \pm 114.86^{*}$ & $6.30 \pm 2.17^{* * *}$ & $367.28 \pm 82.35$ \\
$T_{\max }(\mathrm{h})$ & IV & $21.56 \pm 7.18^{* * * * *}$ & $0.85 \pm 0.40$ & $7.98 \pm 2.34^{* * *}$ \\
$C_{\max }(\mu \mathrm{g} / \mathrm{mL})$ & Oral & $1.71 \pm 0.36^{*}$ & $0.88 \pm 0.11$ & $0.76 \pm 0.40$ \\
$V_{\mathrm{d}}(\mathrm{mL})$ & Oral & $0.55 \pm 0.05^{* *}$ & $2385.10 \pm 364.37$ & $0.78 \pm 0.11$ \\
$K_{\mathrm{a}}\left(\mathrm{h}^{-1}\right)$ & Oral & $2637.13 \pm 846.59$ & $8.53 \pm 3.64$ & $2957.53 \pm 458.19$ \\
Bioavailability $(\%)$ & Oral & $1.23 \pm 0.54$ & 1.75 & $8.69 \pm 2.33$ \\
LOD $(\mu \mathrm{g} / \mathrm{mL})$ & - & 3.32 & 0.09 & 2.10 \\
LOQ $(\mu \mathrm{g} / \mathrm{mL})$ & - & 0.19 & 0.19 & 0.93 \\
\hline
\end{tabular}

Data are expressed as mean $\pm \mathrm{SD}(n=10)$. IV, intravenous. ${ }^{*}$ Polyethylene glycol 400: significance higher than the others in the same route at $P<0.05$. ${ }^{* * *}$ Significance lower than the others in the same route, $P<0.05 .{ }^{* * *}$ Significance lower than the other route. 
TABLE 9: Tissue contents in various rat organs after oral administration of $750 \mathrm{mg} / \mathrm{kg} \mathrm{KP}$ [11].

\begin{tabular}{|c|c|c|c|c|}
\hline \multirow{2}{*}{ Organ } & \multirow{2}{*}{ Methoxyflavone } & \multicolumn{3}{|c|}{ Parameter } \\
\hline & & $\mathrm{AUC}_{(0.083-4 \mathrm{~h})}(\mathrm{h} \cdot \mu \mathrm{g} / \mathrm{g}$ organ $)$ & $C_{\max }(\mu \mathrm{g} / \mathrm{g}$ organ $)$ & $T_{\max }(\mathrm{h})$ \\
\hline \multirow{3}{*}{ Liver } & PMF & $9.07 \pm 1.37$ & $3.10 \pm 1.78$ & $3.43 \pm 0.98^{* * * *}$ \\
\hline & TMF & $7.83 \pm 0.33$ & $3.01 \pm 1.49$ & $2.64 \pm 1.38$ \\
\hline & DMF & $8.60 \pm 1.97$ & $3.85 \pm 1.45$ & $2.57 \pm 1.10$ \\
\hline \multirow{3}{*}{ Kidney } & PMF & $2.03 \pm 0.67^{*}$ & $1.00 \pm 0.39$ & $13.43 \pm 0.98$ \\
\hline & $\mathrm{TMF}$ & $3.01 \pm 0.85$ & $1.64 \pm 0.59$ & $3.43 \pm 0.98$ \\
\hline & DMF & $2.51 \pm 0.68$ & $1.33 \pm 0.49$ & $3.43 \pm 0.98$ \\
\hline \multirow{3}{*}{ Lung } & PMF & $1.60 \pm 0.37^{* *}$ & $2.23 \pm 1.13$ & $0.08 \pm 0.17^{* * *}$ \\
\hline & TMF & $1.88 \pm 0.35$ & $1.41 \pm 0.58$ & $1.76 \pm 0.19$ \\
\hline & DMF & $2.17 \pm 0.31$ & $2.00 \pm 1.20$ & $1.20 \pm 0.19$ \\
\hline \multirow{3}{*}{ Brain } & PMF & $0.76 \pm 0.13^{* * *}$ & $0.26 \pm 0.10^{* * *}$ & $3.14 \pm 1.07$ \\
\hline & TMF & $2.50 \pm 0.37$ & $1.43 \pm 0.58$ & $3.43 \pm 0.98$ \\
\hline & DMF & $1.91 \pm 0.56$ & $0.96 \pm 0.37$ & $3.14 \pm 1.07$ \\
\hline \multirow{3}{*}{ Testes } & PMF & $1.01 \pm 0.24^{* * *}$ & $0.50 \pm 0.31^{* * *}$ & $2.36 \pm 1.25$ \\
\hline & TMF & $1.96 \pm 0.67$ & $1.10 \pm 0.43$ & $3.14 \pm 1.07$ \\
\hline & DMF & $1.90 \pm 0.62$ & $10.91 \pm 0.44$ & $2.86 \pm 1.07$ \\
\hline
\end{tabular}

Data are mean $\pm \mathrm{SD}(n=7) .{ }^{*}$ Significance lower than TMF at $P<0.05 .{ }^{* *}$ Significance lower than DMF at $P<0.05 .{ }^{* * *}$ Significance lower than that of TMF and DMF at $P<0.05 .{ }^{* * * *}$ Significance higher than that of TMF and DMF at $P<0.05$.

TABle 10: Pharmacokinetics parameters of after an oral administration of C. japonicum DC. extract $(n=6)$ [12].

\begin{tabular}{lcccccc}
\hline Compounds & $\begin{array}{c}C_{\max }(\mathrm{ng} / \mathrm{mL}) \\
(\mathrm{mean} \pm \mathrm{SD})\end{array}$ & $T_{\max }(\mathrm{min})$ & $t_{1 / 2}(\mathrm{~min})$ & $\begin{array}{c}\mathrm{AUC}_{(0-\mathrm{t})} \\
(\mathrm{ng} / \mathrm{min} / \mathrm{mL}) \\
(\mathrm{mean} \pm \mathrm{SD})\end{array}$ & $\begin{array}{c}\mathrm{AUC}_{(0-\infty)} \\
(\mathrm{ng} / \mathrm{min} / \mathrm{mL}) \\
(\mathrm{mean} \pm \mathrm{SD})\end{array}$ \\
\hline Pectolinarin & $876.77 \pm 97.34$ & 5.00 & $45.57 \pm 8.72$ & $10,900.17 \pm 1094.58$ & $11,180.40 \pm 109$ & $0.01567 \pm 0.0033$ \\
Linarin & $86.79 \pm 1.70$ & 5.00 & $47.74 \pm 3.25$ & $1966.45 \pm 180.13$ & $2103.55 \pm 201.82$ & $0.0146 \pm 0.0010$ \\
Pectolinarigenin & $6.13 \pm 0.12$ & 5.00 & $47.79 \pm 3.10$ & $232.50 \pm 17.76$ & $252.39 \pm 20.39$ & $0.0145 \pm 0.0010$ \\
Hispidulin & $32.85 \pm 2.50$ & 5.00 & $78.37 \pm 7.31$ & $739.59 \pm 54.58$ & $894.97 \pm 63.52$ & $0.0089 \pm 0.0008$ \\
Diosmetin & $37.20 \pm 2.04$ & 5.00 & $81.68 \pm 16.38$ & $917.08 \pm 23.11$ & $1145.95 \pm 62.04$ & $0.0088 \pm 0.0020$ \\
Acacetin & $19.02 \pm 1.29$ & 5.00 & $69.17 \pm 6.86$ & $426.71 \pm 49.20$ & $529.24 \pm 59.96$ & $0.0101 \pm 0.0010$ \\
Apigenin & $148.26 \pm 20.63$ & 360.00 & $234.17 \pm 18.55$ & $85,538.38 \pm 4570.74$ & $86,165.90 \pm 4650.27$ & $0.0030 \pm 0.0002$ \\
\hline
\end{tabular}

Traditionally, it is used as remedy for epistaxis and metrorrhagia. Additionally, it is also used to improve blood circulation. It contains seven different flavonoids like acacetin, apigenin, diosmetin, hispidulin, linarin, pectolinarin, and pectolinarigenin.

HPLC (1200 series, Agilent Technologies, USA) system was composed of tandem mass spectrometer with a turbo ion spray interface in both positive and negative modes. Chromatographic separation was performed on a C18 column $\left(150 \times 4.6 \mathrm{~mm}, 5.0 \mu \mathrm{m}, 25^{\circ} \mathrm{C}\right.$, Diamonsil, DIKMA Company, USA). The gradient mobile phase was composed of methanol and aqueous solution of $0.1 \%$ formic acid. The injection volume and flow rate were maintained at $10 \mu \mathrm{L}$ and $0.8 \mathrm{~mL} / \mathrm{min}$, respectively. Pharmacokinetics parameters of seven flavonoids are given in Table 10. Isomer pair of hispidulin and diosmetin does not indicate any significant difference in pharmacokinetic profile. Due to enterohepatic recirculation apigenin shows double-peak phenomenon. After oral administration acacetin, diosmetin, hispidulin, linarin, pectolinarin, and pectolinarigenin exhibited quick plasma concentration followed by tapering [12].

2.10. Morus alba L. Rutin, isoquercitrin, and astragalin are the three major flavonoids present in Morus alba L. Mulberry is commonly used in China, India, and Japan to treat fever, improve eyesight, and protect liver. It is also shown as antihyperglycemic, antioxidant, neuroprotective, antihypertensive, and antiatherogenic.

Agilent 1200 liquid chromatography system was composed of an API 3200 triple quadrupole mass spectrometer with ESI in negative ionization mode. Chromatographic separation was performed on C18 column $(2.1 \times 150 \mathrm{~mm}$, $3.5 \mu \mathrm{m}, 30^{\circ} \mathrm{C}$, Eclipse Plus, Agilent, USA). The mobile phase was composed of $0.1 \%$ formic acid in water and acetonitrile. The flow rate and injection volume were $0.3 \mathrm{~mL} / \mathrm{min}$ and $10 \mu \mathrm{L}$, respectively. Pharmacokinetic parameters of the six flavonoids are given in Table 11. Six phytoconstituents divided in two parts, that is, flavonoid glycosides (rutin, isoquercitrin, 
TABLE 11: Pharmacokinetic parameters after single oral administration of total flavonoids from mulberry leaves $(n=8)$, [13].

\begin{tabular}{|c|c|c|c|c|c|c|}
\hline \multirow{2}{*}{ Parameter } & \multicolumn{6}{|c|}{ Mean \pm SD } \\
\hline & Rutin & Isoquercitrin & Astragalin & Quercetin & Kaempferol & Isorhamnetin \\
\hline$C_{\operatorname{maxl}}(\mathrm{ng} / \mathrm{mL})$ & $51.65 \pm 32.28$ & $122.66 \pm 70.32$ & $73.28 \pm 40.60$ & $132.58 \pm 73.39$ & $6.86 \pm 4.68$ & $12.50 \pm 8.81$ \\
\hline$C_{\max 2}(\mathrm{ng} / \mathrm{mL})$ & - & - & - & $103.16 \pm 62.50$ & $6.45 \pm 2.21$ & $11.87 \pm 7.74$ \\
\hline$T_{\max 1}(\mathrm{~h})$ & $0.26 \pm 0.16$ & $0.23 \pm 0.12$ & $0.19 \pm 0.06$ & $0.18 \pm 0.08$ & $0.30 \pm 0.13$ & $0.19 \pm 0.07$ \\
\hline$T_{\max 2}(\mathrm{~h})$ & - & - & - & $6.75 \pm 1.04$ & $7.75 \pm 2.25$ & $7.25 \pm 1.83$ \\
\hline$t_{1 / 2}(\mathrm{~h})$ & $1.19 \pm 0.62$ & $0.88 \pm 0.61$ & $0.87 \pm 0.52$ & $6.09 \pm 1.67$ & $8.33 \pm 2.83$ & $10.03 \pm 4.89$ \\
\hline$K_{\mathrm{e}}\left(\mathrm{h}^{-1}\right)$ & $0.77 \pm 0.45$ & $1.20 \pm 0.78$ & $1.03 \pm 0.54$ & $0.12 \pm 0.04$ & $0.09 \pm 0.03$ & $0.09 \pm 0.06$ \\
\hline $\mathrm{AUC}_{(0-24)}(\mathrm{ng} \cdot \mathrm{h} / \mathrm{L})$ & $85.34 \pm 28.86$ & $99.51 \pm 22.04$ & $61.66 \pm 31.17$ & $755.03 \pm 468.23$ & $45.90 \pm 29.71$ & $99.27 \pm 58.61$ \\
\hline $\mathrm{AUC}_{(0-\infty)}(\mathrm{ng} \cdot \mathrm{h} / \mathrm{L})$ & $85.85 \pm 28.81$ & $106.38 \pm 21.71$ & $69.87 \pm 33.68$ & $772.19 \pm 457.94$ & $56.20 \pm 38.02$ & $108.17 \pm 58.53$ \\
\hline
\end{tabular}

TABLE 12: Pharmacokinetic parameters of genkwanin after oral and i.v. administrations [14].

\begin{tabular}{lcc}
\hline \multirow{2}{*}{ Parameters } & \multicolumn{2}{c}{ Administration mode } \\
& Oral (50 mg/kg) & Intravenous (5 mg/kg) \\
\hline $\mathrm{AUC}_{(0-t)}(\mathrm{ng} \mathrm{h} / \mathrm{mL})$ & $218 \pm 40$ & $2349 \pm 573$ \\
$\mathrm{AUC}_{(0-\infty)}(\mathrm{ng} \mathrm{h} / \mathrm{mL})$ & $246 \pm 50$ & $2367 \pm 581$ \\
$C_{\text {max }}(\mathrm{ng} / \mathrm{mL})$ & $36.9 \pm 9.4$ & $1755 \pm 197$ \\
$T_{\text {max }}(\mathrm{h})$ & $3.83 \pm 1.33$ & - \\
$t_{1 / 2}(\mathrm{~h})$ & $3.07 \pm 0.90$ & $1.79 \pm 0.12$ \\
$\mathrm{MRT}_{(0-t)}(\mathrm{h})$ & $5.35 \pm 0.73$ & $1.93 \pm 0.15$ \\
$\mathrm{MRT}_{(0-\infty)}(\mathrm{h})$ & $6.63 \pm 0.71$ & $2.02 \pm 0.17$ \\
$F(\%)$ & $1.1 \pm 0.4$ & - \\
\hline
\end{tabular}

and astragalin) and their metabolites (quercetin, kaempferol, and isorhamnetin). Three flavonoid glycosides were rapidly absorbed and eliminated from rat plasma. Double peaks phenomenon was observed for quercetin, kaempferol, and isorhamnetin. AUC of quercetin was much higher than that of the other five compounds [13].

2.11. Daphne genkwa Sieb. et Zucc. Genkwanin is a flavonoid present in the Chinese plant Daphne genkwa Sieb. et Zucc. (Thymelaeaceae). The roots and buds of Daphne genkwa exhibit various pharmacological actions. It is used as being abortifacient, antitussive, antileukemia, antitumor, diuretic, and expectorant also. Genkwanin is a flavonoids present in plant. It mostly exhibits anticancer, anti-inflammatory, and analgesic effects and it also shows modulatory effects of cellular immune system. It also serves as marker for quality control of Daphne genkwa.

HPLC (1200 series, Agilent Technologies, USA) system was composed of triple quadrupole mass spectrometer (6410 series, Agilent Technologies, USA) with ESI in negative ion mode. The mobile phase was composed of $65 \%$ methanol and $35 \%$ water containing $5 \mathrm{mM}$ ammonium acetate with $0.1 \%$ formic acid. Chromatographic separation was performed on Agela Venusil MP-C18 analytical column $(2.1 \times 50 \mathrm{~mm}$, $5 \mu \mathrm{m}, 30^{\circ} \mathrm{C}$, Agela Technologies Inc.). The flow rate, injection volume, and run time were $0.30 \mathrm{~mL} / \mathrm{min}, 5.0 \mu \mathrm{L}$, and $4.0 \mathrm{~min}$, respectively. Genistein (purity $>98 \%$ ) was used as IS. The LLOQ of genkwanin was found to be $3.84 \mathrm{ng} / \mathrm{mL}$. Pharmacokinetic parameters of genkwanin are given in Table 12.
Genkwanin shows efficacy on intravenous administration as compared to oral administration. Low bioavailability (1.10\%) of genkwanin was attributed to poor intestinal permeability and rapid first-pass metabolism [14].

2.12. Juglans mandshurica Maxim. Six flavonoids (myricitrin, quercitrin, taxifolin, myricetin, quercetin, and naringenin), gallic acid, and 5,8-dihydroxy-1,4-naphthoquinone are major bioactive components in Cortex Juglans mandshurica (CJM) extract. CMJ is the bark of Juglans mandshurica Maxim. (JMM) (Juglandaceae). CJM shows various pharmacological actions like antioxidant, antitumor, anti-inflammatory, anti$\mathrm{HIV}$, and antiparasitic action.

Ultrahigh performance liquid chromatography (UHPLC, ACQUITYTM, Waters Corp., Milford, USA) system was composed of triple quadrupole tandem mass spectrometer (Waters Corp., Milford, USA) with ESI in negative ionization mode. Chromatographic separation was performed on a Venusil ASB C18 column $\left(2.1 \times 100 \mathrm{~mm}, 5.0 \mu \mathrm{m}, 20^{\circ} \mathrm{C}\right)$. The gradient mobile phase was composed of acetonitrile and $0.1 \%$ formic acid. The flow rate and injection volume were $0.2 \mathrm{~mL} / \mathrm{min}$ and $20 \mu \mathrm{L}$, respectively. The temperature of autosampler was maintained at $4^{\circ} \mathrm{C}$. Chloromycetin was used as IS. Pharmacokinetic parameters after oral administrations of Cortex Juglans mandshurica extract and LLOQ values are given in Table 13. The significant difference in pharmacokinetic parameters for each analyte is due to the complex constituents in plant extract, which could induce drug-drug interactions and affect the pharmacokinetic behavior of each substance. Apart from 5,8-dihydroxy-1,4-naphthoquinone, metabolite is also found in rat plasma [15].

\section{Saponin}

3.1. Gypsophila oldhamiana. Bidesmosidic triterpenoid saponin (BST-1) is the oleanane type saponin present in roots of Gypsophila oldhamiana (Caryophyllaceae). These saponins exhibit anticancer and antidiabetic activities.

LC-2010 instrument (Shimadzu, Japan) was equipped with a UV detector and it was set at $210 \mathrm{~nm}$. Chromatographic separation was performed on C18 column $(250 \times 4.6 \mathrm{~mm}$, $5.0 \mu \mathrm{m}, 30^{\circ} \mathrm{C}$, Welch Materials Inc., USA) and protected by a C18 guard column $(7.5 \times 4.6 \mathrm{~mm})$. The mobile phase was composed of aqueous formic acid $0.05 \%$ and acetonitrile. The flow rate and injection volume are $1.0 \mathrm{~mL} / \mathrm{min}$ and $20 \mu \mathrm{L}$, 
TABLE 13: Pharmacokinetic parameters after oral administrations of Cortex Juglandis Mandshuricae extract to rats $(n=6)$ [15].

\begin{tabular}{|c|c|c|c|c|c|c|}
\hline Parameters & $C_{\max }(\mathrm{ng} / \mathrm{mL})$ & $T_{\max }(\mathrm{h})$ & $\begin{array}{c}t_{1 / 2} \\
(\mathrm{~h})\end{array}$ & $\begin{array}{c}\mathrm{AUC}_{(0-t)} \\
(\mathrm{ng} \mathrm{h} / \mathrm{mL})\end{array}$ & $\begin{array}{l}\mathrm{AUC}_{(0-\infty)} \\
\text { (ng h/mL) }\end{array}$ & $\begin{array}{c}\text { LLOQ } \\
(\mathrm{ng} / \mathrm{mL})\end{array}$ \\
\hline Gallic acid & $3443.76 \pm 590.25$ & $11.33 \pm 1.63$ & $11.11 \pm 1.15$ & $32,197.94 \pm 6726.62$ & $33,181.25 \pm 7003.57$ & 20 \\
\hline Myricitrin & $103.36 \pm 8.49$ & $11.33 \pm 1.63$ & $10.05 \pm 1.63$ & $1009.24 \pm 112.15$ & $1105.05 \pm 125.02$ & 5.0 \\
\hline Quercitrin & $111.29 \pm 26.98$ & $8.33 \pm 1.97$ & $6.20 \pm 1.68$ & $1059.03 \pm 160.82$ & $1095.39 \pm 154.96$ & 3.0 \\
\hline Taxifolin & $110.24 \pm 19.17$ & $8.33 \pm 2.94$ & $9.58 \pm 1.49$ & $914.13 \pm 203.48$ & $1090.99 \pm 234.24$ & 10 \\
\hline Myricetin & $54.10 \pm 2.07$ & $8.33 \pm 1.97$ & $10.99 \pm 1.66$ & $655.64 \pm 93.27$ & $767.51 \pm 118.48$ & 6.0 \\
\hline Quercetin & $33.57 \pm 6.50$ & $6.67 \pm 1.03$ & $11.09 \pm 2.34$ & $328.55 \pm 71.38$ & $382.08 \pm 77.72$ & 3.0 \\
\hline Naringenin & $64.83 \pm 28.90$ & $8.67 \pm 1.63$ & $11.12 \pm 2.85$ & $581.66 \pm 224.28$ & $641.38 \pm 243.09$ & 2.0 \\
\hline $\begin{array}{l}\text { 5,8-Dihydroxy-1,4- } \\
\text { naphthoquinone }\end{array}$ & $\begin{array}{c}9965.75 \pm \\
1745.38\end{array}$ & $4.00 \pm 0.00$ & $10.38 \pm 1.69$ & $63,876.73 \pm 1203.66$ & $66,032.97 \pm 13,172.50$ & 100 \\
\hline
\end{tabular}

TABLE 14: Pharmacokinetic parameters for BTS-1 in rats $(n=5)$ after a single $400 \mathrm{mg} / \mathrm{kg}$ oral dose [16].

\begin{tabular}{lc}
\hline Pharmacokinetic parameters & Value $($ mean $\pm \mathrm{SD})$ \\
\hline$T_{\text {max }}(\mathrm{h})$ & $1.28 \pm 0.29$ \\
$C_{\text {max }}(\mathrm{mg} / \mathrm{mL})$ & $37.4 \pm 5.6$ \\
$V_{\mathrm{d}}(\mathrm{L})$ & $43.0 \pm 3.4$ \\
$\mathrm{CL}_{\text {total }}(\mathrm{L} / \mathrm{h})$ & $3.30 \pm 0.26$ \\
$t_{1 / 2}(\mathrm{~h})$ & $13.19 \pm 6.58$ \\
$\mathrm{AUC}_{(0-t)}(\mathrm{mg} / \mathrm{mL} \cdot \mathrm{h})$ & $121.8 \pm 16.8$ \\
$\mathrm{AUC}_{(0-\infty)}(\mathrm{mg} / \mathrm{mL} \cdot \mathrm{h})$ & $138.3 \pm 13.2$ \\
$\mathrm{MRT}_{(0-\infty)}(\mathrm{h})$ & $12.8 \pm 1.6$ \\
\hline
\end{tabular}

TABLE 15: Pharmacokinetic parameters after oral administration of EsA in beagle dogs $(n=6)$ [17].

\begin{tabular}{lccc}
\hline Parameters & \multicolumn{3}{c}{ Mean $\pm \mathrm{SD}$} \\
\hline$T_{\max }(\mathrm{h})$ & $3.7 \pm 0.8$ & $5.3 \pm 1.0$ & $4.7 \pm 1.0$ \\
$C_{\max }(\mathrm{ng} / \mathrm{mL})$ & $281.4 \pm 35.2$ & $388.2 \pm 51.6$ & $1005 \pm 187$ \\
$t_{1 / 2}(\mathrm{~h})$ & $3.5 \pm 0.5$ & $3.3 \pm 0.4$ & $3.6 \pm 0.5$ \\
MRT $(\mathrm{h})_{\mathrm{AUC}_{(0-24)}(\mathrm{ng} \mathrm{h} / \mathrm{mL})}$ & $8.2 \pm 0.3$ & $8.1 \pm 0.5$ & $7.5 \pm 0.5$ \\
AUC $_{(0-\infty)}(\mathrm{ng} \mathrm{h} / \mathrm{mL})$ & $3085 \pm 226$ & $4496 \pm 340$ & $6828 \pm 757$ \\
\hline
\end{tabular}

respectively. The LOD and LLOQ were found to be 0.032 and $0.089 \mathrm{mg} / \mathrm{mL}$, respectively. Glycyrrhizic acid (purity 98.0\%) was used as IS. The pharmacokinetic data of BTS-1 is given in Table 14. After oral administration of BTS-1 to rats, it was rapidly absorbed and then eliminated slowly, the elimination involving metabolism to secondary glycosides and aglycones with $\alpha$-glucosidase inhibitory activity [16].

3.2. Radix Phytolaccae. Esculentoside A (EsA) is the principal pentacyclic triterpene saponin isolated from the root of Radix Phytolaccae (Phytolacca acinosa Roxb. or Phytolacca americana L.) (Phytolaccaceae). It shows anti-inflammation, antitumor, protective effect on radiation-induced dermatitis, fibrosis, and immunity regulation like activities.

LC-MS/MS system (Thermo Fisher scientific, San Jose, CA, USA) was equipped with EIS in positive ion mode.
Chromatographic separation was performed on a Diamonsil C18 analytical column $\left(2.1 \times 50 \mathrm{~mm}, 3.0 \mu \mathrm{m}, 25^{\circ} \mathrm{C}\right.$, DIKMA, USA) and protected by a Hypersil Gold C18 guard column (2.1 $\times 10 \mathrm{~mm}, 5 \mu \mathrm{m}$, Thermo Scientific, USA). The mobile phase was composed of methanol-water containing $0.1 \%$ acetic acid $(70: 30, \mathrm{v} / \mathrm{v})$. The flow rate, injection volume, and total analysis time were $0.2 \mathrm{~mL} / \mathrm{min}, 10 \mu \mathrm{L}$, and $5.0 \mathrm{~min} / \mathrm{sample}$, respectively. The LLOQ was $5.0 \mathrm{ng} / \mathrm{mL}$. The pharmacokinetic parameters after oral administration of EsA are given in Table 15 . In 2.5 to $10 \mathrm{mg} / \mathrm{kg}$ dose range pharmacokinetic behavior of EsA was found be more linear but on the same line AUC did not increase in direct proportion with administration dosage. The reason behind that is that the bloodtaking spots were too dense in the absorption phase [17].

3.3. Dioscorea zingiberensis C.H. Wright. Total steroid saponins (TSSN) extracted from the rhizomes of Dioscorea zingiberensis C.H. Wright (Dioscoreaceae) are the major potential bioactive constituents. It is commonly used for cough, anthrax, rheumatoid arthritis, and sprain as well as cardiac diseases. TSSN contains five saponins which are protodioscin (A), huangjiangsu A (B), zingiberensis (C), dioscin (D), and gracillin (E).

Liquid chromatography system (2695 serious, Waters, Milford, MA, USA) was composed of a Varian triple quadrupole mass spectrometer (320-MS) with ESI in positive ion interface. Chromatographic separation was performed on Inersil ODS-3 column $\left(250 \times 4.6 \mathrm{~mm}, 5.0 \mu \mathrm{m}, 25^{\circ} \mathrm{C}\right)$. The gradient mobile phase was composed of $0.1 \%$ formic acid in water and acetonitrile. The sample injection volume was $10 \mu \mathrm{L}$. Ginsenoside Rb1 (98\% purity) was used as IS. The pharmacokinetic parameters of five steroid saponins are given in Table 16. Single dose and extract administration show the different pharmacokinetic characteristics. Double-peak absorption phenomenon was observed in steroid saponins A and B (furostanol type saponin) while it is absent in reaming three (spirostanol type saponin) steroidal saponins, respectively, due to F ring cleavage and closed F ring. The spirostanol saponins are more stable than furostanol saponins [18].

3.4. Platycodon grandiflorum. Platycosides are bidesmosidic saponins present in the root of Platycodon grandiflorum (PG), (Campanulaceae). Variety of saponins like platycodins (A, 
TABLE 16: Pharmacokinetic parameters after oral administration of total extract from Dioscorea zingiberensis C.H. Wright $(n=6)$ [18].

\begin{tabular}{lccccc}
\hline Parameters & Protodioscin & Huangjiangsu A & Zingiberensis & Dioscin & Gracillin \\
\hline$C_{\max }(\mathrm{ng} / \mathrm{mL})$ & $29.18 \pm 1.83$ & $14.87 \pm 1.46$ & $14.87 \pm 1.46$ & $38.24 \pm 0.63$ & $130.86 \pm 1.90$ \\
$T_{\max }(\mathrm{h})$ & $11.98 \pm 2.45$ & $11.43 \pm 3.24$ & $10.32 \pm 2.17$ & $10.29 \pm 1.19$ & $12.79 \pm 2.49$ \\
$t_{1 / 2}(\mathrm{~h})$ & $15.86 \pm 2.13$ & $11.04 \pm 2.03$ & $17.04 \pm 2.03$ & $12.79 \pm 1.66$ & $37.29 \pm 1.82$ \\
$K_{\mathrm{e}}\left(\mathrm{h}^{-1}\right)$ & $0.044 \pm 1.01$ & $0.063 \pm 1.98$ & $0.041 \pm 3.32$ & $0.054 \pm 2.84$ & $0.019 \pm 3.72$ \\
$\mathrm{MRT}(\mathrm{h})$ & $18.15 \pm 1.83$ & $21.06 \pm 2.30$ & $48.61 \pm 1.73$ & $25.87 \pm 0.74$ & $57.99 \pm 1.15$ \\
$\mathrm{CL}(\mathrm{L} / \mathrm{h})$ & $0.21 \pm 0.02$ & $0.23 \pm 0.02$ & $0.06 \pm 0.004$ & $0.11 \pm 0.01$ & $0.01 \pm 0.003$ \\
$\mathrm{AUC}_{(0-t)}(\mathrm{h} \mathrm{ng} / \mathrm{mL})$ & $6473.11 \pm 821.05$ & $291.31 \pm 21.14$ & $291.31 \pm 21.14$ & $19990.91 \pm 727.16$ & $106902.70 \pm 2118.13$ \\
$\mathrm{AUC}_{(0-\infty)}(\mathrm{h} \mathrm{ng} / \mathrm{mL})$ & $9098.37 \pm 1656.58$ & $6747.44 \pm 1504.58$ & $6747.44 \pm 1504.58$ & $28379.48 \pm 2066.52$ & $469583.7 \pm 24463.47$ \\
\hline
\end{tabular}

TABLE 17: Pharmacokinetic parameters of PD and PD3 after intravenous $(25 \mathrm{mg} / \mathrm{kg})$ or oral administration of PD $(500 \mathrm{mg} / \mathrm{kg})$ to rats $(n=4)$ [19].

\begin{tabular}{lcc}
\hline Parameter & PD & PD3 \\
\hline & Intravenous & \\
AUC $(\mu \mathrm{g} \cdot \mathrm{h} / \mathrm{mL})$ & $11.42 \pm 3.43$ & $1.96 \pm 0.50$ \\
$t_{1 / 2}(\mathrm{~h})$ & $1.99 \pm 0.41$ & $3.55 \pm 0.87$ \\
$\mathrm{MRT}(\mathrm{h})$ & $1.58 \pm 0.41$ & $2.85 \pm 0.77$ \\
$V_{\mathrm{ss}}(\mathrm{L} / \mathrm{kg})$ & $3.59 \pm 1.28$ & $35.32 \pm 18.69$ \\
$\mathrm{CL}(\mathrm{L} / \mathrm{h} / \mathrm{kg})$ & $2.32 \pm 0.90$ & $11.84 \pm 27.77$ \\
\hline & Oral & \\
$\mathrm{AUC}(\mu \mathrm{g} \cdot \mathrm{h} / \mathrm{mL})$ & $0.66 \pm 0.36$ & $0.53 \pm 0.31$ \\
$t_{1 / 2}(\mathrm{~h})$ & $6.23 \pm 1.84$ & $6.20 \pm 1.05$ \\
$C_{\max }(\mu \mathrm{g} / \mathrm{mL})$ & $0.22 \pm 0.22$ & $0.20 \pm 0.24$ \\
$T_{\max }(\mathrm{h})^{\mathrm{a}}$ & $0.75(0.17-3)$ & $0.48(0.11-1.61)$ \\
\hline
\end{tabular}

Data are mean \pm SD (standard deviation). ${ }^{\mathrm{a}}$ Median (ranges).

$\mathrm{D}$, D2, and D3), polygalacin D2, platyconic acid A, and platycosides (A, B, C, D, E, and F) are present in it. They show anti-inflammation, antiallergy, antitumor, immune response augmentation, antiobesity, antihyperlipidemia, and treatment of respiratory symptoms also.

Liquid chromatographic (Accela) system was composed of quadrupole tandem mass spectrometer (Thermo Fisher Scientific Inc., Waltham, MA, USA) with ESI in positive ion mode. Chromatographic separation was performed on Sepax Polar-Imidazole HILIC HPLC $(100 \times 2.1 \mathrm{~mm}, 3.0 \mu \mathrm{m}$, Sepax Technologies, Delaware, USA) column and protected by a C18 guard column $(4 \times 2 \mathrm{~mm}$, Phenomenex, Torrance, CA, USA). The mobile phase was composed of $0.1 \%$ formic acid $(2 \mu \mathrm{M}$ sodium acetate) water/acetonitrile $(30: 70, \mathrm{v} / \mathrm{v})$. The flow rate was $350 \mu \mathrm{L} / \mathrm{min}$. Notoginsenoside R1 was employed as an IS. The pharmacokinetic parameters of Platycodin D (PD) and Platycodin D3 (PD3) are given in Table 17. PD and PD3 showed remarkable difference in oral bioavailability due to two prime reasons. The first possible reasons were might be the extraction method of PD and PD3 form Platycodon grandiflorum. Second probable reason for the difference in oral absorption of these saponin molecules in vivo was the coexisting ingredients [19].
3.5. Rhizoma Anemarrhenae. Timosaponins, that is, Timosaponin B-II and Timosaponin A-III (TB-II and TA-III), are main two bioactive steroidal saponin moieties present in Rhizoma Anemarrhenae (Asparagaceae). TB-II and TA-III show various pharmacological actions like anti-inflammatory, antioxidant, improving memory and learning dysfunction and anticancer, and antirespiratory syncytial virus properties, respectively. Rhizoma Anemarrhenae are clinically used with the Phellodendron chinense Schneid. to treat the seminal emission, eczema with itching, febrile diseases with high fever, diabetes due to internal heat, and constipation.

HPLC (Shimadzu Corporation, Japan) system was composed of API4000 triple quadrupole mass spectrometer with a turbo ion spray ionization source (AB SCIEX Instruments, USA) in negative ionization mode. Chromatographic separation was performed on XDB-C8 column $(150 \times 2.1 \mathrm{~mm}$, $5.0 \mu \mathrm{m}$, Agilent, USA) with a Security Guard C18 guard column $\left(4 \times 2.0 \mathrm{~mm}, 35^{\circ} \mathrm{C}\right.$, Phenomenex, Torrance, CA, USA). The isocratic mobile phase was composed of acetonitrile $(2 \mathrm{mmol} / \mathrm{L})$ and ammonium acetate $(55: 45, \mathrm{v} / \mathrm{v})$. The flow rate, injection volume, and total run time were $0.25 \mathrm{~mL} / \mathrm{min}$, $5 \mu \mathrm{L}$, and $4.0 \mathrm{~min}$, respectively. The LLOQ of TB-II and TAIII was 3.0 and $0.3 \mathrm{ng} / \mathrm{mL}$, respectively. Ginsenoside Rg2 was used as IS. The pharmacokinetic parameters of TB-II, TA-III and timosaponins-Huangbai alkaloids are given in Tables 18 and 19. Huangbai alkaloids help to improve the absorption of both saponins, that is, TB-II and TA-III. Huangbai alkaloids show approximately 9.0-fold improvement in AUC and $C_{\max }$ of TB-II when administered in 1:1 ration, while they exhibit 2.55-, 1.53-, and 1.43-fold improvement in AUC, $C_{\max }$, and MRT of TA-III, respectively, when administered in 1:1 ratio [20].

3.6. Aralia elata (Miq.) Seem. Aralia-saponin V and Araliasaponin VI are the two major bioactive triterpenoid saponins present in Aralia elata (Miq.) Seem. (Araliaceae). Root bark and young leaves of plant are used to treat the neurasthenia, rheumatic arthritics, hepatitis virus, and diabetes in Northeast China, Korea, Japan, and Russia.

UHPLC (1290 series, Agilent, Waldbronn, Germany) was composed of a 6430 QQQ-MS mass spectrometer with ESI in negative ion mode. Chromatographic separations were performed on an Agilent SB-C18 column $(50 \times 2.1 \mathrm{~mm}$, 
TABLE 18: Pharmacokinetic parameters of TB-II in rats following intragastric administration of timosaponins, timosaponins-Huangbai alkaloids $1: 1$ and $1: 3$ mixtures [20].

\begin{tabular}{lccccc}
\hline Parameters & \multicolumn{2}{c}{ Timosaponins $(n=6)$} & TB-II & $\begin{array}{c}\text { Timosaponins-Huangbai } \\
\text { alkaloids 1:3 (TB-II } \\
300 \mathrm{mg} / \mathrm{kg}, n=5)\end{array}$ & $\begin{array}{c}\text { Timosaponins-Huangbai } \\
\text { alkaloids } 1: 1 \text { (TB-II } \\
300 \mathrm{mg} / \mathrm{kg}, n=5)\end{array}$ \\
\hline $\begin{array}{l}C_{\max }(\mu \mathrm{g} / \mathrm{L}) \\
T_{\max }(\mathrm{h})\end{array}$ & $511.4 \pm 556.7$ & $433.9 \pm 310.5$ & $2182 \pm 1417^{*}$ & $2621 \pm 1432$ & $4034 \pm 2658^{*}$ \\
$t_{1 / 2 \mathrm{z}}(\mathrm{h})$ & $1.04 \pm 1.18$ & $2.38 \pm 1.28$ & $1.92 \pm 0.80$ & $2.10 \pm 0.55$ & $3.40 \pm 0.55$ \\
$\mathrm{AUC}_{(0-t)}$ & $4.12 \pm 3.11$ & $5.47 \pm 3.60$ & $2.45 \pm 1.32$ & $2.50 \pm 2.09$ & $1.01 \pm 0.11$ \\
$(\mu \mathrm{g} \mathrm{h} / \mathrm{L})$ & $866.6 \pm 779.7$ & $1026 \pm 491$ & $4249 \pm 2207^{*}$ & $5013 \pm 2357$ & $9713 \pm 5151^{*}$ \\
$\mathrm{AUC}_{(0-\infty)}$ & $1092 \pm 780$ & $1010 \pm 520$ & $4267 \pm 2204^{*}$ & $5102 \pm 2315$ & $9730 \pm 5157^{*}$ \\
$(\mu \mathrm{g} \mathrm{h} / \mathrm{L})$ & $7.65 \pm 5.98$ & $6.10 \pm 3.22$ & $3.46 \pm 0.80$ & $3.30 \pm 0.84$ & $3.73 \pm 0.24$ \\
$\mathrm{MRT}_{(0-\infty)}(\mathrm{h})$ & & &
\end{tabular}

TABLE 19: Pharmacokinetic parameters of TA-III in rats following intragastric administration of timosaponins, timosaponins-Huangbai alkaloids $1: 1$ and 1:3 mixtures, (1.17 $\mathrm{mg}$ TA-III/kg body weight) [20].

\begin{tabular}{|c|c|c|c|c|c|}
\hline \multirow[b]{2}{*}{ Parameters } & \multicolumn{3}{|c|}{ Timosaponins $(n=6)$} & \multirow{2}{*}{$\begin{array}{c}\text { Timosaponins-Huangbai } \\
\text { alkaloids } 1: 1 \text { (TA-III } 1.17 \mathrm{mg} / \mathrm{kg} \text {, } \\
\qquad n=5)\end{array}$} & \multirow{2}{*}{$\begin{array}{c}\text { Timosaponins-Huangbai } \\
\text { alkaloids } 1: 3 \text { (TA-III } 1.17 \mathrm{mg} / \mathrm{kg}, \\
n=5)\end{array}$} \\
\hline & $\begin{array}{c}\text { TA-III } \\
0.59 \mathrm{mg} / \mathrm{kg}\end{array}$ & $\begin{array}{c}\text { TA-III } \\
1.17 \mathrm{mg} / \mathrm{kg}\end{array}$ & $\begin{array}{c}\text { TA-III } \\
2.34 \mathrm{mg} / \mathrm{kg}\end{array}$ & & \\
\hline$C_{\max }(\mu \mathrm{g} / \mathrm{L})$ & $18.24 \pm 5.81$ & $25.10 \pm 4.09$ & $54.62 \pm 12.15^{*}$ & $38.63 \pm 20.41$ & $27.76 \pm 13.77$ \\
\hline$T_{\max }(\mathrm{h})$ & $6.60 \pm 2.97$ & $5.50 \pm 3.33$ & $6.33 \pm 1.97$ & $7.60 \pm 2.61$ & $8.33 \pm 2.34$ \\
\hline$t_{1 / 2 \mathrm{z}}(\mathrm{h})$ & $6.68 \pm 1.66$ & $6.61 \pm 3.12$ & $5.51 \pm 1.24$ & $10.80 \pm 3.34$ & $9.91 \pm 2.81$ \\
\hline $\mathrm{AUC}_{(0-t)}(\mu \mathrm{gh} / \mathrm{L})$ & $180.5 \pm 64.4$ & $248.5 \pm 62.6$ & $505.8 \pm 155.2^{*}$ & $633.8 \pm 313.2^{*}$ & $434.9 \pm 223.3$ \\
\hline $\mathrm{AUC}_{(0-\infty)}(\mu \mathrm{gh} / \mathrm{L})$ & $208.4 \pm 59.7$ & $290.7 \pm 58.7$ & $547.9 \pm 178.4^{*}$ & $711.1 \pm 344.3^{*}$ & $491.3 \pm 259.7$ \\
\hline $\mathrm{MRT}_{(0-\infty)}(\mathrm{h})$ & $12.18 \pm 1.13$ & $12.54 \pm 3.44$ & $10.33 \pm 1.47$ & $18.01 \pm 3.60$ & $17.30 \pm 2.94$ \\
\hline
\end{tabular}

${ }^{*} P<0.05$ versus oral administration of timosaponins (TA-III $1.17 \mathrm{mg} / \mathrm{kg}$ ).

$\left.1.8 \mu \mathrm{m}, 30^{\circ} \mathrm{C}\right)$. The isocratic mobile phase was composed of acetonitrile- $5 \mathrm{mM}$ ammonium acetate $(90: 10, \mathrm{v} / \mathrm{v})$. The flow rate and injection volume were of $0.2 \mathrm{~mL} / \mathrm{min}$ and $5.0 \mu \mathrm{L}$, respectively. Shengmaxinside $\mathrm{C}$ was used as IS. Pharmacokinetic parameters and LLOQ of Aralia-saponin V, Araliasaponin VI, and extract of A. elata leaves are given in Table 20. Triterpenoid saponins show poor absorption and limited oral bioavailability due to their poor membrane permeability. Extract of $A$. elata leaves helps to postpone the elimination of Aralia-saponin VI in rat plasma due to which they show approximately 1.50 -fold improvement in $t_{1 / 2}$ and $\mathrm{AUC}_{(0-\infty)}$ [21].

3.7. Aesculus hippocastanum. Aesculus hippocastanum seeds contain mixture of triterpenic saponins known as escin. Escin Ia is a main bioactive principal present in escin. Escin Ia was also used as marker for seeds of the horse chestnut. It exhibits various pharmacological actions like anti-inflammatory, antidiabetic, anti-ischemic, and gastro protective actions.

Liquid chromatographic separation (1100 series, Agilent Technologies, Palo Alto, CA, USA) was composed of an Applied Biosystems SCIEX API 4000 Mass Spectrometer (Applied Biosystems SCIEX, Ontario, Canada) with an ESI source. Chromatographic separation was performed on
HC-C18 column $\left(150 \times 4.6 \mathrm{~mm}, 5.0 \mu \mathrm{m}, 25^{\circ} \mathrm{C}\right.$, Agilent Technologies). The gradient mobile phase was composed of $45 \%$ purified water containing $45 \% 10 \mathrm{mM}$ ammonium acetate with $0.05 \%$ formic acid and acetonitrile containing $55 \%$ methanol $(50: 50)$. The flow rate was $1.0 \mathrm{~mL} / \mathrm{min}$. The pharmacokinetic parameter are given in Tables 21 and 22. Regardless the dose escin Ia was rapidly and extensively isomerized to isoescin Ia. Escin Ia $t_{1 / 2}$ increased significantly with increasing i.v. doses. Volume distribution and clearance exhibit the dose-dependent pharmacokinetic [22].

3.8. Rhododendron molle G. Don. In Southern China Rhododendron molle G. Don (Ericaceae) was very well recognized as poisonous shrub. Dried flower of this shrub, that is, Rhododendri Mollis Flos (RMF), is traditionally used for rheumatoid arthritis but it is also used associated with cardiotoxicity. Main bioactive principal present in RMF are Rhodojaponins I, II, and III (R-I, II, and III). Both efficacy and toxicity of RMF are attributed to Rhodojaponins.

HPLC (1200 series, Agilent Technologies, Germany) system was composed of quadruple mass spectrometer (SL G1946D, Agilent Technologies, USA) with ESI in negative ion mode. Chromatography separation was achieved on C18 column (Poroshell $120 \mathrm{SB}, 75 \times 4.6 \mathrm{~mm}, 2.7 \mu \mathrm{m}$ ) and protected by guard SB-C18 $(10 \times 4.6 \mathrm{~mm}, 5 \mu \mathrm{m})$ column. 
TABle 20: Pharmacokinetic parameters after oral administration of Aralia-saponin V, Aralia-saponin VI, and the extract of A. elata leaves [21].

\begin{tabular}{|c|c|c|c|c|}
\hline \multirow[b]{2}{*}{ Parameters } & \multirow{2}{*}{ Aralia-saponin V } & \multirow{2}{*}{$\begin{array}{c}\text { Aralia-saponin } \\
\text { VI }\end{array}$} & \multicolumn{2}{|c|}{$\begin{array}{l}\text { Extract of Aralia } \\
\text { elata leaves }\end{array}$} \\
\hline & & & $\begin{array}{c}\text { Aralia-saponin } \\
\text { V }\end{array}$ & $\begin{array}{c}\text { Aralia-saponin } \\
\text { VI }\end{array}$ \\
\hline$C_{\max }(\mathrm{ng} / \mathrm{mL})$ & $161.8 \pm 20.19$ & $188.55 \pm 35.35$ & $174.5 \pm 5.21$ & $192.59 \pm 18.7$ \\
\hline$T_{\max }(\mathrm{h})$ & $1.08 \pm 0.19$ & $0.88 \pm 0.13$ & $1.04 \pm 0.09$ & $0.88 \pm 0.13$ \\
\hline$K_{\mathrm{e}}$ & $0.10 \pm 0.03$ & $0.09 \pm 0.01$ & $0.16 \pm 0.07$ & $0.09 \pm 0.02$ \\
\hline$t_{1 / 2}(\mathrm{~h})$ & $7.33 \pm 2.59$ & $7.45 \pm 0.61$ & $4.92 \pm 1.89$ & $7.92 \pm 1.67$ \\
\hline $\mathrm{AUC}_{(0-t)}(\mathrm{ng} / \mathrm{mL} / \mathrm{h})$ & $796.0 \pm 135.6$ & $932.45 \pm 95.92$ & $915.7 \pm 79.7$ & $1024.69 \pm 112.5$ \\
\hline $\operatorname{AUC}_{(0-\infty)}(\mathrm{ng} / \mathrm{mL} / \mathrm{h})$ & $1156.9 \pm 286.6$ & $1306.74 \pm 160.24$ & $1210.3 \pm 211.4$ & $1516.73 \pm 197.68$ \\
\hline LLOQ (ng/mL) & 5.70 & 6.15 & - & - \\
\hline
\end{tabular}

TABLE 21: Pharmacokinetic parameters of Escin Ia in rats after i.v. administration of the drug $(n=6)$ [22].

\begin{tabular}{lccr}
\hline Parameters & $0.5 \mathrm{mg} / \mathrm{kg}$ & $1.0 \mathrm{mg} / \mathrm{kg}$ & $2.0 \mathrm{mg} / \mathrm{kg}$ \\
\hline$C_{\max }(\mathrm{ng} / \mathrm{mL})$ & 22807485 & $4362 \pm 1298$ & $11,220 \pm 2330$ \\
$t_{1 / 2}(\mathrm{~h})$ & $7.5 \pm 2.1$ & $9.6 \pm 1.9$ & $12.2 \pm 1.7$ \\
$\mathrm{AUC}_{(0-48 \mathrm{~h})}(\mathrm{ng} \mathrm{h} / \mathrm{mL})$ & $10,036 \pm 4203$ & $12,989 \pm 3101$ & $29,156 \pm 6495$ \\
$\mathrm{AUC}(0-\infty)$ & $(\mathrm{ng} \mathrm{h} / \mathrm{mL})$ & $13,185 \pm 3302$ & $29,941 \pm 6753$ \\
$\mathrm{CL}(\mathrm{mL} / \mathrm{min} / \mathrm{kg})$ & $10,145 \pm 4270$ & $6.05 \pm 1.95$ & $5.81 \pm 1.30$ \\
$V_{\mathrm{d}}(\mathrm{L} / \mathrm{kg})$ & $4.82 \pm 2.13$ & $5.02 \pm 3.85$ & $6.16 \pm 3.53$ \\
MRT $(\mathrm{h})$ & $2.86 \pm 1.39$ & $5.39 \pm 0.880$ & $6.29 \pm 1.16$ \\
\hline
\end{tabular}

The mobile phase was composed of $30 \%$ acetonitrile and $70 \%$ aqueous formic acid $(0.3 \%)$. The flow rate and injection volume were $0.8 \mathrm{~mL} / \mathrm{min}$ and $5.0 \mu \mathrm{L}$, respectively. LLOQ of RI, RII, and RIII was $0.041,0.013$, and $0.0084(\mu \mathrm{g} / \mathrm{mL})$, respectively. Triptolide was used as IS. Pharmacokinetic parameters after oral administration of RMF extract are given in Table 23. Rhodojaponins exhibit myocardial damage in dose-dependent manner and the biochemical indicator of $\mathrm{LDH}$ and $\mathrm{CK}-\mathrm{MB}$ in plasma might serve as potential markers of RMF induced cardiotoxicity [23].

\section{Terpenoids}

4.1. Centella asiatica. Asiatic acid is a triterpenoid component found in Centella asiatica. Asiatic acid could be used for wound healing, various skin conditions, inflammatory, diabetes, hyperlipidemia, also depression, relieving anxiety, and improving cognition.

An Agilent 1100 liquid chromatography system was composed of an Agilent G1946D mass spectrometer (Agilent, USA) with ESI in negative ion mode. Chromatography separation was achieved on C18 column (Waters X bridge, $100 \pm 3.0 \mathrm{~mm}^{2}, 3.0 \mu \mathrm{m}, 25^{\circ} \mathrm{C}$ ) and protected by guard column (XDB-C18, $12.5 \pm 4.6 \mathrm{~mm}, 5.0 \mathrm{~mm}$, Agilent, USA). The isocratic mobile phase was composed of acetonitrile and $5 \mathrm{mM}$ aqueous ammonium acetate $(50: 50, \mathrm{v} / \mathrm{v})$. The total analysis time, injection volume, and flow rate were $8.0 \mathrm{~min}, 5.0 \mu \mathrm{L}$, and $0.8 \mathrm{~mL} / \mathrm{min}$, respectively. LLOD and LLOQ were 20.50 and $51.25 \mathrm{ng} / \mathrm{mL}$, respectively. Pharmacokinetic parameters of asiatic acid are given in Table 24. Absolute oral bioavailability of asiatic acid in rats was very low. Passive diffusion was the main absorption style of asiatic acid and jejunum is the main absorption region in rats. It can be metabolized rapidly in rat liver microsomes. Additionally, it also has good permeability across Caco-2 monolayer cell and rat intestine perfusion. Low bioavailability of asiatic acid was mainly attributed to poor solubility and rapid metabolism [24].

4.2. Salvia miltiorrhiza Bunge. Salvia miltiorrhiza Bunge (SMB) (Lamiaceae) is very well known as "danshen" in TCM. There are two type of bioactive compounds in roots of SMB. Former one is hydrophilic phenolic acids, that is, danshensu (DS) and rosmarinic acid (RA), and tanshinone lipophilic compounds, that is, tanshinone I (TI), dihydro-tanshinone I (DT), tanshinone IIA (TS), and cryptotanshinone (CT). It is widely used in treatment of coronary heart diseases and liver diseases. Moreover, it also exhibits anti-inflammatory, antibacterial, and antineoplastic actions.

HPLC (1100 series, Agilent technology, USA) system was composed of ion trap spectrometer using ESI (Thermo Finnigan, San Jose CA, USA) in negative ion mode. Chromatographic separation was performed on a Capcell Pak MG C18 column $(100 \times 2 \mathrm{~mm}, 5.0 \mu \mathrm{m}$, Shiseido, Japan $)$ protected with a C18 guard column $(10 \times 2 \mathrm{~mm}, 5.0 \mu \mathrm{m}$, Shiseido, Japan) containing the same packing material. The gradient mobile phase was composed of acetonitrile-water and glacial acetic acid $(0.5 \%(\mathrm{v} / \mathrm{v})$ with $\mathrm{pH}$ of 2.5$)$. The run time, flowrate, temperature, and sample injection volume were $13 \mathrm{~min}, 0.2 \mathrm{~mL} / \mathrm{min}, 25^{\circ} \mathrm{C}$, and $10 \mu \mathrm{L}$, respectively. The plasma drug concentration-time data determine by twocompartment open model. The pharmacokinetic parameters after a single oral dose of danshen extracts in rat are given 
TABLE 22: Pharmacokinetic parameters of isoescin Ia in rats after i.v. administration of Escin Ia $(n=6)$ [22].

\begin{tabular}{lccc}
\hline Parameters & $0.5 \mathrm{mg} / \mathrm{kg}$ & $1.0 \mathrm{mg} / \mathrm{kg}$ & $2.0 \mathrm{mg} / \mathrm{kg}$ \\
\hline$C_{\text {max }}(\mathrm{ng} / \mathrm{mL})$ & $584 \pm 172$ & $875 \pm 196$ & $2058 \pm 385$ \\
$T_{\max }(\mathrm{h})$ & $5.7 \pm 2.0$ & $4.5 \pm 1.2$ & $3.5 \pm 0.4$ \\
$t_{1 / 2}(\mathrm{~h})$ & $8.1 \pm 0.8$ & $7.9 \pm 1.51$ & $0.4 \pm 1.8$ \\
$\mathrm{AUC}_{(0-48 \mathrm{~h})}(\mathrm{ng} \mathrm{h} / \mathrm{mL})$ & $9879 \pm 4446$ & $14,094 \pm 4580$ & $32,401 \pm 8791$ \\
$\mathrm{AUC}_{(0-\infty)}(\mathrm{ng} \mathrm{h} / \mathrm{mL})$ & $10,519 \pm 4787$ & $14,431 \pm 4969$ & $33,832 \pm 9336$ \\
$\mathrm{AUC}_{(0-48 \mathrm{~h})}$ ratio of isoescin Ia/Escin Ia & $0.99 \pm 0.25$ & $1.12 \pm 0.06$ & $1.11 \pm 0.10$ \\
\hline
\end{tabular}

TABLE 23: Pharmacokinetic parameters after oral administration of RMF extract $(n=8)$ [23].

\begin{tabular}{|c|c|c|c|c|c|c|c|c|}
\hline \multirow[t]{2}{*}{ Parameters } & \multicolumn{2}{|c|}{$\begin{array}{c}\text { R-I } \\
(\mathrm{mg} / \mathrm{kg})\end{array}$} & \multicolumn{2}{|c|}{$\begin{array}{c}\text { R-II } \\
(\mathrm{mg} / \mathrm{kg})\end{array}$} & \multicolumn{2}{|c|}{$\begin{array}{c}\text { R-III } \\
(\mathrm{mg} / \mathrm{kg})\end{array}$} & \multicolumn{2}{|c|}{ Integrated data $(\mathrm{mg} / \mathrm{kg})$} \\
\hline & 21.44 & 112.56 & 21.44 & 112.56 & 21.44 & 112.56 & 21.44 & 112.56 \\
\hline $\begin{array}{l}\mathrm{AUC}_{(0-t)} \\
(\mathrm{mg} \mathrm{min} / \mathrm{L})\end{array}$ & $4.35 \pm 0.48$ & $56.67 \pm 10.33$ & $6.09 \pm 2.68$ & $47.03 \pm 3.41$ & $3.15 \pm 0.86$ & $46.04 \pm 8.21$ & $4.25 \pm 2.23$ & $53.04 \pm 4.66$ \\
\hline $\begin{array}{l}\mathrm{AUC}_{(0-\infty)} \\
(\mathrm{mg} \mathrm{min} / \mathrm{L})\end{array}$ & $6.47 \pm 0.71$ & $68.02 \pm 10.88$ & $10.29 \pm 3.80$ & $52.60 \pm 9.14$ & $5.98 \pm 2.89$ & $51.56 \pm 10.76$ & $6.12 \pm 2.53$ & $54.59 \pm 620$ \\
\hline$t_{1 / 2}(\min )$ & $63.65 \pm 18.21$ & $147.57 \pm 37.79$ & $133.74 \pm 66.05$ & $215.96 \pm 163.68$ & $83.69 \pm 39.57$ & $219.63 \pm 91.11$ & $97.59 \pm 33.06$ & $128.79 \pm 38.30$ \\
\hline$T_{\max }(\min )$ & $45.00 \pm 21.21$ & $54.00 \pm 48.27$ & $\begin{array}{c}60.007 \pm \\
32.07\end{array}$ & $72.00 \pm 34.21$ & $52.50 \pm 21.21$ & $50.00 \pm 36.74$ & $60.00 \pm 32.07$ & $52.00 \pm 34.93$ \\
\hline$C_{\max }(\mathrm{mg} / \mathrm{L})$ & $0.05 \pm 0.01$ & $0.34 \pm 0.05$ & $0.05 \pm 0.01$ & $0.18 \pm 0.05$ & $0.04 \pm 0.01$ & $0.19 \pm 0.04$ & $0.03 \pm 0.01$ & $0.24 \pm 0.03$ \\
\hline
\end{tabular}

TABLE 24: Pharmacokinetic parameters of asiatic acid after oral administration $(n=6)$ [24].

\begin{tabular}{lcc}
\hline Parameters & $\begin{array}{c}\text { Asiatic acid } \\
\text { (i.g.) }\end{array}$ & $\begin{array}{c}\text { Asiatic acid } \\
\text { (i.v.) }\end{array}$ \\
\hline$T_{\text {max }}(\mathrm{h})$ & 0.5 & 0.083 \\
$C_{\max }(\mathrm{ng} / \mathrm{mL})$ & 0.394 & 1.176 \\
$t_{1 / 2}(\mathrm{~h})$ & 0.642 & 0.348 \\
$\mathrm{AUC}_{(0-24)}\left(\mathrm{ng} / \mathrm{mL} \cdot \mathrm{h}^{2}\right)$ & 0.702 & 0.432 \\
$\mathrm{AUC}_{(0-\infty)}\left(\mathrm{ng} / \mathrm{mL} \cdot \mathrm{h}^{2}\right)$ & 0.766 & 0.482 \\
$\mathrm{AUMC}_{(0-24)}\left(\mathrm{ng} / \mathrm{mL} \cdot \mathrm{h}^{2}\right)$ & 1.213 & 0.109 \\
$\mathrm{AUMC}_{(0-\infty)}\left(\mathrm{ng} / \mathrm{mL} \cdot \mathrm{h}^{2}\right)$ & 1.641 & 0.186 \\
$\mathrm{CL}(\mathrm{L} / \mathrm{h})$ & 6.682 & 4.186 \\
MRT $(\mathrm{h})$ & 0.668 & 0.258 \\
Bioavailability $(\%)$ & 16.25 & - \\
\hline
\end{tabular}

in Table 25. After oral administration both phenolic acids and tanshinone lipophilic components showed relatively moderate absorptions, distribution, and elimination. Plasma concentration also exhibits the accumulation of TS which is due to biotransformation of CT to TS [25].

4.3. Alisma orientale (Sam.) Juz. Alisol A and Alisol B 23acetate are the two major active triterpenoid compounds isolated from Alisma orientale (Sam.) Juz. (Alismataceae). It is used to treat various diseases, including hyperlipidemia, diabetes, hypertension, and urological diseases.

XR LC 20AD Prominence ${ }^{\mathrm{TM}}$ UFLC system was composed of QTRAP $4000 \mathrm{MS} / \mathrm{MS}$ system from Applied AB SCIEX with a turbo positive ion spray source (Foster City, CA, USA). Chromatographic separation was performed on a
Venusil MP C18 column $\left(100 \times 2.1 \mathrm{~mm}, 3.0 \mathrm{~mm}, 30^{\circ} \mathrm{C}\right.$, China $)$ and protected by a high pressure column prefilter $(2.0 \mathrm{~mm}$, Shimadzu, Japan). The gradient mobile phase was composed of $0.1 \%$ acetic acid in water and methanol. The flow rate and sample injection volume are $0.4 \mathrm{~mL} / \mathrm{min}$ and $5.0 \mathrm{~mL}$, respectively. The pharmacokinetic data for Alisol A and Alisol B 23 acetate are given in Table 26. The concentrationtime curves showed that Alismatis Rhizoma was rapidly absorbed in blood, and then the concentration decreased slightly and appeared to be a small peak. It shows double-peak phenomenon. Double-peak phenomenon is due to intertransformed of Alisol B to Alisol A or due to enterohepatic circulation [26].

4.4. Isodi Rubescentis. Herba Isodi Rubescentis is very wellknown Chinese remedy for treatment of different ailments, including bacteriostasis, inflammation, and fever and nowadays it is also used to treat the cancers. It is composed of various active components like diterpenoid oridonin, ponicidin, and rosmarinic acid also.

HPLC (Shimadzu, Kyoto, Japan) system was equipped with tandem mass spectrometer (API 4000 QTRAP MDS SCIEX, Applied Biosystems SCIEX, Concord, Canada) with ESI in both modes. The entire analysis process was divided into two periods. Period I was conducted in negative ion mode for rosmarinic acid during the first $2.0 \mathrm{~min}$. Period II was performed in positive ion mode for oridonin and ponicidin in the remaining $3.0 \mathrm{~min}$. Present chromatographic elution was performed over C18 (BDS Hypersil, $2.1 \times 100 \mathrm{~mm}$, $\left.2.4 \mu \mathrm{m}, 40^{\circ} \mathrm{C}\right)$ column. The mobile phase was composed of water $75 \%(\mathrm{v} / \mathrm{v})$ containing $5.0 \mathrm{mM}$ ammonium acetate and acetonitrile $25 \%(\mathrm{v} / \mathrm{v})$ containing $0.5 \%$ acetic acid with flow rate of $0.2 \mathrm{~mL} / \mathrm{min}$. The injection volume was $5.0 \mathrm{~mL}$. LOD 
TABLE 25: Pharmacokinetic parameters of DS, RA, CT, DT, TI, and TII after oral dose of danshen extracts [25].

\begin{tabular}{|c|c|c|c|c|c|c|}
\hline Parameter & DS & RA & CT & DT & TI & TII \\
\hline$t_{1 / 2 K_{\mathrm{a}}}(\mathrm{h})$ & $0.51 \pm 0.13$ & $0.35 \pm 0.09$ & $0.37 \pm 0.21$ & $0.28 \pm 0.13$ & $0.17 \pm 0.11$ & $0.24 \pm 0.04$ \\
\hline$t_{1 / 2 \alpha}(\mathrm{h})$ & $0.89 \pm 0.16$ & $0.54 \pm 0.11$ & $0.69 \pm 0.18$ & $0.54 \pm 0.14$ & $0.94 \pm 0.36$ & $0.40 \pm 0.04$ \\
\hline$t_{1 / 2 \beta}(\mathrm{h})$ & $3.04 \pm 1.28$ & $3.68 \pm 0.41$ & $2.81 \pm 0.39$ & $3.65 \pm 1.74$ & $4.72 \pm 1.90$ & $3.70 \pm 0.65$ \\
\hline$K_{21}(\mathrm{~L} / \mathrm{h})$ & $0.33 \pm 0.19$ & $0.43 \pm 0.31$ & $0.42 \pm 0.11$ & $0.54 \pm 0.24$ & $0.32 \pm 0.11$ & $0.68 \pm 0.08$ \\
\hline$K_{10}(\mathrm{~L} / \mathrm{h})$ & $0.66 \pm 0.07$ & $0.92 \pm 0.07$ & $0.62 \pm 0.086$ & $0.56 \pm 0.09$ & $0.50 \pm 0.08$ & $0.52 \pm 0.09$ \\
\hline$K_{12}(\mathrm{~L} / \mathrm{h})$ & $0.10 \pm 0.08$ & $0.38 \pm 0.20$ & $0.26 \pm 0.12$ & $0.46 \pm 0.18$ & $0.26 \pm 0.34$ & $0.81 \pm 0.09$ \\
\hline$V_{\mathrm{c}}(\mathrm{L} / \mathrm{kg})$ & $0.07 \pm 0.02$ & $0.18 \pm 0.07$ & $0.13 \pm 0.02$ & $0.33 \pm 0.17$ & $0.06 \pm 0.010$ & $0.24 \pm 0.02$ \\
\hline AUC (ng h/mL) & $220.67 \pm 52.54$ & $89.12 \pm 12.10$ & $123.40 \pm 8.04$ & $34.82 \pm 22.9$ & $169.64 \pm 32.22$ & $81.05 \pm 12.08$ \\
\hline $\mathrm{CL}_{\mathrm{s}}(\mathrm{L}(\mathrm{kg} / \mathrm{h}))$ & $0.05 \pm 0.01$ & $0.12 \pm 0.04$ & $0.08 \pm 0.01$ & $0.18 \pm 0.10$ & $0.03 \pm 0.002$ & $0.14 \pm 0.01$ \\
\hline$T_{\max }(\mathrm{h})$ & $1.11 \pm 0.18$ & $0.74 \pm 0.12$ & $0.86 \pm 0.35$ & $0.74 \pm 0.14$ & $0.60 \pm 0.21$ & $0.61 \pm 0.05$ \\
\hline$C_{\max }(\mathrm{ng} / \mathrm{mL})$ & $71.98 \pm 22.86$ & $37.19 \pm 13.85$ & $42.85 \pm 13.58$ & $11.29 \pm 11.49$ & $54.64 \pm 17.72$ & $22.24 \pm 3.42$ \\
\hline LOQ (ng/mL) & 5 & 0.75 & 0.1 & 0.1 & 1 & 0.5 \\
\hline LOD (ng/mL) & 2.5 & 0.38 & 0.05 & 0.05 & 0.5 & 0.1 \\
\hline
\end{tabular}

TABLE 26: Pharmacokinetic parameters of alisol A and alisol B 23 acetate after oral administration of Rhizoma Alismatis extract $(n=6)$ [26].

\begin{tabular}{lcccr}
\hline Analytes & $\begin{array}{c}\mathrm{AUC}_{(0-t)} \\
(\mathrm{mg} \mathrm{h} / \mathrm{L})\end{array}$ & $\begin{array}{c}\mathrm{AUC}_{(0-\infty)} \\
(\mathrm{mgh} / \mathrm{L})\end{array}$ & $C_{\max }(\mathrm{mg} / \mathrm{L})$ & $t_{1 / 2}(\mathrm{~h})$ \\
\hline Alisol A & $1549 \pm 502$ & $1739 \pm 481$ & $192.2 \pm 40.9$ & $9.28 \pm 2.30$ \\
Alisol B 23-acetate & $3681 \pm 679$ & $3866 \pm 700$ & $427.7 \pm 86.2$ & $8.43 \pm 1.97$ \\
\hline
\end{tabular}

and LOQ were found to be 0.5 and $2.0 \mathrm{ng} / \mathrm{mL}$, respectively. Reported pharmacokinetic profile of these terpenoids is given in Table 27. Diterpenoid oridonin, ponicidin, and rosmarinic acid are poorly water soluble. As we know bioavailability was ultimately attributed to solubility of the compound and hence all three bioactive components exhibit poor bioavailability. Moreover they also show quick metabolism in rat model [27].

\section{Alkaloids}

5.1. Dactylicapnos scandens. The (+) isocorydine and protopine are the bioactive alkaloids present in Dactylicapnos scandens (D. Don) Hutch. (Papaveraceae). In TCM it is used as remedy for pain management, inflammation, and hypertension.

UPLC (Waters, Milford, MA, USA) system was composed of mass spectrometer with ESI in positive ion mode. Chromatographic separation was performed on a C18 (Zorbax SB, $2.1 \times 100 \mathrm{~mm}, 3.5 \mu \mathrm{m}$; Agilent, USA) column. The gradient mobile phase was composed of methanol with $0.2 \%$ formic acid and $5.0 \mathrm{mM}$ ammonium acetate containing $0.2 \%$ formic acid. The flow rate was $0.3 \mathrm{~mL} / \mathrm{min}$. The LLOQ for both isocorydine and protopine was $10 \mathrm{ng} / \mathrm{mL}$. Corydaline was used as IS. The pharmacokinetic data after administration of Dactylicapnos scandens extract are given in Tables 28 and 29. Both alkaloids exhibit quick absorption and rapid elimination. Moreover, very less amount of isocorydine and protopine was excreted in unchanged form. Isocorydine and protopine show significant tissue distribution and also cross the blood brain barrier (BBB) [28].
5.2. Sophora flavescens Ait. Matrine is an alkaloid present in the Chinese herb Sophora flavescens Ait. (Fabaceae). It is commonly used as a quality control marker in antitumor B mixture. Matrine itself also has a wide spectrum of pharmacological actions including hepatoprotective activity, hepatotoxicity, proapoptotic activity in gastric carcinoma cells, and leukemia cells.

Acquity UPLC BEH was composed of diode array detector and API 3200 QTRAP triple quadrupole mass spectrometer (Applied Biosystem/MDS SCIEX, Foster City, CA, USA) with ESI in the positive ion mode. Chromatographic separation was performed on C18 column $(50 \times 2.1 \mathrm{~mm}, 1.7 \mu \mathrm{m}$, $45^{\circ} \mathrm{C}$, Waters, Milford, MA, USA). The gradient mobile phase was composed of acetonitrile and $0.1 \%$ formic acid. The flow rate and injection volume were kept as $0.45 \mathrm{~mL} / \mathrm{min}$ and $10 \mu \mathrm{L}$, respectively. LLOQ was found to be $0.305 \mathrm{ng} / \mathrm{mL}$. Testosterone was used as IS. The pharmacokinetic parameters of matrine after i.v. and oral administration are given in Table 30. Matrine undergoes extensive first-pass metabolism by Cytochromes P450 (CYP450) and UDP-glucuronosyl transferase (UGT) enzymes [29].

5.3. Menispermum dauricum DC. Daurisoline (DS) and dauricine (Dau), the bisbenzyltetrahydroisoquinoline (BBI) alkaloids, were isolated from the root of Menispermum dauricum DC. (Menispermaceae). These alkaloids are known for their antiarrhythmic effects.

HPLC system was equipped with a UV detector set at $284 \mathrm{~nm}$ (Shimadzu, Japan). Chromatographic separation was performed on ODS $(150 \times 4 \mathrm{~mm}, 5.0 \mu \mathrm{m}$, Shimadzu) column 
TABLE 27: Pharmacokinetic parameters of oridonin, ponicidin, and rosmarinic acid after oral and i.v. administration to rats [27].

\begin{tabular}{|c|c|c|c|c|c|c|}
\hline \multirow{2}{*}{$\begin{array}{l}\text { Pharmacokinetic } \\
\text { parameters }\end{array}$} & \multicolumn{5}{|c|}{ Values $($ mean \pm SD) } & \multirow[b]{2}{*}{$\begin{array}{l}\text { Rosmarinic } \\
\text { Acid (PO) }\end{array}$} \\
\hline & Oridonin (IV) & Oridonin (PO) & Ponicidin (IV) & Ponicidin (PO) & $\begin{array}{l}\text { Rosmarinic acid } \\
\text { (IV) }\end{array}$ & \\
\hline $\operatorname{AUC}_{(0-t)}(\mathrm{ng} / \mathrm{mL} / \mathrm{h})$ & $932.81 \pm 226.81$ & $78.45 \pm 33.83$ & $1,105.02 \pm 145.58$ & $112.47 \pm 23.38$ & $2,037.60 \pm 541.76$ & $284.52 \pm 61.10$ \\
\hline $\operatorname{AUC}_{(0-\infty)}(\mathrm{ng} / \mathrm{mL} / \mathrm{h})$ & $980.74 \pm 287.15$ & $79.29 \pm 34.26$ & $1,132.83 \pm 165.29$ & $120.00 \pm 19.61$ & $2,059.44 \pm 546.25$ & $313.51 \pm 75.24$ \\
\hline MRT (h) & $1.79 \pm 0.77$ & $0.495 \pm 0.05$ & $2.85 \pm 0.49$ & $1.81 \pm 0.33$ & $3.04 \pm 0.44$ & $6.46 \pm 0.09$ \\
\hline$t_{1 / 2}(\mathrm{~h})$ & $2.90 \pm 0.87$ & $0.19 \pm 0.05$ & $5.80 \pm 2.00$ & $2.12 \pm 1.02$ & $4.82 \pm 0.65$ & $7.12 \pm 1.96$ \\
\hline$T_{\max }(\mathrm{h})$ & - & $0.69 \pm 0.13$ & - & $0.67 \pm 0.13$ & - & $1.08 \pm 0.38$ \\
\hline Clearance $(\mathrm{L} / \mathrm{h} / \mathrm{kg})$ & $1.08 \pm 0.31$ & $13.99 \pm 4.27$ & $0.90 \pm 0.14$ & $8.54 \pm 1.52$ & $1.28 \pm 0.40$ & $0.07 \pm 0.02$ \\
\hline$V_{\mathrm{d}}(\mathrm{L} / \mathrm{kg})$ & $4.29 \pm 0.54$ & $3.68 \pm 1.42$ & $7.26 \pm 1.72$ & $27.70 \pm 18.34$ & $9.14 \pm 3.96$ & $0.66 \pm 0.11$ \\
\hline$C_{\max }(\mathrm{ng} / \mathrm{mL})$ & - & $164.51 \pm 58.42$ & - & $88.21 \pm 23.85$ & - & $48.67 \pm 11.24$ \\
\hline Bioavailability (\%) & - & $8.41 \pm 3.63$ & - & $10.18 \pm 2.12$ & - & $13.96 \pm 3.00$ \\
\hline
\end{tabular}

TABLE 28: Pharmacokinetic parameters of isocorydine in rats following i.v. (12.66 mg/kg) or i.g. (126.6 mg/kg) administration of $D$. scandens extract $(n=6)$ [28].

\begin{tabular}{lccc}
\hline & Oral & & Intravenous \\
Parameters & Values & Parameters & Values \\
\hline$C_{\max }(\mu \mathrm{g} / \mathrm{L})$ & $977 \pm 159$ & $C_{\max }(\mu \mathrm{g} / \mathrm{L})$ & $2220 \pm 325$ \\
$T_{\max }(\mathrm{h})$ & $0.333 \pm 0.144$ & $T_{\max }(\mathrm{h})$ & $0.033 \pm 0$ \\
$t_{1 / 2 \mathrm{z}}(\mathrm{h})$ & $1.96 \pm 0.387$ & $t_{1 / 2 \mathrm{z}}(\mathrm{h})$ & $2.09 \pm 0.457$ \\
$\mathrm{AUC}_{(0-t)}(\mu \mathrm{g} / \mathrm{L} \cdot \mathrm{h})$ & $3629 \pm 697$ & $\mathrm{AUC}_{(0-t)}(\mu \mathrm{g} / \mathrm{L} \times \mathrm{h})$ & $1209 \pm 129$ \\
$\mathrm{AUC}_{(0-\infty)}(\mu \mathrm{g} / \mathrm{L} \cdot \mathrm{h})$ & $3697 \pm 677$ & $\mathrm{AUC}_{(0-\infty)}(\mu \mathrm{g} / \mathrm{L} \times \mathrm{h})$ & $1269 \pm 158$ \\
$\mathrm{CL}_{\mathrm{z}} / F(\mathrm{~L} / \mathrm{h} / \mathrm{kg})$ & $5.52 \pm 0.924$ & $\mathrm{CL}_{\mathrm{z}}(\mathrm{L} / \mathrm{h} / \mathrm{kg})$ & $1.59 \pm 0.202$ \\
$V_{\mathrm{z}} / F(\mathrm{~L} / \mathrm{kg})$ & $16.0 \pm 5.32$ & $V_{\mathrm{z}}(\mathrm{L} / \mathrm{kg})$ & $4.72 \pm 0.587$ \\
$\mathrm{MRT}_{(0-t)}(\mathrm{h})$ & $3.08 \pm 0.354$ & $\mathrm{MRT}_{(0-t)}(\mathrm{h})$ & $1.42 \pm 0.196$ \\
$\operatorname{MRT}_{(0-\infty)}(\mathrm{h})$ & $3.31 \pm 0.272$ & $\mathrm{MRT}_{(0-\infty)}(\mathrm{h})$ & $1.86 \pm 0.380$ \\
Zeta $_{\text {Bioavailability }(\%)}$ & $0.363 \pm 0.080$ & $\mathrm{Zeta}$ & $0.34 \pm 0.086$ \\
\hline
\end{tabular}

and protected with a guard column packed with the same material. The mobile phase was composed of acetonitrilewater-triethylamine $(18: 82: 0.28)$ pulsing phosphoric acid to $\mathrm{pH} 3.0$ at $1.0 \mathrm{~mL} / \mathrm{min}$. The LOQ was $50 \mu \mathrm{g} / \mathrm{L}$ for plasma. The pharmacokinetic and pharmacodynamic parameters of Dau and DS are given in Tables 31 and 32, respectively. Due to high affinity to tissues and organs both alkaloids were distributed quickly from central compartment to tissue. The main pharmacokinetic parameters of DS were similar to that of Dau, suggesting that both alkaloids had the same process of pharmacokinetics [30].

5.4. Aconitum bulleyanum Diel. Bulleyaconitine A (BLA) is an aconitine-like alkaloid isolated from Aconitum bulleyanum Diel. In China, BLA was commonly used for treatment of rheumatoid arthritis and chronic pain.

HPLC (1200 series, Agilent Technologies Inc., USA) system was composed of API 4000 QTRAP tandem mass spectrometer (AB SCIEX, Foster City, CA, USA) with ESI in positive ion mode. Chromatographic separation was performed on Phenomenex Luna C18 column $(50 \times 2.00 \mathrm{~mm}$, $5.0 \mu \mathrm{m}$, Phenomenex Inc., Torrance, CA, USA) at ambient temperature. The isocratic mobile phase is comprised of methanol and water $(45: 55, \mathrm{v} / \mathrm{v})$ containing $0.1 \%$ formic acid. The flow rate and total run time were $200 \mu \mathrm{L} / \mathrm{min}$ and $2.5 \mathrm{~min}$, respectively. Mesaconitine was used as internal standard. The LLOQ of BLA in rat plasma was $0.02 \mathrm{ng} / \mathrm{mL}$. The pharmacokinetic parameters after oral administration of a single dose of $0.04 \mathrm{mg} / \mathrm{kg}$ BLA are given in Table 33 . Pharmacokinetic profile of BLA shows the rapid absorption and elimination from GIT [31].

5.5. Polygonum jucundum. 2- $\alpha$-Hydroxyl-3- $\beta$-angeloylcinnamolide (HAC) is a drimane-type sesquiterpenoid obtained from the ethanolic extract of Polygonum jucundum. It is commonly used in TCM. it is known for its anti-inflammatory activities.

An Agilent Technologies Series 1200 LC-MSD system (Agilent Technologies, Palo Alto, CA, USA) is composed of an Agilent $1200 \mathrm{MSD}$ single quadruple mass spectrometer coupled with G1956B ESI in positive ion mode. Chromatographic separation was performed on an Agilent Eclipse Plus C18 column $\left(4.6 \times 150 \mathrm{~mm}, 3.5 \mu \mathrm{m}, 25^{\circ} \mathrm{C}\right.$, Agilent Technologies, Palo Alto, CA, USA). The mobile phase is composed of $10 \mathrm{mM}$ ammonium formate containing $0.1 \%$ formic acid and methanol in ration of $25: 75$, v/v. The flow rate, injection volume, and analysis time were $0.5 \mathrm{~mL} / \mathrm{min}, 10 \mu \mathrm{L}$, and $8.0 \mathrm{~min} /$ sample, respectively. The LLOQ of HAC was 
TABLE 29: Pharmacokinetic parameters of protopine in rats following i.v. (12.66 mg/kg) or i.g. (126.6 mg/kg) administration of D. scandens extract $(n=6)$ [28].

\begin{tabular}{lccc}
\hline & Oral & \multicolumn{2}{c}{ Intravenous } \\
Parameters & Values & Parameters & $131 \pm 24.1$ \\
\hline$C_{\max }(\mu \mathrm{g} / \mathrm{L})$ & $108 \pm 24.8$ & $C_{\max }(\mu \mathrm{g} / \mathrm{L})$ & $0.033 \pm 0$ \\
$T_{\max }(\mathrm{h})$ & $2.67 \pm 1.16$ & $T_{\max }(\mathrm{h})$ & $2.43 \pm 0.737$ \\
$t_{1 / 2 \mathrm{z}}(\mathrm{h})$ & $2.61 \pm 0.739$ & $t_{1 / 2 \mathrm{z}}(\mathrm{h})$ & $170 \pm 23.7$ \\
$\mathrm{AUC}_{(0-t)}(\mu \mathrm{g} / \mathrm{L} \cdot \mathrm{h})$ & $598 \pm 53.0$ & $\mathrm{AUC}_{(0-t)}(\mu \mathrm{g} / \mathrm{L} \times \mathrm{h})$ & $246 \pm 35.5$ \\
$\mathrm{AUC}_{(0-\infty)}(\mu \mathrm{g} / \mathrm{L} \cdot \mathrm{h})$ & $635 \pm 60.9$ & $\mathrm{AUC}_{(0-\infty)}(\mu \mathrm{g} / \mathrm{L} \times \mathrm{h})$ & $3.36 \pm 0.450$ \\
$\mathrm{CL}_{\mathrm{z}} / F(\mathrm{~L} / \mathrm{h} / \mathrm{kg})$ & $13.0 \pm 1.30$ & $\mathrm{CL}_{\mathrm{z}}(\mathrm{L} / \mathrm{h} / \mathrm{kg})$ & $25.7 \pm 4.62$ \\
$V_{\mathrm{z}} / F(\mathrm{~L} / \mathrm{kg})$ & $48.3 \pm 12.1$ & $V_{\mathrm{z}}(\mathrm{L} / \mathrm{kg})$ & $2.66 \pm 0.094$ \\
$\mathrm{MRT}_{(0-t)}(\mathrm{h})$ & $4.06 \pm 0.230$ & $\mathrm{MRT}_{(0-t)}(\mathrm{h})$ & $6.70 \pm 0.534$ \\
$\mathrm{MRT}_{(0-\infty)}(\mathrm{h})$ & $4.75 \pm 0.681$ & $\mathrm{MRT}_{(0-\infty)}(\mathrm{h})$ & $0.132 \pm 0.010$ \\
Zeta & $0.279 \pm 0.071$ & Zeta & - \\
Bioavailability $(\%)$ & 25.8 & - & - \\
\hline
\end{tabular}

TABLE 30: Pharmacokinetic parameters of matrine after i.v. and oral administration of matrine in rat plasma $(n=4)$ [29].

\begin{tabular}{lcc}
\hline Parameter & i.v. & p.o. \\
\hline$C_{\max }(\mathrm{ng} / \mathrm{mL})$ & - & $94.6 \pm 38.6$ \\
$T_{\max }(\mathrm{min})$ & - & $105 \pm 30$ \\
$\mathrm{AUC}_{(0-t)}(\mathrm{min} \mathrm{ng} / \mathrm{mL})$ & $108,637 \pm 11,801$ & $18,453 \pm 5885$ \\
$\mathrm{AUC}_{(0-\infty)}(\mathrm{min} \mathrm{ng} / \mathrm{mL})$ & $108,794 \pm 11,712$ & $18,593 \pm 5931$ \\
$t_{1 / 2}(\mathrm{~min})$ & $142 \pm 79$ & $92 \pm 32$ \\
$K_{\mathrm{e}}(\mathrm{L} / \mathrm{min})$ & $0.0060 \pm 0.0030$ & $0.0081 \pm 0.0023$ \\
$V(\mathrm{~mL} / \mathrm{kg})$ & $3704 \pm 1874$ & $2433 \pm 1668$ \\
$\mathrm{CL}(\mathrm{mL} / \mathrm{min} / \mathrm{kg})$ & $18.6 \pm 2.0$ & $19.7 \pm 5.5$ \\
Bioavailability $(\%)$ & - & $17.1 \pm 5.4$ \\
\hline
\end{tabular}

TABLE 31: Pharmacokinetic parameters of Dau and DS after i.v. administration in beagle dogs $(6 \mathrm{mg} / \mathrm{kg}, n=4)$ [30].

\begin{tabular}{lcc}
\hline Parameters & DS & Dau \\
\hline$\alpha / \mathrm{h}^{-1}$ & $32 \pm 13$ & $16 \pm 6^{\mathrm{a}}$ \\
$\beta / \mathrm{h}^{-1}$ & $0.24 \pm 0.07$ & $0.27 \pm 0.07^{\mathrm{a}}$ \\
$t_{1 / 2 \alpha} / \mathrm{h}$ & $0.026 \pm 0.014$ & $0.049 \pm 0.016^{\mathrm{a}}$ \\
$t_{1 / 2 \beta} / \mathrm{h}$ & $3.1 \pm 0.9$ & $2.7 \pm 0.6^{\mathrm{a}}$ \\
$K_{21} / \mathrm{h}^{-1}$ & $3.3 \pm 1.5$ & $2.1 \pm 0.9^{\mathrm{a}}$ \\
$K_{10} / \mathrm{h}^{-1}$ & $2.3 \pm 0.4$ & $2.0 \pm 0.5^{\mathrm{a}}$ \\
$K_{12} / \mathrm{h}^{-1}$ & $27 \pm 12$ & $12 \pm 5^{\mathrm{a}}$ \\
$\mathrm{MRT} / \mathrm{h}$ & $8.0 \pm 1.9$ & $7.5 \pm 1.0^{\mathrm{a}}$ \\
$V_{\mathrm{d}} / \mathrm{L} / \mathrm{kg}$ & $12 \pm 3$ & $16 \pm 3^{\mathrm{a}}$ \\
$\mathrm{AUC} / \mathrm{mg} \cdot \mathrm{h} / \mathrm{L}$ & $2.17 \pm 0.17$ & $1.48 \pm 0.17^{\mathrm{c}}$ \\
$C_{0} / \mathrm{mg} / \mathrm{L}$ & $3.8 \pm 0.7$ & $2.26 \pm 0.23^{\mathrm{b}}$ \\
\hline${ }^{\mathrm{a}} P>0.05{ }^{\mathrm{b}} P<0.05$ and $^{\mathrm{c}} P<0.01$ versus $\mathrm{DS}$ &
\end{tabular}

$10 \mathrm{ng} / \mathrm{mL}$ in plasma samples and $20 \mathrm{ng} / \mathrm{mL}$ in tissue samples. Diazepam was used as IS. The pharmacokinetic parameters are given in Table 34. Half-lives of HAC in the plasma were relatively short. The high concentration of HAC was found in kidney, followed by lung, heart, spleen, and liver. It indicates that HAC was metabolized rapidly, and it could no longer be detected in tissues after $4 \mathrm{~h} \mathrm{[32].}$

\section{Lignans}

6.1. Arctium lappa L. Arctiin is one of the key bioactive lignans extracted from seeds of Arctium lappa L. (Asteraceae). Arctiin shows numerous biological activities like treatment of the acute progress nephritis, chronic glomerulonephritis, nephritis, enhancement of immunological activities, antiinflammatory, PAF antagonist, calcium channel antagonist, and antihypertension action.

HPLC system (1100 series, Agilent Technology, Palo Alto, CA, USA) was equipped with a G1314A VWD detector. Chromatographic separation was performed on an Agilent TM C18 HPLC column $\left(250 \times 4.6 \mathrm{~mm}, 5.0 \mu \mathrm{m}, 30^{\circ} \mathrm{C}\right.$, Agilent Technologies, Beijing, China). The mobile phase was composed of acetonitrile and water $(31: 69, \mathrm{v} / \mathrm{v})$. The flow rate and injection volume were set to $1.0 \mathrm{~mL} / \mathrm{min}$ and $20 \mu \mathrm{L}$, respectively. Baicalin was used as internal standard. The wavelength of detection was $280 \mathrm{~nm}$. The LOQ and LOD are found to be $0.50 \mu \mathrm{g} / \mathrm{mL}$ and $0.25 \mu \mathrm{g} / \mathrm{mL}$, respectively. The pharmacokinetic parameters for arctiin in rats are given in Table 35. Arctiin absorption shows nonlinear kinetics. After oral administration, arctiin shows rapid absorption, distribution, and slow elimination. Due to estrogen-like effect of arctiin, male and female rats show significant difference in pharmacokinetic parameters. Female rats show 1.15- and 2.54-fold improvement in AUC and $C_{\max }$ of arctiin (dose $70 \mathrm{mg} / \mathrm{kg}$ ) in comparison to male rats. Elimination rate of arctiin in female was slower than in male [33].

6.2. Acanthopanax sessiliflorus. Asarinin, sesamin, helioxanthin, and savinin are the major bioactive lignans present in shrub Acanthopanax sessiliflorus (Rupr. et Maxim.) Seem. (Araliaceae). It is widely used in China, Japan, and Korea for rheumatism, reinforcing kidney, strengthening bones, and promoting blood circulation.

UPLC system (ACQUITY, Waters Corp., Milford, MA, USA) was composed of Micromass ${ }^{\circledR}$ Quattro microTM 
TABLE 32: Pharmacodynamic parameters of Dau and DS after i.v. administration in beagle dogs (dose $6 \mathrm{mg} / \mathrm{kg}$ and $n=4)$ [30].

\begin{tabular}{|c|c|c|c|c|c|c|c|c|}
\hline \multirow{2}{*}{ Parameters } & \multicolumn{2}{|c|}{$K_{\mathrm{e} 0} / \mathrm{h}^{-1}$} & \multicolumn{2}{|c|}{$E_{\max } / \%$} & \multicolumn{2}{|c|}{$\mathrm{EC}_{50} / \mathrm{mg} \cdot \mathrm{L}^{-1}$} & \multicolumn{2}{|c|}{$\gamma$} \\
\hline & DS & Dau & DS & Dau & DS & Dau & DS & Dau \\
\hline $\operatorname{HR}\left(\min ^{-1}\right)$ & $5.4 \pm 2.2$ & $6.0 \pm 0.8$ & $59 \pm 30$ & $34 \pm 12$ & $0.42 \pm 0.15$ & $0.29 \pm 0.04$ & $4.2 \pm 1.5$ & $2.5 \pm 0.4$ \\
\hline $\mathrm{SBP}(\mathrm{kPa})$ & $5.1 \pm 1.6$ & $4.9 \pm 1.2$ & $75 \pm 24$ & $32 \pm 6$ & $0.40 \pm 0.12$ & $0.33 \pm 0.15$ & $3.7 \pm 2.1$ & $1.9 \pm 0.9$ \\
\hline LVSP $(\mathrm{kPa})$ & $5.5 \pm 2.4$ & $7 \pm 3$ & $72 \pm 44$ & $33 \pm 9$ & $0.34 \pm 0.07$ & $0.32 \pm 0.04$ & $3.5 \pm 2.6$ & $3.6 \pm 2.0$ \\
\hline$d p / d t_{\max }(\mathrm{kPa} / \mathrm{s})$ & $4.0 \pm 1.8$ & $4.6 \pm 1.3$ & $66 \pm 8$ & $59 \pm 23$ & $0.28 \pm 0.06$ & $0.29 \pm 0.06$ & $3.4 \pm 1.9$ & $3.8 \pm 2.5$ \\
\hline
\end{tabular}

TABLE 33: Pharmacokinetic parameters after oral administration of BLA (dose $0.04 \mathrm{mg} / \mathrm{kg}$ ) [31].

\begin{tabular}{lc}
\hline Parameters & Values \\
\hline$C_{\max }(\mathrm{ng} / \mathrm{mL})$ & $2.61 \pm 1.78$ \\
$\mathrm{AUC}_{(0-\infty)}(\mathrm{ng} \cdot \mathrm{h} / \mathrm{mL})$ & $3.61 \pm 0.86$ \\
$t_{1 / 2}(\mathrm{~h})$ & $1.56 \pm 0.49$ \\
\hline
\end{tabular}

TABLE 34: The pharmacokinetic parameters after oral administration of HAC [32].

\begin{tabular}{lc}
\hline Parameters & Value \\
\hline$T_{\max }(\min )$ & $25.2 \pm 3.6$ \\
$C_{\max }(\mathrm{ng} / \mathrm{mL})$ & $541.3 \pm 129.4$ \\
$t_{1 / 2}(\min )$ & 25 (oral) \\
\end{tabular}

API triple quadrupole tandem mass spectrometer (Waters Corp., Milford, MA, USA) with ESI in positive ionization mode. Chromatographic separations were performed on an ACQUITY UPLCTM BEH C18 column $(100 \times 2.1 \mathrm{~mm}$, $\left.1.7 \mu \mathrm{m}, 30^{\circ} \mathrm{C}\right)$. The isocratic mobile phase was composed of methanol and $2.0 \mathrm{mM}$ ammonium acetate $(68: 32, \mathrm{v} / \mathrm{v})$. The flow rate and injection volume were $0.15 \mathrm{~mL} / \mathrm{min}$ and $10 \mu \mathrm{L}$, respectively. Phenacetin was used as IS. Pharmacokinetic parameters and LLOQ values are given in Table 36. All analytes exhibited consistent plasma concentration-time profiles and this is due to similar oral absorption and distribution phenomenon which may be attributed to their similar structures [34].

6.3. Eucommia ulmoides Oliv. (+)-Pinoresinol-di- $\beta$-d-glucopyranoside (PG) is the lignans present in Eucommia ulmoides Oliv. PG serves as makers for quality control of E. ulmoides Oliv. It shows variety of pharmacological actions like strengthening of muscles, bones, and tendons. PG is also known for benefitting kidney, liver, and preventing miscarriage. Additionally PG act as important antihypertensive compound.

HPLC (1200 series, Agilent, USA) system was coupled with tandem mass spectrometer (6430 series, Quad, Agilent). Chromatographic separation was achieved on C18 column (Eclipse plus, $2.1 \times 150 \mathrm{~mm}, 5.0 \mu \mathrm{m}, 30^{\circ} \mathrm{C}$, Agilent, USA) and protected by guard column. The gradient mobile phase was composed of acetonitrile and water containing $0.01 \%$ acetic acid. The flow rate was $0.3 \mathrm{~mL} / \mathrm{min}$. The LLOQ was $0.05 \mathrm{ng} / \mathrm{mL}$ and warfarin was used as IS. Pharmacokinetic parameters after oral administration of the extract of Eucommia ulmoides are given in Table 37. The pharmacokinetic profile shows that PG pertains to one-compartment model. PG exhibited poor GIT absorption. It was eliminated quickly (95\% of PG was eliminated within $12 \mathrm{~h}$ ) in rats. Moreover, the symmetric structure of PG might be easily excreted [35].

6.4. Schisandra chinensis (Turcz.) Baill. Sedative and hypnotic lignans (schisandrin, schisandrol B, schisantherin A, deoxyshisandrin, $\gamma$-schisandrin, and gomisin N) are the main bioactive components of Schisandra chinensis (Turcz.) Baill. It is extensively used to treat insomnia in TCM.

A Prominence TM UFLC (Shimadzu, Kyoto, Japan) system was composed of Q TRAPTM 4000 MS/MS system from Applied AB SCIEX (Foster City, CA, USA) with ESI in positive ion mode. Chromatographic separation was performed on Shim-pack XR-ODS column $(75 \times 3.0 \mathrm{~mm}$, $2.2 \mu \mathrm{m}, 30^{\circ} \mathrm{C}$, Shimadzu, Kyoto, Japan) with a guard cartridge. The mobile phase was composed of acetonitrile and water containing $0.1 \%$ formic acid. The flow rate, injection time, and total run time were $0.4 \mathrm{~mL} / \mathrm{min}, 2.0 \mu \mathrm{L}$, and $11.0 \mathrm{~min} / \mathrm{sample}$, respectively. Bifendate was used as IS. Pharmacokinetic parameters of the six lignans are given in Table 38. Both normal and insomnic group show significant difference in pharmacokinetic parameters. All six lignans show better absorption and slower elimination in insomnic group in comparison to normal group [36].

\section{Acid}

7.1. Polygonum capitatum Buch.-Ham. ex D. Don. Gallic acid (GA) and protocatechuic acid (PCA) are two of the main bioactive compounds present in Polygonum capitatum Buch.Ham. ex D. Don. Traditionally in China herbs it is used for treatments of urinary tract infections and pyelonephritis.

Accela 1250 UHPLC system was composed of a TSQ Quantum ultra-triple quadrupole mass spectrometer (Thermo Fisher Scientific Inc., Waltham, MA, USA) with ESI in negative ion mode. Chromatographic separations were performed on a Phenomenex Kinetex XB-C18 $(2.1 \times 150 \mathrm{~mm}$, $\left.1.7 \mu \mathrm{m}, 25^{\circ} \mathrm{C}\right)$ column. The gradient mobile phase was composed of acetonitrile containing $0.1 \%$ formic acid and water containing $0.1 \%$ formic acid. The flow rate and injection volume were $200 \mu \mathrm{L} / \mathrm{min}$ and $5.0 \mu \mathrm{L}$, respectively. Bergenin was used as IS. LLOQ for GA and PCA was $30 \mathrm{ng} / \mathrm{mL}$ and $10 \mathrm{ng} / \mathrm{mL}$, respectively. Pharmacokinetic parameters of GA and PCA after oral administrations are given in Table 39. Pharmacokinetic data revealed that after oral administration of $P$. capitatum extract, GA, and PCA was quickly absorbed 
TABLE 35: Pharmacokinetic parameters of arctiin after oral administration in rats $(n=6)$ [33].

\begin{tabular}{lcccccc}
\hline Pharmacokinetic parameter & \multicolumn{3}{c}{ Male } & & \multicolumn{2}{c}{ Female } \\
& $30 \mathrm{mg} / \mathrm{kg}$ & $50 \mathrm{mg} / \mathrm{kg}$ & $70 \mathrm{mg} / \mathrm{kg}$ & $30 \mathrm{mg} / \mathrm{kg}$ & $50 \mathrm{mg} / \mathrm{kg}$ & $70 \mathrm{mg} / \mathrm{kg}$ \\
\hline$t_{1 / 2}(\mathrm{~min})$ & $59.21 \pm 6.218$ & $63.70 \pm 7.372$ & $62.79 \pm 4.321$ & $58.85 \pm 5.010$ & $69.99 \pm 8.733$ & $89.97 \pm 11.959^{* *}$ \\
$K_{\mathrm{e}}(\mathrm{L} / \mathrm{min})$ & $0.02 \pm 0.003$ & $0.054 \pm 0.009$ & $0.04 \pm 0.006$ & $0.02 \pm 0.003$ & $0.06 \pm 0.010$ & $0.07 \pm 0.011^{* *}$ \\
$V_{1} / F(\mathrm{~L} / \mathrm{kg})$ & $5.83 \pm 0.953$ & $15.70 \pm 3.260$ & $24.69 \pm 3.14$ & $16.08 \pm 2.283^{* *}$ & $14.32 \pm 2.260$ & $11.19 \pm 1.830^{* *}$ \\
$\mathrm{CL} / F(\mathrm{~L} / \mathrm{min} / \mathrm{kg})$ & $0.07 \pm 0.008$ & $0.153 \pm 0.024$ & $0.26 \pm 0.034$ & $0.13 \pm 0.026^{* *}$ & $0.29 \pm 0.079^{* *}$ & $0.41 \pm 0.062^{* *}$ \\
$\mathrm{AUC}_{(0-t)}(\mathrm{mg} / \mathrm{L} \cdot \mathrm{min})^{*}$ & $98.77 \pm 9.78$ & $111.17 \pm 13.074$ & $130.77 \pm 6.728$ & $112.25 \pm 10.820^{*}$ & $134.29 \pm 21.313^{*}$ & $168.08 \pm 23.249^{* *}$ \\
$\mathrm{AUC}_{(0-\infty)}(\mathrm{mg} / \mathrm{L} \cdot \mathrm{min})^{*}$ & $131.17 \pm 7.23$ & $146.16 \pm 15.050$ & $177.67 \pm 19.005$ & $145.09 \pm 10.751^{*}$ & $175.01 \pm 26.106^{*}$ & $205.67 \pm 19.964^{*}$ \\
$K_{\mathrm{a}}(\mathrm{L} / \mathrm{min})$ & $0.059 \pm 0.005$ & $0.07 \pm 0.009$ & $0.100 \pm 0.006$ & $0.13 \pm 0.013^{* *}$ & $0.12 \pm 0.014^{* *}$ & $0.14 \pm 0.004^{* *}$ \\
$C_{\max }(\mathrm{mg} / \mathrm{L})$ & $0.78 \pm 0.03$ & $1.16 \pm 0.16$ & $1.88 \pm 0.05$ & $0.85 \pm 0.07^{*}$ & $4.104 \pm 0.594^{* *}$ & $4.79 \pm 1.07^{*}$ \\
\hline
\end{tabular}

${ }^{*}$ Significant $(P<0.05)$ and ${ }^{* *}$ significantly higher $(P<0.01)$ than that of male rats.

TABLE 36: Pharmacokinetic parameters asarinin, sesamin, helioxanthin, and savinin after oral administration of Acanthopanax sessiliflorus extract in rats $(n=6)$ [34].

\begin{tabular}{lcccc}
\hline Parameters & Asarinin & Sesamin & Helioxanthin & Savinin \\
\hline$C_{\max }(\mathrm{ng} / \mathrm{mL})$ & $392.8 \pm 51.2$ & $1285.6 \pm 117.4$ & $39.1 \pm 4.1$ & $121.2 \pm 21.2$ \\
$T_{\max }(\mathrm{h})$ & $2.50 \pm 0.15$ & $1.94 \pm 0.28$ & $2.22 \pm 0.48$ & $2.83 \pm 0.29$ \\
$t_{1 / 2}(\mathrm{~h})$ & $6.08 \pm 1.10$ & $11.69 \pm 0.50$ & $7.16 \pm 0.52$ & $6.26 \pm 0.57$ \\
$\mathrm{AUC}_{(0-t)}(\mathrm{ng} \mathrm{h} / \mathrm{mL})$ & $1839.9 \pm 402.2$ & $14822.1 \pm 1852.4$ & $171.5 \pm 16.8$ & $964.1 \pm 119.0$ \\
AUC $_{(0-\infty)}(\mathrm{ng} \mathrm{h} / \mathrm{mL})$ & $1933.9 \pm 446.2$ & $16783.3 \pm 1843.3$ & $186.1 \pm 17.0$ & $1043.8 \pm 109.4$ \\
LLOQ $_{(\mathrm{ng} / \mathrm{mL})}$ & 10.80 & 106 & 1.960 & 8.320 \\
\hline
\end{tabular}

TABLE 37: Main pharmacokinetic parameters of Eucommia ulmoides extract after oral administration in rats $(n=7)$ [35].

\begin{tabular}{lcc}
\hline Parameter & Mean & SD \\
\hline$A$ & 14.45 & 10.76 \\
$K$ & 29.86 & 36.76 \\
$K_{\mathrm{a}}(1 / \mathrm{h})$ & 10.89 & 8.92 \\
$K_{\mathrm{e}}(1 / \mathrm{h})$ & 0.20 & 0.12 \\
$V / F(\mathrm{~L})$ & 0.89 & 0.35 \\
$t_{1 / 2 K_{\mathrm{a}}}(\mathrm{h})$ & 0.10 & 0.10 \\
$t_{1 / 2 \alpha}(\mathrm{h})$ & 4.24 & 1.54 \\
$\mathrm{Lag}_{\text {time }}(\mathrm{h})$ & 0.05 & 0.03 \\
$\mathrm{AUC}$ & $(0-t)$ \\
$\mathrm{AUC}_{(0-\infty)}(\mathrm{ng} / \mathrm{mL} / \mathrm{h} / \mathrm{mL} \cdot \mathrm{h})$ & 64.75 & 17.75 \\
$T_{\max }(\mathrm{h})$ & 68.31 & 19.97 \\
$C_{\max }(\mathrm{ng} / \mathrm{mL})$ & 1.57 & 0.87 \\
\hline
\end{tabular}

and showed a dose-dependent profile. Particularly, P. capitatum extract demonstrated a better $t_{1 / 2}$ and $T_{\max }$ of GA as compared to its pure form. Other compounds in P. capitatum extract may be metabolized to GA, which affected the pharmacokinetic profiles of GA [37].

7.2. Solanum lyratum Thunb. Chlorogenic acid (3-O-caffeoylquinic acid) is composed of quinic acid and caffeic acid. It is a major bioactive component of Solanum lyratum Thunb. (Solanaceae). It shows variety of biological activities such as antimicrobes, antivirus, oxidation prevention, antitumor, and antihypertension. In TCM it is used to regulate body immune function.
HPLC system was equipped with UV (SPD-10AV) detector. Chromatographic separation was performed on a Diamonsil-C18 column $\left(250 \times 4.6 \mathrm{~mm}, 5 \mathrm{~mm}, 30^{\circ} \mathrm{C}\right)$. The mobile phase was composed of methanol, $0.05 \%$ phosphoric acid $(23: 77, v / v)$. The flow rate and injection volume were kept at $1.0 \mathrm{~mL} / \mathrm{min}$ and $20 \mathrm{~mL}$. UV detector was set at $327 \mathrm{~nm}$. The pharmacokinetic parameters of chlorogenic acid and S. lyratum extract are given in Table 40. Compounds in S. lyratum prohibit the absorption of chlorogenic acid and accelerate the elimination of chlorogenic acid in rats. Most of chlorogenic acid was metabolized easily in intestine. The main metabolites were benzoic acid, benzene propanoic acid, and cinnamic acid [38].

\section{Phenol}

8.1. Ainsliaea fragrans Champ. Caffeoylquinic acids (CQAs) are the bioactive phenolic constituents present in plant Ainsliaea fragrans (Asteraceae). CQAs was classified as mono-, di-, and tricaffeoylquinic acid according to the number of caffeic acids. Mono-CQAs (MCQAs) include 3-, 4-, and 5MCQA isomers, while di-CQAs (DCQAs) consist of 1,3-, 3,4-, 3,5-, 4,5-, and 1,5-DCQA isomers. MCQAs act as precursor for DCQAs. CQAs show antioxidant, radical scavenging, antiviral, and anti-inflammatory activities.

UHPLC system was composed of MS/MS (AB SCIEX QTRAP 4500) system with ESI in negative ion mode. Chromatographic separation was performed on Waters CORTECS ${ }^{\mathrm{TM}}$ UHPLC $^{\circledR} \mathrm{C} 18$ Column $\left(100 \times 2.1 \mathrm{~mm}, 1.6 \mu \mathrm{m}, 35^{\circ} \mathrm{C}\right.$, Waters, Ireland). The gradient mobile phase was composed of acetonitrile and deionized water containing $0.1 \%$ formic acid. The flow rate, injection volume, and total run time were 
TABLE 38: Pharmacokinetic parameters six lignans after oral administration of S. chinensis extract to rats (dose $7.5 \mathrm{~g} / \mathrm{kg}$ ) [36].

\begin{tabular}{|c|c|c|c|c|c|c|}
\hline Parameters & Schisandrin & Schisandrol B & Schisantherin A & Deoxyshisandrin & $\gamma$-Schisandrin & Gomisin N \\
\hline \multicolumn{7}{|c|}{ Normal group } \\
\hline $\mathrm{AUC}_{(0-t)}(\mu \mathrm{g} \cdot \mathrm{h} / \mathrm{L})$ & $15811 \pm 3774$ & $1305 \pm 441.6$ & $1654 \pm 359.4$ & $2155 \pm 508.9$ & $682.3 \pm 229.5$ & $1433 \pm 314.8$ \\
\hline $\operatorname{AUC}_{(0-\infty)}(\mu \mathrm{g} \cdot \mathrm{h} / \mathrm{L})$ & $16071 \pm 3809$ & $1347 \pm 457.9$ & $1730 \pm 408.4$ & $2243 \pm 523.4$ & $700.5 \pm 228.5$ & $1486 \pm 337.4$ \\
\hline $\operatorname{MRT}(\mathrm{h})$ & $10.93 \pm 1.00$ & $11.96 \pm 0.48$ & $12.09 \pm 2.20$ & $12.81 \pm 1.22$ & $10.89 \pm 0.78$ & $11.28 \pm 0.72$ \\
\hline$t_{1 / 2}(\mathrm{~h})$ & $5.77 \pm 0.70$ & $6.40 \pm 0.50$ & $7.81 \pm 2.16$ & $7.55 \pm 1.02$ & $7.06 \pm 1.26$ & $7.25 \pm 0.74$ \\
\hline$T_{\max }(\mathrm{h})$ & $1.75 \pm 0.42$ & $1.75 \pm 0.27$ & $2.08 \pm 0.49$ & $4.00 \pm 0.63$ & $6.66 \pm 1.03$ & $5.66 \pm 1.21$ \\
\hline$C_{\max }(\mu \mathrm{g} / \mathrm{L})$ & $1542 \pm 329.4$ & $141.95 \pm 45.06$ & $141.2 \pm 25.15$ & $168.3 \pm 32.22$ & $73.58 \pm 16.83$ & $142.7 \pm 28.13$ \\
\hline $\mathrm{CL}_{\mathrm{z}}(\mathrm{L} / \mathrm{kg} / \mathrm{h})$ & $5.296 \pm 1.368$ & $13.52 \pm 5.555$ & $1.99 \pm 0.38$ & $14.26 \pm 4.175$ & $13.34 \pm 4.230$ & $22.79 \pm 6.030$ \\
\hline \multicolumn{7}{|c|}{ Insomnic group } \\
\hline $\mathrm{AUC}_{(0-t)}(\mu \mathrm{g} \cdot \mathrm{h} / \mathrm{L})$ & $22288 \pm 5452^{*}$ & $1935 \pm 558.2$ & $2261 \pm 506.7^{*}$ & $2753 \pm 259.6^{*}$ & $1486 \pm 458.7^{*}$ & $1828 \pm 268.9^{*}$ \\
\hline $\mathrm{AUC}_{(0-\infty)}(\mu \mathrm{g} \cdot \mathrm{h} / \mathrm{L})$ & $23118 \pm 5532^{*}$ & $2059 \pm 542.0^{*}$ & $2475 \pm 502.4^{*}$ & $3010 \pm 333.9^{*}$ & $1598 \pm 526.6^{*}$ & $1937 \pm 272.2^{*}$ \\
\hline $\operatorname{MRT}(\mathrm{h})$ & $12.67 \pm 1.34^{*}$ & $14.25 \pm 2.34^{*}$ & $15.51 \pm 2.22^{*}$ & $15.32 \pm 1.76^{*}$ & $13.49 \pm 1.49^{*}$ & $12.54 \pm 0.72^{*}$ \\
\hline$t_{1 / 2}(\mathrm{~h})$ & $7.38 \pm 1.65$ & $8.07 \pm 1.68^{*}$ & $10.77 \pm 3.51$ & $9.77 \pm 2.40$ & $9.17 \pm 1.75^{*}$ & $8.98 \pm 2.55$ \\
\hline$T_{\max }(\mathrm{h})$ & $1.75 \pm 0.27$ & $1.83 \pm 0.26$ & $1.92 \pm 0.59$ & $4.17 \pm 0.75$ & $7.03 \pm 1.10$ & $5.83 \pm 1.17$ \\
\hline$C_{\max }(\mu \mathrm{g} / \mathrm{L})$ & $2284 \pm 227.4^{*}$ & $225.2 \pm 53.95^{*}$ & $202.8 \pm 24.77^{*}$ & $233.8 \pm 34.37^{*}$ & $125.1 \pm 20.51^{*}$ & $207.7 \pm 39.26^{*}$ \\
\hline $\mathrm{CL}_{\mathrm{z}}(\mathrm{L} / \mathrm{kg} / \mathrm{h})$ & $3.684 \pm 0.953^{*}$ & $8.349 \pm 2.292^{*}$ & $1.378 \pm 0.242^{*}$ & $10.14 \pm 1.041^{*}$ & $5.859 \pm 1.826^{*}$ & $16.95 \pm 2.646^{*}$ \\
\hline
\end{tabular}

${ }^{*} P<0.05$ compared with normal group (mean $\pm \mathrm{SD} ; n=6$ ).

$0.2 \mathrm{~mL} / \mathrm{min}, 2.0 \mu \mathrm{L}$, and $17.8 \mathrm{~min}$. Chloramphenicol was used as IS. The LLOQs for caffeic acids, 3,5-DCQA and 4,5-DCQA and 1,5-DCQA and 3,4-DCQA in plasma, were 3.13 and $2.34 \mathrm{ng} \cdot \mathrm{mL}^{-1}$, respectively. Pharmacokinetic parameters of DCQA and caffeic acid after oral administration are given in Table 41. DCAQs were mainly absorbed in small intestine and its isomers also absorbed quickly. MCQAs were chiefly found in tissues, not in plasma. DCQA and MCQA isomers were all high in the ovary and uterus, and some could pass through the barrier between the blood and brain [39].

8.2. Rhodiola crenulata. Salidroside and p-tyroso are the two bioactive biophenols present in Rhodiola species ( $R$. crenulata) (Crassulaceae). It is commonly used in TCM as adaptogenic, transient focal cerebral ischemia and cellular antioxidant defenses products ingredient.

Agilent 1100 Series HPLC system is composed of FLD (G1321A, at $\lambda_{\text {ex }} 262 \mathrm{~nm}$ and $\lambda_{\text {em }} 425 \mathrm{~nm}$ ) and mass spectrometer (1100 Series LC-MSD Trap-SL (ion trap), Bruker Daltonik, Bremen, Germany) with ESI in positive ion mode. Chromatographic separation was performed on reversed phase Akasil-C18 column $(4.6 \times 250 \mathrm{~mm}, 5 \mu \mathrm{m}$, Angela Technologies Inc., USA). The gradient mobile phase was composed of acetonitrile and 5\% aqueous acetonitrile. The flow rate was $1.0 \mathrm{~mL} / \mathrm{min}$. The pharmacokinetic parameters of representative salidroside and its different dosage form are given in Table 42. Among the four samples, salidroside form $R$. crenulata showed smallest elimination rate constant $\left(K_{\mathrm{e}}\right)$ and largest $t_{1 / 2} . C_{\max }$ of salidroside in tablet sample was larger than others preparations. Additionally, tablets also showed with better $\mathrm{AUC}_{(0-t)}$ and $\mathrm{AUC}_{(0-\infty)}$. The raw herb showed the longer $t_{1 / 2}$ but lower $C_{\max }$, and on the other side its preparations led to the shorter $t_{1 / 2}$ but higher $C_{\max }$, demonstrating that the absorption of herb-related products was more rapid than that of the raw herb. Meanwhile, the results of other pharmacokinetic parameters showed the sustained release effect of raw herb. The oral bioavailability of tablet was higher than that of other three samples [40].

\section{Glycoside}

9.1. Polygonum multiflorum. 2,3,5,4'-Tetrahydroxystilbene2-O- $\beta$-d-glucoside (PM-SG) is a bioactive stilbene glycoside present in Polygonum multiflorum. It shows various pharmacological actions like antioxidative, anti-inflammatory, endothelial protective, and oncogenic enzyme inhibitory activity.

Reversed phase-high performance liquid chromatography (RP-HPLC, 1200 Series, Agilent Technologies, Palo Alto, CA, USA) equipped G1315B DAD. Chromatographic separation was performed on an Ultimate XB-C18 column $(150 \times$ $4.6 \mathrm{~mm}, 5 \mu \mathrm{m}$, Welch, MD, USA) and coupled with Agilent C18 precolumn $(15 \times 4.6 \mathrm{~mm}, 5 \mu \mathrm{m}$, Palo Alto, CA, USA $)$ at $25^{\circ} \mathrm{C}$ temperature. The mobile phase was composed of acetonitrile and water $(20: 80, \mathrm{v} / \mathrm{v})$. The flow rate, injection volume, and detection wavelength were $1.0 \mathrm{~mL} / \mathrm{min}, 5.0 \mu \mathrm{L}$, and $320 \mathrm{~nm}$, respectively. The LOQ and LOD of PM-SG in rat plasma were 1.325 and $0.265 \mathrm{ng} / \mathrm{mL}$, respectively. Pharmacokinetic parameters of PM-SG are given in Table 43. Pharmacokinetic parameters were determined by both compartment and noncompartment models. It was suggested that PM-SG was rapidly absorbed into the body fluids and widely distributed throughout the body with quick elimination. PMSG was highly distrusted in liver and lungs while little in brain and testes. PM-SG can hardly penetrate the blood brain and blood-testicle barriers [41].

9.2. Ajuga decumbens Thunb. 8-O-Acetyl harpagide and harpagide are the main iridoid glycosides present in Ajuga decumbens Thunb. (Jingucao) (Ajuga). These glycosides are 


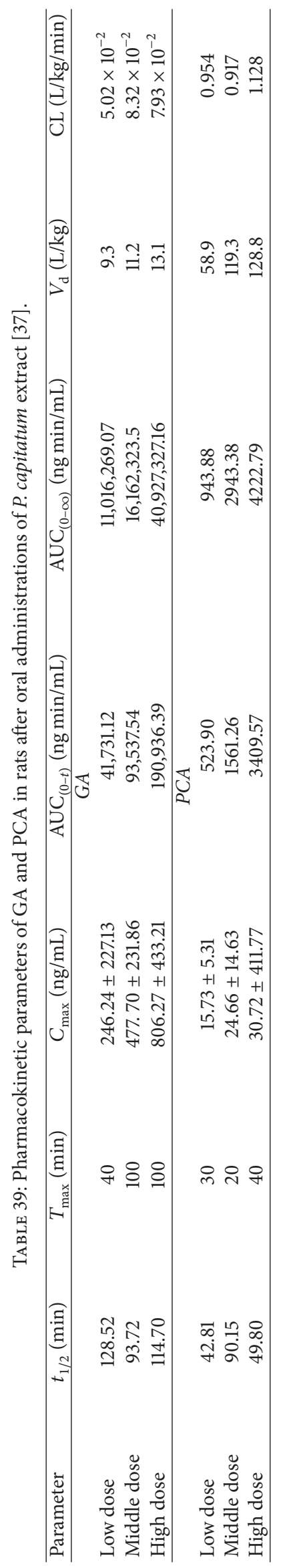


TABLE 40: Pharmacokinetic parameters after oral administration of chlorogenic acid $(50.0 \mathrm{mg} / \mathrm{kg}$ ) and extract of $S$. lyratum (equal to $50.0 \mathrm{mg} / \mathrm{kg}$ chlorogenic acid) ( $n=6 /$ group) [38].

\begin{tabular}{|c|c|c|}
\hline Parameters & Chlorogenic acid (p.o.) & Extract of S. lyratum (p.o.) \\
\hline $\mathrm{AUC}_{(0-t)}(\mathrm{mgh} / \mathrm{L})$ & $1.50 \pm 0.91$ & $0.76 \pm 0.26^{*}$ \\
\hline $\mathrm{AUC}_{(0-\infty)}(\mathrm{mg} \mathrm{h} / \mathrm{L})$ & $1.61 \pm 0.92$ & $0.83 \pm 0.27^{*}$ \\
\hline$t_{1 / 2}(\mathrm{~h})$ & $1.70 \pm 0.24$ & $1.7 \pm 0.2$ \\
\hline$T_{\max }(\mathrm{h})$ & $0.48 \pm 0.29$ & $0.36 \pm 0.07$ \\
\hline $\mathrm{CL}_{\mathrm{z}} / F[\mathrm{~L} /(\mathrm{h} \cdot \mathrm{kg})]$ & $39 \pm 17$ & $65 \pm 21^{*}$ \\
\hline$V_{\mathrm{z}} / F(\mathrm{~L} / \mathrm{kg})$ & $97.5 \pm 47$ & $154 \pm 33$ \\
\hline$C_{\max }(\mathrm{mg} / \mathrm{L})$ & $0.55 \pm 0.22$ & $0.37 \pm 0.12$ \\
\hline$K_{\mathrm{e}}(\mathrm{L} / \mathrm{h})$ & $0.41 \pm 0.06$ & $0.41 \pm 0.19$ \\
\hline
\end{tabular}

${ }^{*}$ Significant difference or $P<0.05$.

responsible for various pharmacological actions like antiinflammatory, antibacterial, and antiviral actions and vascular contraction also.

HPLC (1200 series, Agilent, USA) system was composed of a 6410 triple quadrupole mass spectrometer with ESI in positive ionization mode. Chromatographic separation was achieved on an Agilent ZORBAX XDB-C18 column $(2.1 \times 50 \mathrm{~mm}, 3.5 \mu \mathrm{m})$. The gradient mobile phase was composed of acetonitrile and $0.1 \%$ formic acid. The flow rate was $0.3 \mathrm{~mL} / \mathrm{min}$. Cinnamic acid was used as IS. Pharmacokinetic parameters are given in Tables 44 and 45. 8-OAcetyl harpagide and harpagide get rapidly absorbed when administered as extract. $T_{\max }$ shows significant difference as compared to all other reported pharmacokinetic parameters in both pure form and extract form. 8-O-Acetyl harpagide was metabolized to harpagide when administered in form of extract [42].

\section{Lactones}

10.1. Withania somnifera L. Withaferin A (WA) and withanolide A (WLD) are two main steroidal lactones present in Withania somnifera L. (Solanaceae). WA shows wide range of pharmacological actions like cytotoxic, apoptotic, anticancer, antimetastatic, anti-inflammatory, antimitotic, antiangiogenesis, antiangiogenesis, antiparasitic, and hepatoprotective actions. WLD is well known for reconstruction of neural networks. It helps to promote synaptic and outgrowth reconstruction. It is widely used for various neurodegenerative diseases treatments. It is useful in cognitive function impairment, Parkinson's, convulsions, and Alzheimer's.

HPLC system was composed of Applied Biosystem/MDS SCIEX API-3000 triple quadrupole mass spectrometer with ESI in positive ion mode. Chromatographic separation was carried out on a reverse phase Hypurity C18 column $(50 \times$ $4.6 \mathrm{~mm}, 5 \mu \mathrm{m}, 25^{\circ} \mathrm{C}$, Thermo scientific, India). The isocratic mobile phase was composed of methanol and $2.0 \mathrm{mM}$ ammonium acetate $(95: 5, \mathrm{v} / \mathrm{v})$. The flow rate and total analytical run time were $0.4 \mathrm{~mL} / \mathrm{min}$ and $3.0 \mathrm{~min}$, respectively. The LOD for WA and WLD was $0.1 \mathrm{ng} / \mathrm{mL}$ in mice plasma and LLOQs were 0.484 and $0.476 \mathrm{ng} / \mathrm{mL}$ for WA and WLD, respectively. Tianeptine and clonazepam were used as IS for WA and WLD, respectively. The pharmacokinetic parameters of WA and WLD in mice plasma after oral administration of $W$. somnifera root aqueous extract (WSE) are given in Table 46. Withanolides show rapid oral absorption. Relative oral bioavailability of WLD (1.44 times) is greater than WA [43].

10.2. Dioscorea bulbifera L. Diosbulbin B is a diterpenoid lactone identified in the leaves and stems of Dioscorea bulbifera L. It shows various pharmacological activities like antitumor, responsible activities in human promyelocytic leukemia cell HL-60, human epidermal cancer cells A431, mouse sarcoma S180, and mouse hematoma H22.

HPLC (LC-20AD series, Shimadzu, Tokyo, Japan) system was composed of an Applied Biosystems SCIEX 4000 QTRAP mass spectrometer via a turbo ion spray ionization interface with ESI in positive ion mode (Concord, Ontario, Canada). Chromatographic separation was performed on an Agilent ZorbaxXDB-C18 column $(50 \times 2.0 \mathrm{~mm}, 3.5 \mu \mathrm{m}$, $25^{\circ} \mathrm{C}$, Agilent Technologies, CA, USA). The gradient mobile phase is composed of a mixture of $0.1 \%$ formic acid in water and $0.1 \%$ formic acid in methanol. The flow rate was $0.5 \mathrm{~mL} / \mathrm{min}$. Pharmacokinetic parameters of diosbulbin $\mathrm{B}$ after oral administration are given in Table 47. Diosbulbin B shows high MRT and delayed excretion mainly due to enterohepatic circulation. It may lead to cumulative toxicity [44].

\section{Miscellaneous}

11.1. Radix Angelicae Dahuricae. Isoimperatorin (ISOIM) is one of the bioactive components present in dried root of $A$. dahurica (Fisch. ex hoffm.) Benth. Et Hook. f. and A. dahurica (Fisch. Ex hoffm.) Benth. Et Hook. f. var. formosana (Boiss.) (Umbelifera). ISOIM possesses a variety of pharmacological and biochemical properties such as cyclooxygenase 1 and 2 inhibition and leukotriene C4 (LTC4) inhibition and selectively inhibits TNF-alpha-induced expression of VCAM-1 and hepatoprotective.

HPLC (Shimadzu) system was composed of photodiode array detector and mass spectrometer (LC-MS-2010EV Shimadzu, Kyoto, Japan) with ESI in positive ion mode. Chromatographic separation was performed on a C18 analytical column $\left(150 \times 2.0 \mathrm{~mm}, 5 \mu \mathrm{m}, 25^{\circ} \mathrm{C}\right.$, Shim-pack (VP-ODS), Shimadzu Corporation, Kyoto, Japan). The mobile phase was composed of mixture of acetonitrile and $0.5 \%$ formic acid 


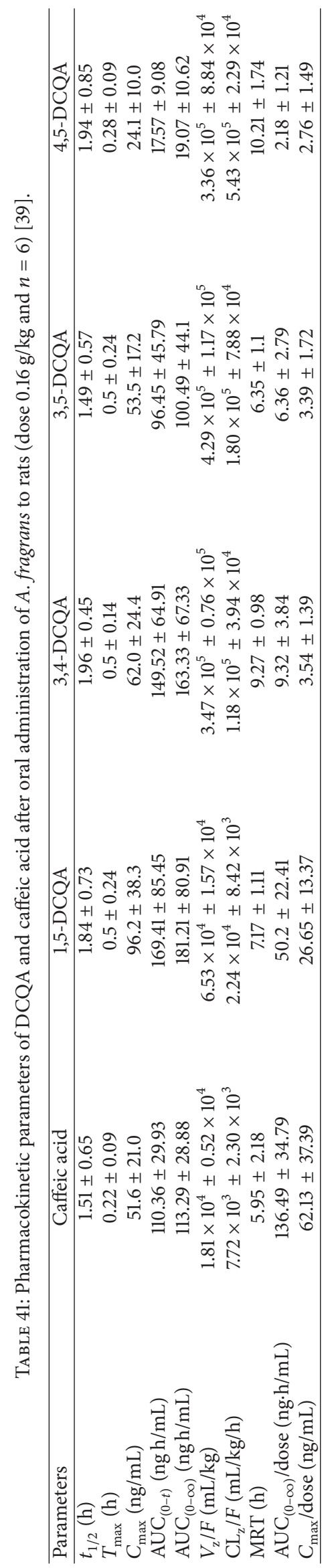




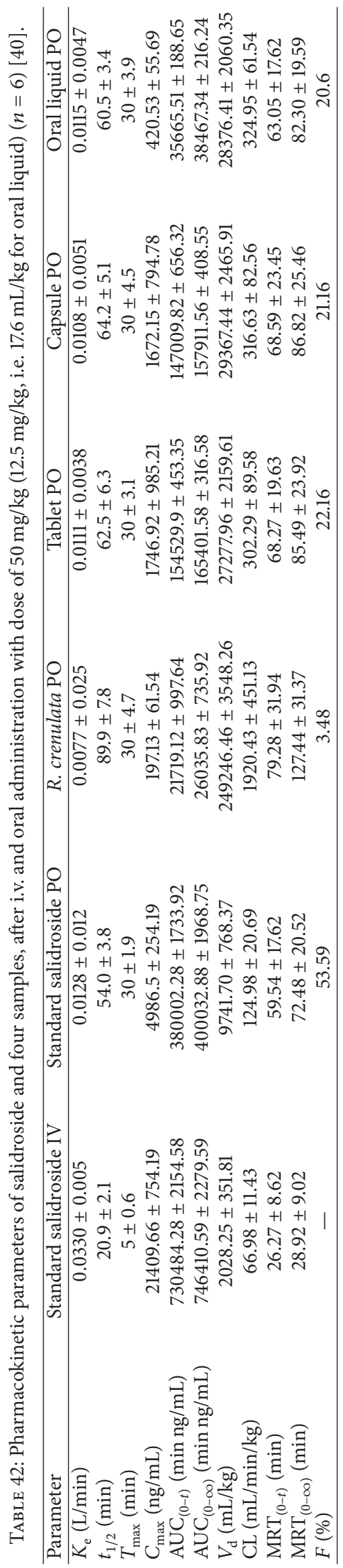


TABLE 43: Pharmacokinetic parameters of PM-SG after oral administration $n$ to rats $(n=5)$ [41].

\begin{tabular}{|c|c|c|c|}
\hline \multicolumn{2}{|c|}{ Compartmental } & \multicolumn{2}{|c|}{ Noncompartmental } \\
\hline Parameters & Values & Parameters & Values \\
\hline$t_{1 / 2 K_{\mathrm{a}}}(\min )$ & 6.41 & $C_{\max }(\mu \mathrm{g} / \mathrm{mL})$ & 31.91 \\
\hline$K_{10}\left(\min ^{-1}\right)$ & 0.16 & $\operatorname{MRT}_{(0-\infty)}(\min )$ & 52.44 \\
\hline$K_{12}\left(\min ^{-1}\right)$ & 0.11 & $T_{\max }(\min )$ & 40.00 \\
\hline$K_{21}\left(\min ^{-1}\right)$ & 0.05 & $\operatorname{VRT}_{(0-t)}\left(\min ^{2}\right)$ & 689.66 \\
\hline$K_{\mathrm{a}}\left(\min ^{-1}\right)$ & 0.11 & $\mathrm{AUC}_{(0-t)}(\mu \mathrm{g} \mathrm{min} / \mathrm{mL})$ & 1202.64 \\
\hline$t_{1 / 2 \alpha}(\min )$ & 9.37 & $\operatorname{VRT}_{(0-\infty)}\left(\min ^{2}\right)$ & 804.44 \\
\hline$t_{1 / 2 \beta}(\min )$ & 20.43 & $\mathrm{AUC}_{(0-\infty)}(\mu \mathrm{g} \min / \mathrm{mL})$ & 1205.33 \\
\hline$V_{\mathrm{L}} / F(\mathrm{~mL} / \mathrm{kg})$ & 678.00 & $t_{1 / 2 z}(\min )$ & 17.09 \\
\hline $\mathrm{CL} / F(\mathrm{~mL} / \mathrm{min} / \mathrm{kg})$ & 111.00 & $\operatorname{AUMC}_{(0-t)}(\mu \mathrm{g} \mathrm{min} / \mathrm{mL})$ & 61919.73 \\
\hline $\mathrm{AUC}_{(0-t)}(\mu \mathrm{g} \min / \mathrm{mL})$ & 892.91 & $V_{\mathrm{z}} / F(\mathrm{~L} / \mathrm{kg})$ & 2046.00 \\
\hline $\mathrm{AUC}_{(0-\infty)}(\mu \mathrm{g} \min / \mathrm{mL})$ & 899.79 & $\operatorname{AUMC}_{(0-\infty)}(\mu \mathrm{g} \mathrm{min} / \mathrm{mL})$ & 63201.44 \\
\hline- & - & $\mathrm{CL}_{\mathrm{z}} / F(\mathrm{~L} / \mathrm{min} / \mathrm{kg})$ & 83.00 \\
\hline- & - & $\operatorname{MRT}_{(0-t)}(\min )$ & 51.49 \\
\hline
\end{tabular}

TABLE 44: Pharmacokinetic parameters of 8-O-acetyl harpagide and harpagide in rats after oral administration of Ajuga decumbens Thunb. extract $(n=6)$ [42].

\begin{tabular}{lcccccc}
\hline Compounds & Dose $(\mathrm{mg} / \mathrm{kg})$ & $C_{\max }(\mathrm{ng} / \mathrm{mL})$ & $T_{\max }(\mathrm{h})$ & $t_{1 / 2}(\mathrm{~h})$ & $\mathrm{AUC}_{(0-t)}(\mathrm{h} / \mathrm{ng} / \mathrm{mL})$ & $\mathrm{AUC}(0-\infty)$ \\
\hline & 60 & 3631.57299 .46 & $0.33 \pm 0.07$ & $2.46 \pm 0.25$ & $3539.48 \pm 544.05$ & $3822.17 \pm 261.30$ \\
8-O-Acetyl harpagide & 30 & $1383.20 \pm 191.25$ & $0.39 \pm 0.09$ & $2.88 \pm 0.38$ & $1279.56 \pm 181.41$ & $1503.31 \pm 131.74$ \\
& 15 & $502.65 \pm 63.27$ & $0.40 \pm 0.02$ & $2.74 \pm 0.33$ & $883.27 \pm 80.03$ & $919.807 \pm 5.33$ \\
\hline \multirow{3}{*}{ Harpagide } & 60 & $844.02 \pm 111.48$ & $0.37 \pm 0.12$ & $2.77 \pm 0.43$ & $1636.18 \pm 103.42$ & $1995.30 \pm 187.12$ \\
& 30 & $496.50 \pm 64.21$ & $0.39 \pm 0.04$ & $2.67 \pm 0.43$ & $866.94 \pm 33.36$ & $958.42 \pm 110.99$ \\
& 15 & $151.81 \pm 13.21$ & $0.38 \pm 0.12$ & $2.44 \pm 0.54$ & $544.70 \pm 53.61$ & $614.83 \pm 103.28$ \\
\hline
\end{tabular}

solution $(75: 25, \mathrm{v} / \mathrm{v})$ at a flow rate of $0.2 \mathrm{~mL} / \mathrm{min}$. The LLOQ was $2.0 \mathrm{ng} / \mathrm{mL}$ and osthole was used as IS. Pharmacokinetic parameters of isoimperatorin after oral administration are given in Table 48. ISOIM gets easily absorbed from circulatory system. It exhibits relatively higher tissue distribution in organs like kidney and liver [45].

11.2. Cnidium monnieri $L$. Osthole is one type of the major bioactive coumarin present in plant Cnidium monnieri (L.) Cuss (Umbelifera). It shows various activities like in vitro inhibition of hepatitis B virus surface antigens and inhibits platelet aggregation and suppression of thromboxane formation and phosphoinositide breakdown. Osthole is also used as one of the marker compounds for the characterization of Fructus Cnidii.

HPLC (Elite, Dalian, China) system was equipped with UV detector. Chromatographic separation was performed on analytical column (Hypersil ODS2, $250 \times 4.6 \mathrm{~mm}, 5.0 \mu \mathrm{m}$, at room temperature). The mobile phase consisted of methanol and $0.4 \%$ acetic acid $(65: 35, \mathrm{v} / \mathrm{v})$. The flow rate was set as $0.7 \mathrm{~mL} / \mathrm{min}$ with detection wavelength of $322 \mathrm{~nm}$. The LOQ was found to be $0.0520 \mu \mathrm{g} / \mathrm{mL}$. The pharmacokinetic parameters of osthole in rats are given in Table 49. Coexisting ingredients of extract may enhance the absorption of osthole in GIT [46].
11.3. Andrographis paniculata. Andrographis paniculata (AP) (Acanthaceae) is well known in Asian countries including China, India, and Thailand to treat various diseases conditions. In China AP extract (APE) is available as both oral and injections for therapeutic use. The aqueous ethanol extract of AP leaves (Hutchison Medipharma Ltd. (HMP) named as HMPL-004) has been used to treat various inflammatory diseases. It contains various active constituents like andrographolide (AND), neoandrographolide (NAND), 14deoxyandrographolide (DAND), and 14-deoxy-11,12-didehydroandrographolide (DDAND) which have already been shown to be the major diterpenoid components in AP. Apigenin-7-O- $\beta$-d-glucopyranoside (AODG) and chlorogenic acid (CLA) were identified to be the major representative flavonoid and polyphenol components.

LC (1200 series, Agilent) system was composed of triple quadrupole mass spectrometer (API4000, AB SCIEX, Foster City, CA, USA) with ESI in negative ion mode. Chromatographic separation was achieved on RP C18 column $(50 \times$ $2.1 \mathrm{~mm}, 5.0 \mu \mathrm{m}, 30^{\circ} \mathrm{C}$, Waters Xbridge Shield, Mildford, MA, USA) and protected with a Supelco filter $(0.5 \mu \mathrm{m}$, SigmaAldrich, St Louis, MO, USA). The gradient mobile phase was composed of mixture of acetonitrile and methanol (50\% $\mathrm{v} / \mathrm{v}$ ) and water containing $0.1 \%$ acetic acid. The flow rate and injection volume are $0.4 \mathrm{~mL} / \mathrm{min}$ and $10 \mu \mathrm{L}$, respectively. 
TABLE 45: Pharmacokinetic parameters of 8-O-acetyl harpagide and harpagide in rats $(n=6)$ [42].

\begin{tabular}{lcccccc}
\hline Compounds & Dose & $C_{\max }(\mathrm{ng} / \mathrm{mL})$ & $T_{\max }(\mathrm{h})$ & $t_{1 / 2}(\mathrm{~h})$ & $\mathrm{AUC}_{(0-t)}(\mathrm{h} / \mathrm{ng} / \mathrm{mL})$ & $\mathrm{AUC}$ \\
\hline 8-O-Acetyl harpagide & $12 \mathrm{mg} / \mathrm{kg}$ & $1444.17 \pm 131.96$ & $0.83 \pm 0.25$ & $3.37 \pm 0.32$ & $1635.03 \pm 102.18$ & $1674.84 \pm 169.09$ \\
Harpagide (as a metabolite) & - & $189.04 \pm 17.34$ & $1.00 \pm 0.05$ & $2.58 \pm 0.16$ & $684.11 \pm 99.37$ & $1104.87 \pm 141.70$ \\
Harpagide & $3 \mathrm{mg} / \mathrm{kg}$ & $338.81 \pm 31.86$ & $0.21 \pm 0.06$ & $2.34 \pm 0.58$ & $604.44 \pm 52.09$ & $806.30 \pm 31.76$ \\
\hline
\end{tabular}

TABLE 46: Pharmacokinetic parameters of WA and WLD after oral administration of WSE in mice [43].

\begin{tabular}{lcr}
\hline Parameter & Withaferin A & Withanolide A \\
\hline$C_{\max }(\mathrm{ng} / \mathrm{mL})$ & $16.69 \pm 4.02$ & $26.59 \pm 4.47$ \\
$T_{\max }(\mathrm{min})$ & $20(20-30)$ & $10(10-30)$ \\
$t_{1 / 2}(\mathrm{~min})$ & $59.92 \pm 15.90$ & $45.22 \pm 9.95$ \\
$\mathrm{AUC}_{(0-t)}(\mathrm{ng} / \mathrm{mL} \mathrm{min})$ & $1572.27 \pm 57.80$ & $2458.47 \pm 212.72$ \\
$\mathrm{AUC}_{(0-\infty)}(\mathrm{ng} / \mathrm{mL}$ min $)$ & $1673.10 \pm 54.53$ & $2516.41 \pm 212.10$ \\
$\mathrm{CL}(\mathrm{mL} / \mathrm{min} / \mathrm{kg})$ & $274.10 \pm 9.10$ & $191.10 \pm 16.74$ \\
\hline
\end{tabular}

Data expressed as mean $\pm \mathrm{SD}(n=6)$ except $T_{\max }$ mentioned as median.

TABLE 47: Pharmacokinetic parameters of diosbulbin B after oral administration of D. bulbifera L. in rats $(n=6)$ [44].

\begin{tabular}{lc}
\hline Parameters & Values \\
\hline $\mathrm{AUC}_{(0-t)}(\mu \mathrm{gh} / \mathrm{L})$ & $132.1 \pm 25.1$ \\
$C_{\max }(\mathrm{ng} / \mathrm{mL})$ & $18.0 \pm 3.1$ \\
$\mathrm{AUC}_{(0-\infty)}(\mu \mathrm{gh} / \mathrm{L})$ & $144.7 \pm 29.7$ \\
$t_{1 / 2}(\mathrm{~h})$ & $6.89 \pm 1.0$ \\
$K_{\mathrm{e}}(\mathrm{L} / \mathrm{h})$ & $0.103 \pm 0.01$ \\
$V_{\mathrm{c}}(\mathrm{L} / \mathrm{kg})$ & $140.5 \pm 17.2$ \\
$T_{\max }(\mathrm{h})$ & $1.88 \pm 0.22$ \\
$\mathrm{CL}(\mathrm{L} / \mathrm{h} / \mathrm{kg})$ & $14.8 \pm 3.3$ \\
\hline
\end{tabular}

TABLE 48: Pharmacokinetic parameters of isoimperatorin after oral administration $(25 \mathrm{mg} / \mathrm{kg}, n=6)$ and i.v. injection (dose $5 \mathrm{mg} / \mathrm{kg}$, $n=6)[45]$.

\begin{tabular}{lcccc}
\hline \multirow{2}{*}{ Parameter } & \multicolumn{2}{c}{ Oral administration } & \multicolumn{2}{c}{$\begin{array}{c}\text { Intravenous } \\
\text { administration }\end{array}$} \\
& Mean & S.D. & Mean & S.D. \\
\hline$K_{\mathrm{a}}(\mathrm{L} / \mathrm{min})$ & 0.028 & 0.003 & - & - \\
$t_{1 / 2 \alpha}(\mathrm{min})$ & 38.35 & 7.95 & 3.64 & 0.92 \\
$t_{1 / 2 \beta}(\mathrm{min})$ & 883.15 & 198.27 & 44.46 & 12.25 \\
$t_{1 / 2 K_{\mathrm{a}}}(\mathrm{L} / \mathrm{min})$ & 24.65 & 4.26 & - & - \\
$\mathrm{AUC}$ & & & & \\
$(\mu \mathrm{g} / \mathrm{mL}) \cdot \mathrm{min}$ & 364.14 & 232.18 & 106.84 & 23.44 \\
$\mathrm{CL}(\mathrm{s})$ & & & & \\
$(\mathrm{mg} / \mathrm{kg} / \mathrm{min} / \mu \mathrm{g} / \mathrm{mL})$ & 0.069 & 0.014 & 0.047 & 0.012 \\
$T_{\text {peak }}(\mathrm{min})$ & 49.68 & 13.36 & - & - \\
$C_{\mathrm{max}}(\mu \mathrm{g} / \mathrm{mL})$ & 1.18 & 0.24 & - & - \\
$V_{\mathrm{c}} / F$ & & & & - \\
$(\mathrm{mg} / \mathrm{kg} / \mu \mathrm{g} / \mathrm{mL})$ & 12.10 & 2.33 & - & - \\
$V_{\mathrm{c}}(\mathrm{mg} / \mathrm{kg} / \mu \mathrm{g} / \mathrm{mL})$ & - & - & 1.26 & 0.31 \\
\hline
\end{tabular}

The LLOQ for all components was found to be $4 \mathrm{ng} / \mathrm{mL}$. Cortisone was used as IS. Pharmacokinetic parameters of all
TABLE 49: Pharmacokinetic parameters of osthole after oral administration of $F$. cnidii extract in rats $(n=6)$ [46].

\begin{tabular}{lc}
\hline Parameters & Values \\
\hline$C_{\text {max }}(\mu \mathrm{g} / \mathrm{mL})$ & $0.776 \pm 0.069$ \\
$T_{\max }(\mathrm{h})$ & $1.0 \pm 0.3$ \\
$t_{1 / 2}(\mathrm{~h})$ & $3.6 \pm 0.6$ \\
$K_{\mathrm{e}}\left(\mathrm{h}^{-1}\right)$ & $0.192 \pm 0.0282$ \\
$\mathrm{AUC}_{(0-t)}(\mu \mathrm{g} \cdot \mathrm{h} / \mathrm{mL})$ & $3.20 \pm 0.386$ \\
$\mathrm{AUC}_{(0-\infty)}(\mu \mathrm{g} \cdot \mathrm{h} / \mathrm{mL})$ & $3.55 \pm 0.385$ \\
\hline
\end{tabular}

components after oral administration HMPL-004 are given in Table 50. AND was hydrolyzed to its metabolite, that is, HM5013620. It shows 3-fold higher AUC than its parent compound and highest plasma exposure among all seven analytes [47].

11.4. Dendrobium Species. Chrysotoxine (CTX) is the bibenzyl moiety present in the Dendrobium species like Dendrobium nobile Lindl., Dendrobium chrysotoxum Lindl., and Dendrobium fimbriatum Hook, (Orchidaceae). Plant shows variety of pharmacological actions like hypoglycaemic, antitumor, antiaging, immunomodulatory effects, and protection against neurodegeneration.

HPLC (LC-2010 series, Shimadzu, Kyoto, Japan) system was composed of Thermo Finnigan TSQAM tandem mass spectrometer (Thermo Finnigan, San Jose, CA, USA) with ESI in positive ion mode. Chromatographic separation was performed on YMC-Pack ODS-A column $(50 \times 4.6 \mathrm{~mm}$, $3.0 \mu \mathrm{m}, 30^{\circ} \mathrm{C}$, YMC Co., Ltd., Kyoto, Japan). The mobile phase was composed of acetonitrile-water $(90: 10, \mathrm{v} / \mathrm{v})$. The flow rate, injection volume, and total run time were $0.7 \mathrm{~mL} / \mathrm{min}$, $10 \mu \mathrm{L}$, and $3 \mathrm{~min}$, respectively. Wogonin (purity > 99.5\%) was used as IS. The LLOQ of CTX was $0.5 \mathrm{ng} / \mathrm{mL}$. Pharmacokinetic parameters of CTX after oral and intravenous administration are given in Table 51. Low oral bioavailability of CTX was credited to rapid excretion rate and poor absorption in gastrointestinal portion [48]. 
TABLE 50: Pharmacokinetic parameters of all components in rats after oral administration of HMPL-004 (dose $750 \mathrm{mg} / \mathrm{kg}$ and $n=6)$ [47].

\begin{tabular}{|c|c|c|c|c|c|c|c|}
\hline Parameters & AND & NAND & DAND & DDAND & CLA & AODG & HM5013620 \\
\hline$t_{1 / 2}(\mathrm{~h})$ & $3.10 \pm 1.92$ & $7.99 \pm 7.65$ & $3.15 \pm 2.20$ & $2.61 \pm 2.43$ & $2.88 \pm 3.17$ & $5.96 \pm 9.69$ & $3.37 \pm 1.65$ \\
\hline MRT (h) & $4.53 \pm 1.49$ & $10.62 \pm 10.90$ & $7.21 \pm 2.54$ & $3.77 \pm 3.13$ & $3.39 \pm 1.32$ & $11.62 \pm 13.06$ & $5.66 \pm 2.17$ \\
\hline $\mathrm{AUC}_{\text {last }}(\mathrm{h} \mathrm{ng} / \mathrm{mL})$ & $467.73 \pm 102.32$ & $358.48 \pm 139.62$ & $232.41 \pm 144.07$ & $677.31 \pm 261.04$ & $977.88 \pm 326.59$ & $613.44 \pm 629.80$ & $1378.26 \pm 531.08$ \\
\hline $\mathrm{AUC}_{\text {total }}(\mathrm{h} \mathrm{ng} / \mathrm{mL})$ & $523.86 \pm 134.30$ & $591.79 \pm 364.24$ & $291.81 \pm 201.35$ & $695.04 \pm 187.67$ & $1049.80 \pm 283.68$ & $810.21 \pm 669.78$ & $1575.12 \pm 635.54$ \\
\hline$C_{\max }(\mathrm{ng} / \mathrm{mL})$ & $180.98 \pm 71.16$ & $156.73 \pm 95.29$ & $62.10 \pm 29.00$ & $386.17 \pm 100.64$ & $299.67 \pm 100.13$ & $98.87 \pm 93.19$ & $366.33 \pm 86.63$ \\
\hline$T_{\max }(\mathrm{h})$ & $0.29 \pm 0.10$ & $0.29 \pm 0.10$ & $0.29 \pm 0.10$ & $0.29 \pm 0.10$ & $1.71 \pm 1.35$ & $6.00 \pm 2.19$ & $0.67 \pm 0.49$ \\
\hline
\end{tabular}

TABLE 51: Pharmacokinetic parameters of CTX after i.v. and oral administration in rats $(n=5)$ [48].

\begin{tabular}{lcc}
\hline Parameters & Intravenous & Oral \\
\hline $\mathrm{AUC}_{(0-t)}(\mu \mathrm{g} \mathrm{h} / \mathrm{L})$ & $1257.6 \pm 570.7$ & $172.8 \pm 118.9$ \\
$\mathrm{AUC}_{(0-\infty)}(\mu \mathrm{g} \mathrm{h} / \mathrm{L})$ & $1270.1 \pm 560.6$ & $202.5 \pm 123.8$ \\
$\mathrm{MRT}_{(0-t)}(\mu \mathrm{g} \mathrm{h} / \mathrm{L})$ & $0.467 \pm 0.056$ & $1.2 \pm 0.46$ \\
$\mathrm{MRT}_{(0-\infty)}(\mu \mathrm{g} \mathrm{h} / \mathrm{L})$ & $0.59 \pm 0.21$ & $2.4 \pm 1.8$ \\
$t_{1 / 2 \mathrm{z}}(\mathrm{h})$ & $1.4 \pm 0.76$ & $1.7 \pm 1.1$ \\
$T_{\max }(\mathrm{h})$ & - & $0.098 \pm 0.040$ \\
$\mathrm{CL}_{\mathrm{z}} / F(\mathrm{~L} / \mathrm{h} / \mathrm{kg})$ & $22.9 \pm 11.2$ & $668.7 \pm 396.9$ \\
$V_{\mathrm{z}} / F(\mathrm{~L} / \mathrm{kg})$ & $55.3 \pm 54.1$ & $1443.2 \pm 943.0$ \\
$C_{\max }(\mu \mathrm{g} / \mathrm{L})$ & $4961.2 \pm 3254.8$ & $408.8 \pm 160.5$ \\
$F(\%)$ & - & $3.4 \pm 2.4$ \\
\hline
\end{tabular}

11.5. Ailanthus altissima. Ailanthone is a natural quassinoid extracted from Ailanthus altissima (Simaroubaceae). It shows antituberculosis, anti-Epstein-Barr virus, anti-Amiba virus, antimalarial activity, and antitumor activity. In TCM it is used to treat cold and gastric diseases.

LC (1290 series, Agilent Technologies, USA) system consists of 6460 triple quadrupole mass spectrometer (Agilent Technologies, USA), with ESI in negative ion mode. Chromatography separation was performed on an Agilent Zorbax Eclipse Plus C18 column $\left(2.1 \times 50 \mathrm{~mm}, 1.8 \mu \mathrm{m}, 40^{\circ} \mathrm{C}\right)$ and protected by a Phenomenex C18 guard column (Torrance, CA, USA). The gradient mobile phase was composed of methanol and water. The flow rate, injection volume, and total run time were $0.2 \mathrm{~mL} / \mathrm{min}, 1.0 \mu \mathrm{L}$, and $7.0 \mathrm{~min}$, respectively. The LLOQ of ailanthone was $5.0 \mathrm{ng} / \mathrm{mL}$. Brusatol was used as IS. Pharmacokinetics of parameters of ailanthone after intravenous injection are given in Table 52. After i.v. administration ailanthone shows linear pharmacokinetics. Reported pharmacokinetics profile of ailanthone indicates that ailanthone was extensively distributed in tissues and eliminated fast in rats. Statistical analysis showed no considerable variation in $t_{1 / 2}, \mathrm{CL}, \mathrm{MRT}$, and Vd among the three clusters $(P>0.05)$. Ailanthone followed linear pharmacokinetic profile [49].

11.6. Artemisia annua L. Scoparone is an important bioactive constituent of Artemisia annua L. (Yinchenhao). In TCM it is used for prevention and treatment of jaundice and liver disorders.

UPLC system was composed of high-definition mass spectrometer (Waters Corp., Milford, USA). Chromatography separation was performed on ACQUITY $1.8 \mu \mathrm{m}$ HSS T3 column $\left(2.1 \times 100 \mathrm{~mm}, 40^{\circ} \mathrm{C}\right.$, Waters Corp., Milford, USA). The gradient mobile phase is composed of $0.1 \%$ formic acid in acetonitrile and $0.1 \%$ formic acid in water. The flow rate and injection volume were $0.50 \mathrm{~mL} / \mathrm{min}$ and $10 \mu \mathrm{L}$, respectively. LLOQ was found to be $0.003 \mathrm{~g} / \mathrm{mL}$. Pharmacokinetic parameters of scoparone after oral administration are given in Table 53. Scoparone was mainly distributed in liver, kidney, and spleen and very less amount was found in muscle, thyroid, and adrenal. Scoparone was not able to cross the BBB. Major distribution of scoparone into liver helps to cure liver diseases. In rats it was rapidly distributed in various tissues and quickly eliminated also [50].

11.7. Cimicifuga foetida L. Cimicifugosides, that is, cimicifugoside H-1 (Cim A), 23-epi-26-deoxyactein (Cim B), cimigenolxyloside ( $\mathrm{Cim} \mathrm{C}$ ), and 25-O-acetylcimigenoside (Cim D), are the four major bioactive principles present in Cimicifuga foetida L. (Ranunculaceae). It is commonly used as antipyretic, analgesic and anti-inflammatory in TCM.

HPLC (1100 Series, Agilent Technologies, USA) system was composed of an Applied Biosystems SCIEX API 4000 mass spectrometer (Applied Biosystems SCIEX, Canada) with an ESI in negative ion mode. Chromatographic separation was performed on a Sunfire C18 $\left(2.1 \times 50 \mathrm{~mm}^{2}, 3.0 \mathrm{~mm}\right.$, $35^{\circ} \mathrm{C}$, Waters, Ireland). The gradient mobile phase consisted of methanol and ammonium fluoride $(0.2 \mathrm{mM})$. The flow rate was $0.4 \mathrm{~mL} / \mathrm{min}$. The LLOQs of Cims A, B, C, and D are 0.82 , $0.75,0.81$, and $0.76 \mathrm{pmol} / \mathrm{mL}$, respectively. Ginsenosides $\mathrm{Rg} 3$ (98\%, purity) was used as IS. Pharmacokinetic parameters of cimicifugosides are given in Tables 54 and 55. Difference in pharmacokinetic profile of cimicifugosides was attributed to their clearance mechanism. After oral administration Cim A was transformed to Cim $\mathrm{C}$ and hence apart from Cim A all other cimicifugosides (Cims B, C, and D) show significant systemic exposure [51]. 
TABLE 52: Pharmacokinetics of parameters of ailanthone after i.v. administration to rats $(n=6)$ [49].

\begin{tabular}{lccc}
\hline Parameters & $0.5 \mathrm{mg} / \mathrm{kg}$ & $1 \mathrm{mg} / \mathrm{kg}$ & $1.5 \mathrm{mg} / \mathrm{kg}$ \\
\hline$C_{0}(\mathrm{ng} / \mathrm{mL})$ & $813.5 \pm 164.6$ & $1653.2 \pm 98.6$ & $2375.3 \pm 499.1$ \\
$\mathrm{AUC}_{(0-6 \mathrm{~h})}(\mathrm{min} \mathrm{ng} / \mathrm{mL})$ & $23,475.8 \pm 4043.7$ & $57,874.3 \pm 6871.1$ & $84,534.5 \pm 10,716.0$ \\
$\mathrm{AUC}_{(0-\infty)}(\mathrm{min} \mathrm{ng} / \mathrm{mL})$ & $24,823.1 \pm 3975.8$ & $61,517.4 \pm 5986.2$ & $89,176.5 \pm 13,481.6$ \\
$t_{1 / 2}(\mathrm{~min})$ & $105.5 \pm 13.6$ & $113.3 \pm 39.6$ & $95.8 \pm 23.9$ \\
$V_{\mathrm{d}}(\mathrm{mL} / \mathrm{kg})$ & $2955.4 \pm 595.7$ & $2181.5 \pm 518.4$ & $2072.1 \pm 273.4$ \\
$\mathrm{CL}(\mathrm{mL} / \mathrm{min} / \mathrm{kg})$ & $20.2 \pm 3.6$ & $15.8 \pm 0.9$ & $15.9 \pm 2.5$ \\
MRT $(\mathrm{min})$ & $66.2 \pm 5.1$ & $61.6 \pm 6.2$ & $57.7 \pm 6.8$ \\
\hline
\end{tabular}

TABLE 53: Pharmacokinetic parameters of scoparone after oral administration in rats $(n=5)$ [50].

\begin{tabular}{lc}
\hline Parameters & Value \\
\hline$A(\mu \mathrm{g} / \mathrm{mL})$ & 4.99 \\
$K_{\mathrm{e}}(1 / \mathrm{h})$ & 0.15 \\
$K_{\mathrm{a}}(1 / \mathrm{h})$ & 55.69 \\
Lag time $(\mathrm{h})$ & 0.15 \\
$t_{1 / 2}\left(K_{\mathrm{a}}\right)(\mathrm{h})$ & 0.01 \\
$t_{1 / 2}\left(K_{\mathrm{e}}\right)(\mathrm{h})$ & 3.76 \\
$T_{\text {peak }}(\mathrm{h})$ & 0.10 \\
$C_{\text {max }}(\mathrm{mg} / \mathrm{L})$ & 14.67 \\
$\mathrm{AUC}(\mathrm{mg} \cdot \mathrm{h} / \mathrm{L})$ & 81.15 \\
$\mathrm{CL}(\mathrm{L} / \mathrm{h} / \mathrm{kg})$ & 1.23 \\
$V_{\mathrm{ss}}(\mathrm{L} / \mathrm{kg})$ & 6.69 \\
\hline
\end{tabular}

11.8. Ligusticum chuanxiong Hort. Senkyunolide I (SEI) is a bioactive principal present in the Ligusticum chuanxiong Hort. (Umbelliferae). It is used for treatment of migraine and cardiovascular diseases in China for centuries.

Shimadzu LC system consisted of API 4000 QTRAP mass spectrometer (Applied Biosystems, Concord, Ontario, Canada) and is equipped with a turbo ion spray (ESI) source in positive ion mode. Chromatographic separations were obtained on a Sapphire C18 $\left(4.6 \times 250 \mathrm{~mm}, 5.0 \mathrm{~mm}, 25^{\circ} \mathrm{C}\right)$ protected by a security column Phenomenex C18, $4 \times 3.0 \mathrm{~mm}$. The gradient mobile phase was composed of mixture of acetonitrile and methanol $(50: 50, \mathrm{v} / \mathrm{v})$ with formic acid $(0.1 \%)$ and $5 \mathrm{mM}$ ammonium acetate in water. The flow rate and injection volume were $0.8 \mathrm{~mL} / \mathrm{min}$ and $10 \mathrm{~mL}$. Agilent 1200 series HPLC system (Agilent Corp., USA) was equipped with an ultraviolet (UV) detector for quantitative determinations. The chromatographic separations were performed on a Sapphire C18 $\left(4.6 \times 250 \mathrm{~mm}, 5 \mathrm{~mm}, 30^{\circ} \mathrm{C}\right)$ and protected by a security column (Phenomenex C18, $4 \times 3.0 \mathrm{~mm}$ ). The mobile phase was composed of $0.5 \%$ aqueous acetic acid and acetonitrile $(65: 35, \mathrm{v} / \mathrm{v})$. The flow rate, injection volume, and detective wavelength were $1.0 \mathrm{~mL} / \mathrm{min}, 20 \mathrm{~mL}$, and $278 \mathrm{~nm}$, respectively. Pharmacokinetic parameters of SEI in rat plasma after single intravenous and oral administration were given in Tables 56 and 57. After oral administration of SEI, it was metabolized to nine different metabolites which is attributed to phase II biotransformation pathway, that is, glutathione conjugation, methylation, and glucuronidation. SEI was quickly eliminated but first-pass metabolism was very negligible. SEI easily penetrates blood brain barrier. It is mainly found in kidney, liver, lung, brain, and heart in descending order [52].

11.9. Solanum nigrum L. and Solanum lycocarpum. Solasonine is known as a steroidal glycoalkaloids found plant of Solanaceae family like Solanum nigrum L. and S. lycocarpum. It shows anticancer, antifungal, antiparasitic, antidiabetic, cytolysis, and antihepatitis B virus actions.

UPLC (ACQUITY, Waters, Milford, MA, USA) system was composed of Micromass Quattro micro-API benchtop triple quadrupole tandem mass spectrometer with ESI in positive ion mode. Chromatographic separation was performed on HSST3 $\left(100 \times 2.1 \mathrm{~mm}, 1.8 \mu \mathrm{m}, 35^{\circ} \mathrm{C}\right)$ column with a security guard column. The gradient mobile phase was composed of acetonitrile and $0.1 \%$ formic acid. The flow rate and injection volume were $0.3 \mathrm{~mL} / \mathrm{min}$ and $5 \mu \mathrm{L}$, respectively. The LLOQ and LOD were 0.5 and $0.1 \mathrm{ng} / \mathrm{mL}$, respectively. Dendrobine was used as IS. The pharmacokinetic data of solasonine after oral and sublingual i.v. administration are given in Table 58. The extremely low absolute oral bioavailability of solasonine was attributed to a significant first-pass metabolism and inhibition of gastric emptying. Solasonine showed two-compartmental model and noncompartmental model after i.v. and p.o. administration, respectively [53].

\section{Discussion}

Knowledge on pharmacokinetics of numerous TCM has been grown regularly during the last few years. ADME are four essential aspects of pharmacokinetics and to judge the exact therapeutic response of TCM, it is essential to know the key difference in ADME mechanism. The pharmacokinetic profile of TCM helps to link pharmacological assays and clinical studies.

From the present review, it is found that most of the constituents of the reviewed 50 TCM exhibit low bioavailability and poor oral absorption because of various reasons like poor aqueous solubility, extensive first-pass metabolism due to large number of intestinal enzymes, and poor membrane permeability. Low bioavailability of flavonoids can be attributed to low permeability through the intestinal epithelial membrane [54]. In case of saponins low bioavailability is due to their physicochemical virtues, like large molecular weight, 
TABLE 54: Pharmacokinetic parameters of cimicifugosides in rat plasma after oral administration of C. foetida L. extract [51].

\begin{tabular}{|c|c|c|c|c|c|c|}
\hline Dose $(\mathrm{mg} / \mathrm{kg})$ & Compound & $\mathrm{AUC}_{(0-48 \mathrm{~h})}(\mathrm{pmolh} / \mathrm{mL})$ & $T_{\max }(\mathrm{h})$ & $C_{\max }(\mathrm{pmol} / \mathrm{mL})$ & $t_{1 / 2}(\mathrm{~h})$ & $F(\%)$ \\
\hline \multirow{4}{*}{12.5} & A & $7.72 \pm 5.29$ & $0.46 \pm 0.36$ & $4.05 \pm 3.96$ & $6.74 \pm 6.59$ & 1.86 \\
\hline & B & $583.3 \pm 194.2$ & $2.00 \pm 0.78$ & $90.93 \pm 38.46$ & $5.77 \pm 4.10$ & 26.8 \\
\hline & $\mathrm{C}$ & $11,350 \pm 3500$ & $16.67 \pm 5.01$ & $407.1 \pm 87.70$ & $11.16 \pm 2.31$ & 319 \\
\hline & $\mathrm{D}$ & $254.9 \pm 107.3$ & $8.08 \pm 6.86$ & $21.56 \pm 8.46$ & $4.69 \pm 1.52$ & 48 \\
\hline \multirow{4}{*}{25} & A & $0.93 \pm 53.19$ & $1.28 \pm 1.48$ & $9.36 \pm 7.39$ & $2.67 \pm 2.33$ & 6.13 \\
\hline & B & $2106 \pm 428$ & $2.88 \pm 1.80$ & $239.4 \pm 53.66$ & $3.48 \pm 0.55$ & 48.5 \\
\hline & $\mathrm{C}$ & $16,950 \pm 5500$ & $14.67 \pm 3.72$ & $713.1 \pm 262.0$ & $11.05 \pm 1.06$ & 238 \\
\hline & $\mathrm{D}$ & $349.3 \pm 168.5$ & $8.42 \pm 7.77$ & $32.66 \pm 21.66$ & $4.04 \pm 0.66$ & 32.9 \\
\hline \multirow{4}{*}{50} & $\mathrm{~A}$ & $115.9 \pm 45.9$ & $0.75 \pm 0.66$ & $17.69 \pm 12.37$ & $1.46 \pm 0.61$ & 6.97 \\
\hline & $\mathrm{B}$ & $4094 \pm 1146$ & $4.67 \pm 2.94$ & $395.7 \pm 153.9$ & $6.66 \pm 3.76$ & 47 \\
\hline & $\mathrm{C}$ & $35,980 \pm 9386$ & $19.67 \pm 5.57$ & $1180 \pm 262$ & $17.37 \pm 8.02$ & 253 \\
\hline & $\mathrm{D}$ & $804.6 \pm 251.2$ & $14.17 \pm 6.34$ & $45.09 \pm 17.55$ & $4.38 \pm 1.08$ & 37.9 \\
\hline
\end{tabular}

TABLE 55: Pharmacokinetic parameters of cimicifugosides in rat plasma after i.v. administration of single cimicifugosides [51].

\begin{tabular}{cccccccc}
\hline Dose $(\mathrm{mg} / \mathrm{kg})$ & Compound & $\mathrm{AUC}_{(0-48 \mathrm{~h})}(\mathrm{pmolh} / \mathrm{mL})$ & $t_{1 / 2}(\mathrm{~h})$ & $\mathrm{MRT}(\mathrm{h})$ & $C_{\max }(\mathrm{pmol} / \mathrm{mL})$ & $\mathrm{CL}(\mathrm{mL} / \mathrm{h} \mathrm{kg})$ & $V_{\mathrm{d}}(\mathrm{mL} / \mathrm{kg})$ \\
\hline & $\mathrm{A}$ & $484.9 \pm 203.4$ & $1.13 \pm 0.53$ & $0.39 \pm 0.16$ & $1219 \pm 153.3$ & $15.7 \pm 7.37$ & $26.7 \pm 21.1$ \\
5 & $\mathrm{~B}$ & $17,100 \pm 4183$ & $2.50 \pm 0.53$ & $2.54 \pm 0.68$ & $9106 \pm 692.9$ & $0.48 \pm 0.14$ & $1.77 \pm 0.79$ \\
& $\mathrm{C}$ & $31,820 \pm 1741$ & $5.69 \pm 1.29$ & $9.74 \pm 1.07$ & $6824 \pm 2267$ & $0.24 \pm 0.01$ & $1.98 \pm 0.44$ \\
& $\mathrm{D}$ & $7924 \pm 3026$ & $4.17 \pm 0.34$ & $2.86 \pm 0.38$ & $4682 \pm 943$ & $1.13 \pm 0.42$ & $6.75 \pm 2.25$ \\
\hline
\end{tabular}

TABLE 56: Pharmacokinetic parameters of SEI after i.v. administration of SEI in rat plasma $(n=5)$ [52].

\begin{tabular}{lccr}
\hline Parameters & \multicolumn{1}{c}{ Dose } & $72(\mathrm{mg} / \mathrm{kg})$ \\
\hline $\mathrm{AUC}_{(0-\infty)}(\mathrm{mg} \mathrm{min} / \mathrm{mL})$ & $18(\mathrm{mg} / \mathrm{kg})$ & $807.72 \pm 82.70$ & $1796.51 \pm 201.03$ \\
$\mathrm{AUC}_{(0-t)}(\mathrm{mg} \mathrm{min} / \mathrm{mL})$ & $454.26 \pm 41.73$ & $797.02 \pm 84.53$ & $1773.63 \pm 191.35$ \\
$\mathrm{MRT}_{(0-\infty)}(\mathrm{min})$ & $449.39 \pm 36.95$ & $38.68 \pm 3.30$ & $42.96 \pm 8.99$ \\
$\mathrm{MRT}_{(0-t)}(\mathrm{min})$ & $36.85 \pm 6.95$ & $34.96 \pm 2.27$ & $39.73 \pm 7.00$ \\
$t_{1 / 2}(\mathrm{~min})$ & $34.16 \pm 4.08$ & $43.54 \pm 6.94$ & $39.69 \pm 9.17$ \\
$V_{\mathrm{d}}(\mathrm{mL} / \mathrm{kg})$ & $38.26 \pm 8.47$ & $2839.20 \pm 707.02$ & $2291.80 \pm 486.14$ \\
$\mathrm{CL}(\mathrm{mL} / \mathrm{min} / \mathrm{kg})$ & $2181.40 \pm 373.98$ & $44.60 \pm 5.13$ & $40.02 \pm 4.66$ \\
\hline
\end{tabular}

TABLE 57: Pharmacokinetic parameters of SEI after oral administration of SEI in rat plasma $(n=5)$ [52].

\begin{tabular}{lccc}
\hline Parameters & \multicolumn{1}{c}{ Dose } & $72(\mathrm{mg} / \mathrm{kg})$ \\
\hline $\mathrm{AUC}_{(0-\infty)}(\mathrm{mg} \mathrm{min} / \mathrm{mL})$ & $18(\mathrm{mg} / \mathrm{kg})$ & $36(\mathrm{mg} / \mathrm{kg})$ & $618.98 \pm 128.58$ \\
$\mathrm{AUC}_{(0-t)}(\mathrm{mg} \mathrm{min} / \mathrm{mL})$ & $169.21 \pm 13.94$ & $307.00 \pm 65.17$ & $596.27 \pm 109.85$ \\
$\mathrm{MRT}_{(0-\infty)}(\mathrm{min})$ & $167.97 \pm 14.90$ & $300.77 \pm 68.64$ & $66.64 \pm 11.96$ \\
$\mathrm{MRT}_{(0-t)}(\mathrm{min})$ & $47.82 \pm 12.35$ & $62.47 \pm 13.24$ & $58.32 \pm 6.40$ \\
$t_{1 / 2}(\mathrm{~min})$ & $45.94 \pm 9.51$ & $56.73 \pm 7.78$ & $45.19 \pm 7.77$ \\
$T_{\max }(\mathrm{min})$ & $30.92 \pm 9.77$ & $39.44 \pm 12.61$ & $22.00 \pm 8.37$ \\
$V_{\mathrm{d}}(\mathrm{mL} / \mathrm{kg})$ & $13.00 \pm 4.47$ & $24.00 \pm 8.94$ & $7716.40 \pm 1366.67$ \\
$\mathrm{CL}(\mathrm{mL} / \mathrm{min} / \mathrm{kg})$ & $4818.80 \pm 1818.65$ & $7118.80 \pm 3334.98$ & $120.40 \pm 24.56$ \\
$C_{\max }(\mu \mathrm{g} / \mathrm{mL})$ & $110.00 \pm 10.00$ & $121.60 \pm 23.65$ & $8.96 \pm 1.08$ \\
$F(\%)$ & $3.31 \pm 0.55$ & $4.42 \pm 1.52$ & 34.45 \\
\hline
\end{tabular}


TABLE 58: The noncompartmental PK parameters of solasonine after oral and sublingual i.v. administration of 30 and $3 \mathrm{mg} / \mathrm{kg}$, respectively $(n=6)[53]$.

\begin{tabular}{|c|c|c|}
\hline \multirow{2}{*}{ Parameter } & \multicolumn{2}{|c|}{ Dose } \\
\hline & p.o. $(30 \mathrm{mg} / \mathrm{kg})$ & i.v. (3 mg/kg) \\
\hline$T_{\max }(\mathrm{h})$ & $0.7 \pm 0.3$ & 0.1 \\
\hline$C_{\max }(\mu \mathrm{g} / \mathrm{L})$ & $172.3 \pm 87.1$ & $2777.5 \pm 1227.7$ \\
\hline$t_{1 / 2 \mathrm{z}}(\mathrm{h})$ & $3.5 \pm 1.8$ & $1.4 \pm 0.2$ \\
\hline$V_{\mathrm{z}} / F(\mathrm{~L} / \mathrm{kg})$ & $275.4 \pm 170.2$ & $1.5 \pm 0.2$ \\
\hline $\mathrm{CL}_{\mathrm{z}} / F(\mathrm{~L} / \mathrm{h} / \mathrm{kg})$ & $67.3 \pm 59.8$ & $0.8 \pm 0.1$ \\
\hline $\operatorname{AUC}_{(0-t)}(\mu \mathrm{g} / \mathrm{L} \cdot \mathrm{h})$ & $615.7 \pm 345.0$ & $4101.1 \pm 719.3$ \\
\hline $\operatorname{AUC}_{(0-\infty)}(\mu \mathrm{g} / \mathrm{L} \cdot \mathrm{h})$ & $688.1 \pm 413.91$ & $4118.9 \pm 717.8$ \\
\hline$F(\%)$ & 1.7 & 100 \\
\hline
\end{tabular}

high hydrogen-bonding, and extensive biliary excretion [55]. Most of the phytochemicals like flavonoids, alkaloids, and terpenoids contain various subclasses and hence it is very essential to know specific bioavailability and metabolites related to each subclass. Solasonine (steroidal glycoalkaloid) shows low absolute bioavailability while isocorydine and protopine (isocorydine alkaloid) exhibit rapid absorption and wide distribution into tissues and effectively cross the BBB. In number of cases pharmacokinetic profile and bioavailability of herbal products are also influenced by the type of extract, formulation attributes, and dosage forms [56]. Most of the studies deal with the pharmacokinetics of pure active ingredient from TCM. However most of TCM are prescribed in form of complex preparation (i.e., extracts or decoctions) or formulation containing multicomponent; then pharmacokinetic properties of bioactive ingredient may be altered due to the presence of other coexisting components. This needs to be studied in detail. This consequence of poor absorption and low bioavailability can be resolved by simply modifying the extraction procedures, formulation strategy, and/or designing of prodrugs. Chemical complexity is the major challenge in TCM. With one medicinal plant, the presence of huge number of constituents made the analysis difficult whereas a TCM formulation containing more plant ingredients will be a major challenge for analysis. For such formulations, considering the pharmacokinetic data of single constituent will be meaningless. The future directions of pharmacokinetic studies of TCM should focus on comparative pharmacokinetic study of active constituent in pure form and after administration of extract/formulations as well. This will explain the influence of other unknown ingredients on the pharmacokinetic property of active ingredient. Further, TCM are frequently vary with prescription and the complexity of TCM may result in drug interaction and complex degradation dynamics in vivo. This further put significant restrictions in understanding the efficacies and toxicities of TCM [57]. Double-peak phenomenon is also one of the characteristics of TCM due to enterohepatic circulation and in vivo isomerization of chemical constituent. Interconversion of chemical structure of most of steroidal saponins and triterpenoid leads to the double-peak phenomenon. In case of diosbulbin B (diterpenoid lactone) enterohepatic circulation leads to extended residence time and delayed excretion and it may lead to cumulative toxicity. Hence studies emphasising on pharmacokinetics of multicomponent of TCM in correlation with the pharmacodynamics are essential.

By looking at the overall researches reported so far with TCM, it can be suggested that instead of focusing on pharmacokinetic studies for single constituent from many plants, the researchers should narrow their studies to focus only on particular plant which is known for potent therapeutic activity. For example, if a herbal product deals with 5 plants, then each 5 plants should be studied thoroughly for pharmacokinetic properties for active constituents and possible other ingredients interaction with each other. The study results should be correlated with the pharmacological activities. Such approach will ensure the efficacy of the final product scientifically. The entire picture of kinetic properties including metabolic pathway should be thoroughly studied and documented. The sophisticated analytical tools with high sensitive detectors should be employed for such studies and the basic level equipment with low sensitive detectors should be avoided.

\section{Abbreviations}

\section{Related to Pharmacokinetic Study}

A: $\quad$ Amount of drug in the body at any time

AUC: $\quad$ Area under the plasma concentration-time curve

$\mathrm{AUC}_{(0-t)}: \quad$ Area under the plasma concentration-time curve from zero $(0)$ hours to time $(t)$

$\mathrm{AUC}_{(0-\infty)}$ : Area under the plasma concentration-time curve from zero (0) hours to infinity $(\infty)$

$\operatorname{AUMC}_{(0-t)}$ : Area under the first moment of the plasma concentration-time curve from time zero to time $t$

$\operatorname{AUMC}_{(0-\infty)}$ : Area under the first moment of the plasma concentration-time curve from time zero to infinity

$C_{\text {max }}: \quad$ Maximum drug concentration

$C_{0}: \quad$ Initial or back-extrapolated plasma drug concentration at time zero following bolus intravenous injection

CL: $\quad$ Clearance 


\begin{tabular}{|c|c|}
\hline $\mathrm{CL}_{\mathrm{z}} / F:$ & $\begin{array}{l}\text { Apparent total clearance of the drug from } \\
\text { plasma after oral administration }\end{array}$ \\
\hline$F:$ & $\begin{array}{l}\text { Bioavailability (systemic availability of the } \\
\text { administered dose) }\end{array}$ \\
\hline$K:$ & First-order rate constant \\
\hline$K_{\mathrm{a}}:$ & Absorption rate constant (first-order) \\
\hline$K_{\mathrm{e}}:$ & $\begin{array}{l}\text { Elimination rate constant from the central } \\
\text { compartment }\end{array}$ \\
\hline$K_{10}:$ & Elimination rate constant \\
\hline$K_{21}:$ & $\begin{array}{l}\text { Transfer rate constant (first-order) from } \\
\text { the peripheral to central compartment }\end{array}$ \\
\hline$K_{12}:$ & $\begin{array}{l}\text { Transfer rate constant (first-order) from } \\
\text { the central to peripheral compartment }\end{array}$ \\
\hline MRT: & Mean residence time \\
\hline $\operatorname{MRT}_{(0-t)}$ : & $\begin{array}{l}\text { Mean residence time from time zero to } \\
\text { time } t\end{array}$ \\
\hline $\operatorname{MRT}_{(0-\infty)}:$ & $\begin{array}{l}\text { Mean residence time from time zero to } \\
\text { infinity }\end{array}$ \\
\hline$t_{1 / 2}:$ & Terminal elimination half-life \\
\hline$t_{1 / 2 \alpha}:$ & Initial or disposition half-life \\
\hline$t_{1 / 2 \beta}:$ & $\begin{array}{l}\text { Terminal elimination half-life (to be used } \\
\text { in two-compartmental model) }\end{array}$ \\
\hline$t_{1 / 2 K_{\mathrm{a}}}:$ & Absorption half-life \\
\hline$T_{\max }:$ & Time of maximum concentration \\
\hline$V_{\mathrm{z}}:$ & $\begin{array}{l}\text { Apparent volume of distribution during } \\
\text { terminal phase }\end{array}$ \\
\hline$V_{\text {ss }}:$ & $\begin{array}{l}\text { Apparent volume of distribution at } \\
\text { equilibrium }\end{array}$ \\
\hline$V_{\mathrm{d}}:$ & Volume of distribution \\
\hline$V / F$ & $\begin{array}{l}\text { Apparent volume of distribution after } \\
\text { nonintravenous administration }\end{array}$ \\
\hline VRT: & Variance of retention time. \\
\hline
\end{tabular}

Used in Manuscript

$\begin{array}{ll}\text { ADME: } & \begin{array}{l}\text { Absorption, distribution, metabolism, and } \\ \text { excretion }\end{array} \\ \text { BBB: } & \text { Blood brain barrier } \\ \text { CYP450: } & \text { Cytochromes P450 } \\ \text { DAD: } & \text { Diode array detector } \\ \text { ESI: } & \text { Electrospray ionization } \\ \text { GIT: } & \text { Gastrointestinal tract } \\ \text { HPLC: } & \text { High performance liquid chromatography } \\ \text { i.v:: } & \text { Intravenous } \\ \text { IS: } & \text { Internal standard } \\ \text { LOD: } & \text { Limit of detection } \\ \text { LOQ: } & \text { Limit of quantitation } \\ \text { LLOQ: } & \text { Lowest limit of quantification } \\ \text { LC: } & \text { Liquid chromatography } \\ \text { LC-MS/MS: } & \text { Liquid chromatography-tandem mass } \\ & \text { spectrometry } \\ \text { RP-HPLC: } & \text { Reversed phase high performance liquid } \\ & \text { chromatography } \\ \text { SIM: } & \text { Selected ion monitoring } \\ \text { TCM: } & \text { Traditional Chinese medicines } \\ \text { UFLC: } & \text { Ultra-Fast Liquid Chromatography } \\ \text { UPLC: } & \text { Ultra performance liquid chromatography } \\ \text { UHPLC: } & \text { Ultrahigh performance liquid } \\ & \text { chromatography }\end{array}$

UV: Ultraviolet detector

VWD: Variable wavelength detector

WHO: World Health Organization.

\section{Competing Interests}

The authors declare that there are no competing interests regarding the publication of this paper.

\section{References}

[1] B. Schmidt, D. M. Ribnicky, A. Poulev, S. Logendra, W. T. Cefalu, and I. Raskin, "A natural history of botanical therapeutics," Metabolism: Clinical and Experimental, vol. 57, supplement 1, pp. S3-S9, 2008.

[2] P. Mehta, R. Shah, L. Sathiyanarayanan et al., "Pharmacokinetic profile of phytoconstituent(s) isolated from medicinal plants-a comprehensive review," Journal of Traditional and Complementary Medicine, vol. 5, pp. 207-227, 2015.

[3] World Health Organization, General Guidelines for Methodologies on Research and Evaluation of Traditional Medicine, WHO, Geneva, Switzerland, 2000.

[4] S. Tian, G. He, J. Song et al., "Pharmacokinetic study of baicalein after oral administration in monkeys," Fitoterapia, vol. 83, no. 3, pp. 532-540, 2012.

[5] S. Hou, F. Wang, Y. Li et al., "Pharmacokinetic study of mangiferin in human plasma after oral administration," Food Chemistry, vol. 132, no. 1, pp. 289-294, 2012.

[6] Y. Liang, Q. Xu, A. Kang et al., "Validation and application of an LC-ESI-MS method for simultaneous determination of astilbin and its major metabolite $3^{\prime}$-O-methylastilbin in rat plasma," Journal of Chromatography B, vol. 877, no. 18-19, pp. 1765-1770, 2009.

[7] X. Chen, L. Cui, X. Duan, B. Ma, and D. Zhong, "Pharmacokinetics and metabolism of the flavonoid scutellarin in humans after a single oral administration," Drug Metabolism and Disposition, vol. 34, no. 8, pp. 1345-1352, 2006.

[8] R. Yin, F. Han, Z. Tang et al., "UFLC-MS/MS method for simultaneous determination of luteolin-7-O-gentiobioside, luteolin7-O- $\beta$-d-glucoside and luteolin-7-O- $\beta$-d-glucuronide in beagle dog plasma and its application to a pharmacokinetic study after administration of traditional Chinese medicinal preparation: kudiezi injection," Journal of Pharmaceutical and Biomedical Analysis, vol. 72, pp. 127-133, 2013.

[9] Z. Chen, S. Kong, F. Song, L. Li, and H. Jiang, "Pharmacokinetic study of luteolin, apigenin, chrysoeriol and diosmetin after oral administration of Flos Chrysanthemi extract in rats," Fitoterapia, vol. 83, no. 8, pp. 1616-1622, 2012.

[10] L. Tong, D. Zhou, J. Gao, Y. Zhu, H. Sun, and K. Bi, "Simultaneous determination of naringin, hesperidin, neohesperidin, naringenin and hesperetin of Fractus aurantii extract in rat plasma by liquid chromatography tandem mass spectrometry," Journal of Pharmaceutical and Biomedical Analysis, vol. 58, no. 1, pp. 58-64, 2012.

[11] C. Mekjaruskul, M. Jay, and B. Sripanidkulchai, "Pharmacokinetics, bioavailability, tissue distribution, excretion, and metabolite identification of methoxyflavones in Kaempferia parviflora extract in rats," Drug Metabolism and Disposition, vol. 40, no. 12, pp. 2342-2353, 2012.

[12] Z. Zhang, P. Jia, X. Zhang et al., "LC-MS/MS determination and pharmacokinetic study of seven flavonoids in rat plasma after 
oral administration of Cirsium japonicum DC. extract," Journal of Ethnopharmacology, vol. 158, pp. 66-75, 2014.

[13] J. He, Y. Feng, H.-Z. Ouyang et al., "A sensitive LC-MS/MS method for simultaneous determination of six flavonoids in rat plasma: application to a pharmacokinetic study of total flavonoids from mulberry leaves," Journal of Pharmaceutical and Biomedical Analysis, vol. 84, pp. 189-195, 2013.

[14] Y. Song, S. Zhang, H. Liu, and X. Jin, "Determination of genkwanin in rat plasma by liquid chromatography-tandem mass spectrometry: application to a bioavailability study," Journal of Pharmaceutical and Biomedical Analysis, vol. 84, pp. 129134, 2013.

[15] Z. Sun, L. Zhao, L. Zuo et al., "A UHPLC-MS/MS method for simultaneous determination of six flavonoids, gallic acid and 5, 8-dihydroxy-1, 4-naphthoquinone in rat plasma and its application to a pharmacokinetic study of Cortex Juglandis Mandshuricae extract," Journal of Chromatography B, vol. 958, pp. 5562, 2014.

[16] J. Luo, C. Zhou, W. Zhang, and L. Kong, "Pharmacokinetic study and metabolite identification of the bidesmosidic triterpenoid saponin BTS-1 in rat plasma," Acta Pharmaceutica Sinica B, vol. 3, no. 3, pp. 174-179, 2013.

[17] X. Guan, H. Chang, F. Sun, X. Chen, W. Zhang, and G. Fan, "Determination of esculentoside A in dog plasma by LCMS/MS method: application to pre-clinical pharmacokinetics," Journal of Pharmaceutical and Biomedical Analysis, vol. 72, pp. 261-266, 2013.

[18] X. Zhang, J. Li, Y. Ito, and W. Sun, "Simultaneous quantification of five steroid saponins from Dioscorea zingiberensis C.H. Wright in rat plasma by HPLC-MS/MS and its application to the pharmacokinetic studies," Steroids, vol. 93, pp. 16-24, 2015.

[19] T.-H. Kim, B. E. Lee, E. J. Kim et al., "Determination of platycodin D and platycodin D3 in rat plasma using liquid chromatography-tandem mass spectrometry," The Scientific World Journal, vol. 2014, Article ID 231293, 10 pages, 2014.

[20] Y. Feng, B. Chen, A. Lin, and Y. Liu, "Simultaneous determination of timosaponin B-II and A-III in rat plasma by LCMS/MS and its application to pharmacokinetic study," Journal of Chromatography B, vol. 965, pp. 119-126, 2014.

[21] Z. Wang, Q. Wu, Y. Meng et al., "Determination and pharmacokinetic study of two triterpenoid saponins in rat plasma after oral administration of the extract of Aralia elata leaves by UHPLC-ESI-MS/MS," Journal of Chromatography B: Analytical Technologies in the Biomedical and Life Sciences, vol. 985, pp. 164-171, 2015.

[22] X.-J. Wu, X.-Y. Cui, L.-T. Tian, F. Gao, X. Guan, and J.-K. Gu, "Pharmacokinetics of escin Ia in rats after intravenous administration," Journal of Ethnopharmacology, vol. 156, pp. 125-129, 2014.

[23] L. Dong, X. Zhang, J. Ma et al., "The integrated pharmacokinetics of major rhodojaponins correlates with the cardiotoxicity after oral administration of Rhododendri Mollis Flos extract in rats," Journal of Ethnopharmacology, vol. 157, pp. 69-78, 2014.

[24] Y. Yuan, H. Zhang, F. Sun, S. Sun, Z. Zhu, and Y. Chai, "Biopharmaceutical and pharmacokinetic characterization of asiatic acid in Centella asiatica as determined by a sensitive and robust HPLC-MS method," Journal of Ethnopharmacology, vol. 163, pp. 31-38, 2015.

[25] Y. Liu, X. Li, Y. Li, L. Wang, and M. Xue, "Simultaneous determination of danshensu, rosmarinic acid, cryptotanshinone, tanshinone IIA, tanshinone I and dihydrotanshinone I by liquid chromatographic-mass spectrometry and the application to pharmacokinetics in rats," Journal of Pharmaceutical and Biomedical Analysis, vol. 53, no. 3, pp. 698-704, 2010.

[26] Y. Zhang, Q. Li, C. Lv, Y. Yin, and K. Bi, "A UFLC/MS/MS method for simultaneous quantitation of alisol A and alisol B 23-acetate from Alisma orientale (Sam.) Juz. in rat plasma," Asian Journal of Pharmaceutical Sciences, vol. 9, no. 5, pp. 279285, 2014.

[27] B. Ma, Y. Wang, Q. Zhang et al., "Simultaneous determination of oridonin, ponicidin and rosmarinic acid from herba Isodi rubescentis extract by LC-MS-MS in rat plasma," Journal of Chromatographic Science, vol. 51, no. 10, pp. 910-918, 2013.

[28] C. Guo, Y. Jiang, L. Li et al., "Application of a liquid chromatography-tandem mass spectrometry method to the pharmacokinetics, tissue distribution and excretion studies of Dactylicapnos scandens in rats," Journal of Pharmaceutical and Biomedical Analysis, vol. 74, pp. 92-100, 2013.

[29] Z. Yang, S. Gao, T. Yin et al., "Biopharmaceutical and pharmacokinetic characterization of matrine as determined by a sensitive and robust UPLC-MS/MS method," Journal of Pharmaceutical and Biomedical Analysis, vol. 51, no. 5, pp. 1120-1127, 2010.

[30] S.-J. Shi, H. Chen, S.-F. Gu, and F.-D. Zeng, "Pharmacokinetic pharmacodynamic modeling of daurisoline and dauricine in beagle dogs," Acta Pharmacologica Sinica, vol. 24, no. 10, pp. 1011-1015, 2003.

[31] Q. Wang, B. Tan, Y. Gong et al., "Determination of bulleyaconitine A in plasma by a sensitive LC-MS/MS method and its application to an oral pharmacokinetic study in rats," Journal of Pharmaceutical and Biomedical Analysis, vol. 71, pp. 202-206, 2012.

[32] F. Zhang, X. Gong, B. Xiao, C. Zhang, and Z. Wang, "Pharmacokinetics and tissue distribution of a bioactive sesquiterpenoid from Polygonum jucundum following oral and intravenous administrations to rats," Journal of Pharmaceutical and Biomedical Analysis, vol. 83, pp. 135-140, 2013.

[33] H. Fan, D. De-Qiang, S. Yu, and K. Ting-Guo, "Determination of arctiin in rat plasma by HPLC method and its application to pharmacokinetic studies," Journal of Medicinal Plants Research, vol. 5, no. 4, pp. 549-557, 2011.

[34] Y. Song, Y. Deng, D. Huang, J. Wen, Z. Liu, and F. Li, "LCMS/MS determination and pharmacokinetic study of four lignan components in rat plasma after oral administration of Acanthopanax sessiliflorus extract," Journal of Ethnopharmacology, vol. 141, no. 3, pp. 957-963, 2012.

[35] J.-L. Wang, E.-W. Liu, Y. Zhang, T. Wang, L.-F. Han, and X.-M. Gao, "Validation of a HPLC-tandem MS/MS method for pharmacokinetics study of (+)-pinoresinol-di- $\beta$-D-glucopyranoside from Eucommia ulmoides Oliv extract in rats' plasma," Journal of Ethnopharmacology, vol. 139, no. 2, pp. 337-342, 2012.

[36] B. Wei, Q. Li, D. Su et al., "Development of a UFLC-MS/MS method for simultaneous determination of six lignans of Schisandra chinensis (Turcz.) Baill. in rat plasma and its application to a comparative pharmacokinetic study in normal and insomnic rats," Journal of Pharmaceutical and Biomedical Analysis, vol. 77, pp. 120-127, 2013.

[37] F. Ma, X. Gong, X. Zhou, Y. Zhao, and M. Li, "An UHPLCMS/MS method for simultaneous quantification of gallic acid and protocatechuic acid in rat plasma after oral administration of Polygonum capitatum extract and its application to pharmacokinetics," Journal of Ethnopharmacology, vol. 162, pp. 377-383, 2015. 
[38] W. Qi, T. Zhao, W.-W. Yang et al., "Comparative pharmacokinetics of chlorogenic acid after oral administration in rats," Journal of Pharmaceutical Analysis, vol. 1, no. 4, pp. 270-274, 2011.

[39] D. Su, J. Huang, Y. Song, and Y. Feng, "Comparative pharmacokinetics and tissue distribution study of mono-, and di-caffeoylquinic acids isomers of Ainsliaea fragrans Champ by a fast UHPLC-MS/MS method," Fitoterapia, vol. 99, no. 1, pp. 139-152, 2014.

[40] G. Chen, J. Li, S. Zhang et al., "A sensitive and efficient method to systematically detect two biophenols in medicinal herb, herbal products and rat plasma based on thorough study of derivatization and its convenient application to pharmacokinetics with semi-automated device," Journal of Chromatography A, vol. 1249, pp. 190-200, 2012.

[41] G. Lv, Z. Lou, S. Chen, H. Gu, and L. Shan, "Pharmacokinetics and tissue distribution of 2,3,5,4/-tetrahydroxystilbene-2-O$\beta$-d-glucoside from traditional Chinese medicine Polygonum multiflorum following oral administration to rats," Journal of Ethnopharmacology, vol. 137, no. 1, pp. 449-456, 2011.

[42] B. Wen, R. He, P. Li et al., "Pharmacokinetics of 8-O-acetylharpagide and harpagide after oral administration of Ajuga decumbens Thunb extract in rats," Journal of Ethnopharmacology, vol. 147, no. 2, pp. 503-508, 2013.

[43] D. Patil, M. Gautam, S. Mishra et al., "Determination of withaferin $\mathrm{A}$ and withanolide $\mathrm{A}$ in mice plasma using high-performance liquid chromatography-tandem mass spectrometry: application to pharmacokinetics after oral administration of Withania somnifera aqueous extract," Journal of Pharmaceutical and Biomedical Analysis, vol. 80, pp. 203-212, 2013.

[44] Y. Li, Y. Tian, L. Gan, Y. Li, B. Chen, and J. Qiao, "Determination of diosbulbin B in rat plasma and urine by LC-MS/MS and its application in pharmacokinetic and urinary excretion studies," Journal of Pharmaceutical and Biomedical Analysis, vol. 77, pp. 133-138, 2013.

[45] J. Zhang, F. Tao, Y. Li et al., "Pharmacokinetics, tissue distribution and oral bioavailability evaluation of isoimperatorin by high-performance liquid chromatography coupled with mass spectrometry," Journal of Medicinal Plants Research, vol. 6, no. 9, pp. 1721-1729, 2012.

[46] Y. Li, F. Meng, Z. Xiong, H. Liu, and F. Li, "HPLC determination and pharmacokinetics of osthole in rat plasma after oral administration of Fructus cnidii extract," Journal of Chromatographic Science, vol. 43, no. 8, pp. 426-429, 2005.

[47] J. Wang, W. Yang, G. Wang, P. Tang, and Y. Sai, "Determination of six components of Andrographis paniculata extract and one major metabolite of andrographolide in rat plasma by liquid chromatography-tandem mass spectrometry," Journal of Chromatography B: Analytical Technologies in the Biomedical and Life Sciences, vol. 951-952, no. 1, pp. 78-88, 2014.

[48] J. Fan, L. Guan, Z. Kou, F. Feng, Y. Zhang, and W. Liu, "Determination of chrysotoxine in rat plasma by liquid chromatographytandem mass spectrometry and its application to a rat pharmacokinetic study," Journal of Chromatography B, vol. 967, pp. 5762, 2014.

[49] A. Chen, X. Qin, J. Lu, Z. Yi, M. Liu, and X. Wang, "Development of a validated LC-MS/MS method for the determination of ailanthone in rat plasma with application to pharmacokinetic study," Journal of Pharmaceutical and Biomedical Analysis, vol. 102, pp. 514-518, 2015.

[50] Q. Yin, H. Sun, A. Zhang, and X. Wang, "Pharmacokinetics and tissue distribution study of scoparone in rats by ultraperformance liquid-chromatography with tandem high-definition mass spectrometry," Fitoterapia, vol. 83 , no. 4, pp. 795-800, 2012.

[51] Y.-Y. Gai, W.-H. Liu, C.-J. Sha et al., "Pharmacokinetics and bioavailability of cimicifugosides after oral administration of Cimicifuga foetida L. extract to rats," Journal of Ethnopharmacology, vol. 143, no. 1, pp. 249-255, 2012.

[52] C.-Y. He, S. Wang, Y. Feng et al., "Pharmacokinetics, tissue distribution and metabolism of senkyunolide I, a major bioactive component in Ligusticum chuanxiong Hort. (Umbelliferae)," Journal of Ethnopharmacology, vol. 142, no. 3, pp. 706-713, 2012.

[53] Y. Chen, S. Zhang, D. Chen, M. Zhou, J. Zheng, and Z. Xiang, "An UPLC-MS/MS method for determination of solasonine in rat plasma and its application of a pharmacokinetic and bioavailability study," Journal of Chromatography B, vol. 985, pp. 15, 2015.

[54] Y. Lou, H. Hu, Y. Liu et al., "Determination of chamaechromone in rat plasma by liquid chromatography-tandem mass spectrometry: application to pharmacokinetic study," Journal of Pharmaceutical and Biomedical Analysis, vol. 55, no. 5, pp. 1163 1169, 2011.

[55] K. Yu, F. Chen, and C. Li, "Absorption, disposition, and pharmacokinetics of saponins from Chinese medicinal herbs: what do we know and what do we need to know more?" Current Drug Metabolism, vol. 13, no. 5, pp. 577-598, 2012.

[56] V. Bhattaram, U. Graefe, C. Kohlert et al., "Pharmacokinetics and bioavailability of herbal medicinal products," Phytomedicine, vol. 9, no. 1, pp. 33-40, 2002.

[57] M. Zeng, L. Pan, and S. Qi, "Systematic review of recent advances in pharmacokinetics of four classical Chinese medicines used for the treatment of cerebrovascular disease," Fitoterapia, vol. 88, pp. 50-75, 2013. 

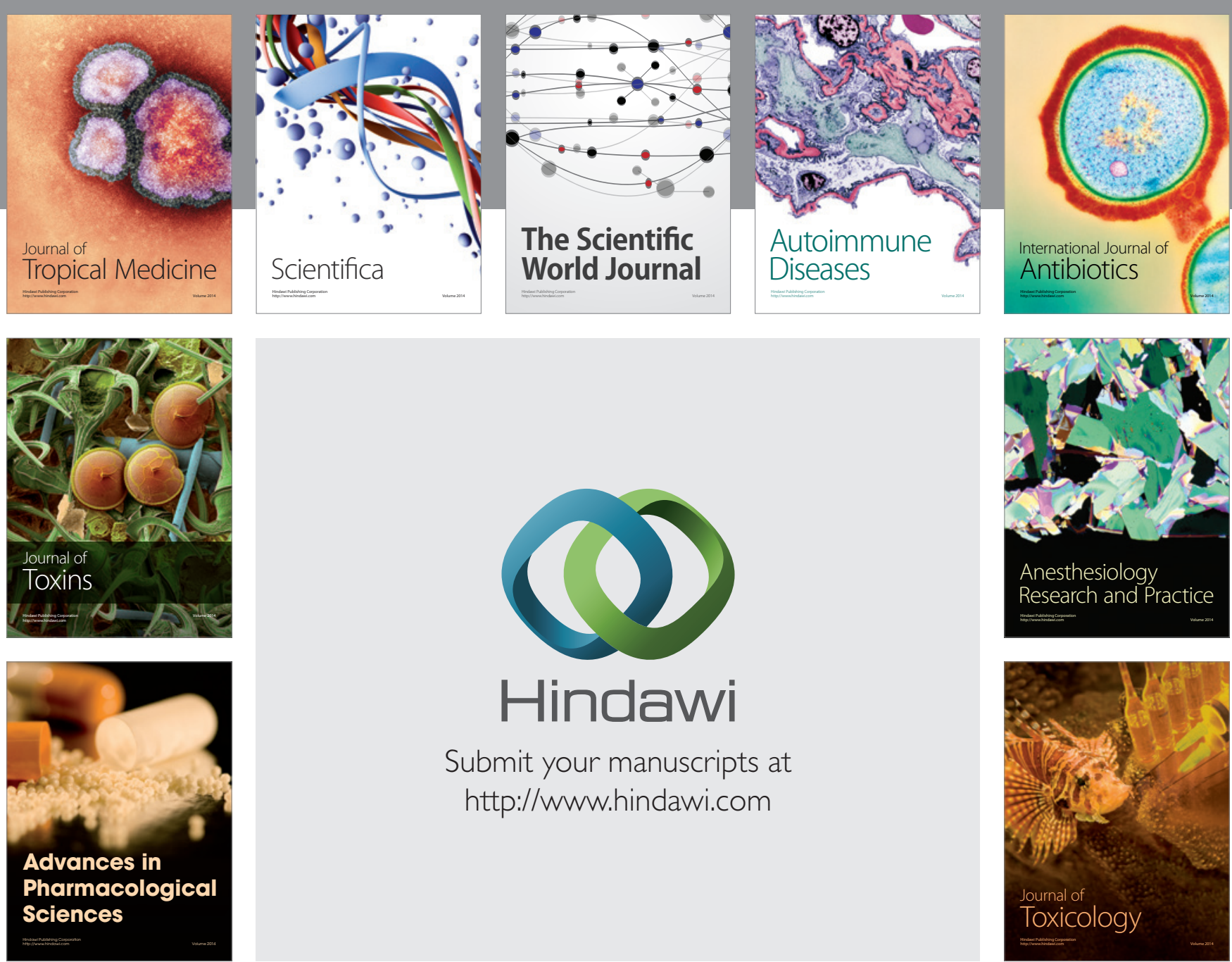

\section{Hindawi}

Submit your manuscripts at

http://www.hindawi.com
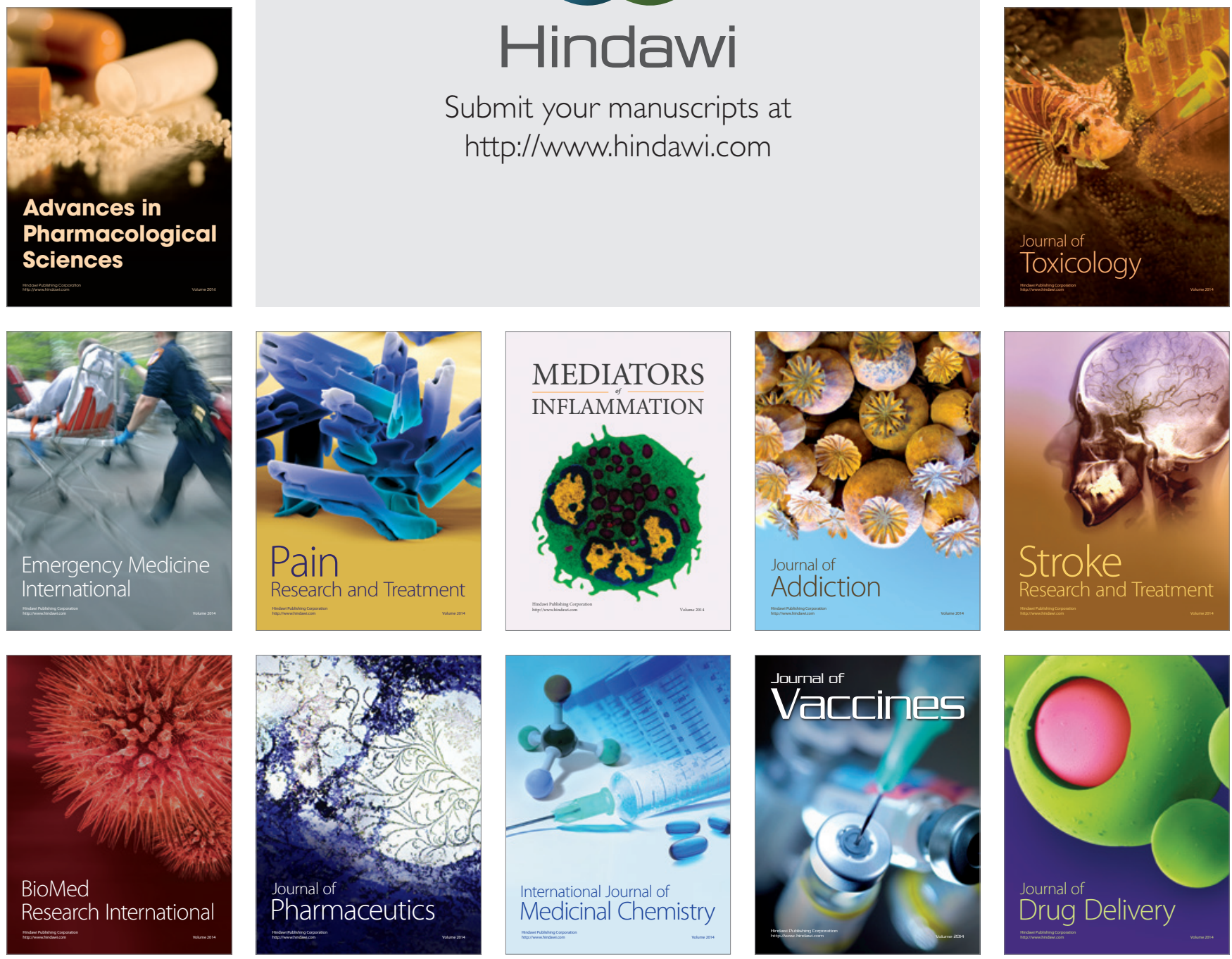